\title{
SABRINA DEGASPARI
}

\author{
Alteração na sinalização inflamatória e na proteína Klotho em \\ pacientes com Doença Renal Crônica (DRC), em hemodiálise, na \\ presença e ausência de déficit cognitivo e em modelo animal de DRC \\ (nefrectomia 5/6)
}

Tese apresentada ao Programa de PósGraduação em Farmacologia do Instituto de Ciências Biomédicas da Universidade de São Paulo, para obtenção do Título de Doutor em Ciências. 


\section{SABRINA DEGASPARI}

Alteração na sinalização inflamatória e na proteína Klotho em pacientes com Doença Renal Crônica (DRC), em hemodiálise, na presença e ausência de déficit cognitivo e em modelo animal de DRC (nefrectomia 5/6)

Tese apresentada ao Programa de Pós-Graduação em Farmacologia do Instituto de Ciências Biomédicas da Universidade de São Paulo, para obtenção do Título de Doutor em Ciências.

Área de concentração: Farmacologia

Orientador: Prof. Dr. Cristoforo Scavone

Co-orientador: Prof ${ }^{a}$. $\mathrm{Dr}^{\mathrm{a}}$. Elisa Mitiko Kawamoto.

Versão original 
DADOS DE CATALOGAÇÃO NA PUBLICAÇÃO (CIP)

Serviço de Biblioteca e Informação Biomédica do

Instituto de Ciências Biomédicas da Universidade de São Paulo

reprodução não autorizada pelo autor

Degaspari, Sabrina.

Alteração na sinalização inflamatória e na Klotho em pacientes com Doença Renal Crônica (DRC), em hemodiálise, na presença e ausência de déficit cognitivo e em modelo animal de DRC (nefrectomia 5/6) / Sabrina Degaspari. -- São Paulo, 2013.

Orientador: Prof. Dr. Cristoforo Scavone.

Tese (Doutorado) - Universidade de São Paulo. Instituto de Ciências Biomédicas. Departamento de Farmacologia. Área de concentração: Farmacologia. Linha de pesquisa: Cognição.

Versão do título para o inglês: Influence of inflammatory signaling and Klotho in cognitive deficit linked to Chronic Kidney Disease (CKD) patients on hemodialysis and animal model of CKD (5/6 nephrectomy).

1. Rim 2. Cérebro 3. Inflamação I. Scavone, Prof. Dr. Cristoforo II. Universidade de São Paulo. Instituto de Ciências Biomédicas. Programa de Pós-Graduação em Farmacologia III. Título. 
Candidato(a):

Título da Tese:
Sabrina Degaspari.

Alteração na sinalização inflamatória e na Klotho em pacientes com Doença Renal Crônica (DRC), em hemodiálise, na presença e ausência de déficit cognitivo e em modelo animal de DRC (nefrectomia 5/6).

Orientador(a):

Prof. Dr. Cristoforo Scavone.

A Comissão Julgadora dos trabalhos de Defesa da Tese de Doutorado, em sessão pública realizada a considerou

( ) Aprovado(a)

( ) Reprovado(a)

\begin{tabular}{|c|c|}
\hline Examinador(a): & $\begin{array}{l}\text { Assinatura: } \\
\text { Nome: ........ } \\
\text { Instituição: }\end{array}$ \\
\hline Examinador(a): & $\begin{array}{l}\text { Assinatura: } \\
\text { Nome: ....... } \\
\text { Instituição: }\end{array}$ \\
\hline Examinador(a): & $\begin{array}{l}\text { Assinatura: } \\
\text { Nome: ....... } \\
\text { Instituição: }\end{array}$ \\
\hline Examinador(a): & $\begin{array}{l}\text { Assinatura: } \\
\text { Nome: ....... } \\
\text { Instituição: }\end{array}$ \\
\hline Presidente: & $\begin{array}{l}\text { Assinatura: } \\
\text { Nome: ....... } \\
\text { Instituição: }\end{array}$ \\
\hline
\end{tabular}


Decl. CEPSH.079/10

\section{DE CLARA Ç ̃̃ O}

Em adendo ao Parecer 897/CEP, de 22-maio-2009, aprovo a inserção das dosagens séricas da proteína C reativa, no Projeto intitulado: "Estudo da via de sinalização WNT em indivíduos com doença renal crônica em hemodiálise na presença e ausência de déficit cognitivo" sob responsabilidade dos pesquisadores CRISTOFORO SCAVONE e SABRINA DEGASPARI, pois as mesmas não afetam os aspectos éticos da pesquisa.

São Paulo, 29 de julho de 2010.

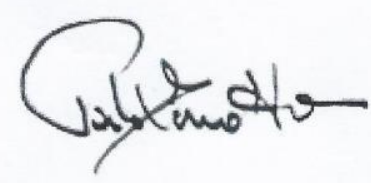

Prof. Dr. Paolo M.A Zanotto

Coordenador da Comissão de Ética em

Pesquisas com Seres Humanos - ICB /USP 


\section{PARECER 897/CEP}

Prezada Senhora,

Atendendo sua solicitação, a Comissão de Ética em Pesquisas com Seres Humanos do ICB, em sua $95^{\text {a }}$ reunião realizada em 22.05.09, analisou o projeto de sua responsabilidade intitulado: "Estudo da via de sinalização WNT em indivíduos com doença renal crônica em hemodiálise na presença e ausência de déficit cognitivo".

Informo a V.Sa. que, após análise e discussão, o referido projeto foi aprovado por esta Comissão.

Lembramos que cabe ao pesquisador elaborar e apresentar a este Comitê, relatórios anuais (parciais ou final), de acordo com a resolução 196/06 do Conselho Nacional da Saúde, item IX.2 letra c.

O primeiro relatório deverá ser encaminhado à Secretaria deste CEP em 22 de maio de 2010.

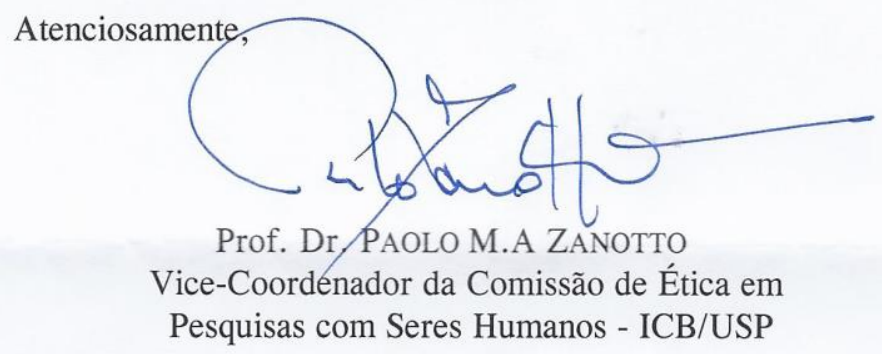

Ilma Sra.

SABRINA DEGASPARI

Departamento de Farmacologia

Instituto de Ciências Biomédicas -USP

Comissão de Ética em Pesquisa com Seres Humanos do Instituto de Ciências Biomédicas / USP Aprovada pela Comissão Nacional de Ética em Pesquisa - CONEP, em 10 de fevereiro de 1998. 


\section{CerTificado}

Certificamos que o protocolo registrado sob $n^{\circ} 015$ nas fls. 099 do livro 02 para uso de animais em experimentação, sob a responsabilidade do Prof(a) Dr(a)) Cristoforo Scavone, Coordenador(a) da Linha de pesquisa "Estudo da via sinalização WNT associada a doença renal crônica" do qual participam o(s) alunos Sabrina Degaspari, Elisa Mitiko Kawamoto, Alexandre Chagas de Santana e os pesquisadores Tânia Viel, Irene de Lourdes Noranha, está de acordo com os Princípios Éticos de Experimentação Animal adotado pela Sociedade Brasileira de Ciência de Animais de Laboratório (SBCAL) e foi aprovado pela COMISSÃO DE ÉTICA NO USO DE ANIMAIS (CEUA) em 17.05.2011, com validade de 3 anos.

São Paulo, 23 de maio de 2011.

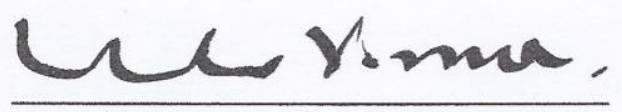

Prof.Dr.WOTHAN TAVARES DE LIMA Coordenador CEUA - ICB/USP

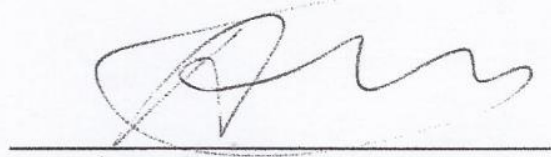

Prof. Dr. ARIEL MARIANO SILBER Secretário CEUA - ICB/USP 
Aos meus pais, Rose e Ricardo, pelo incansável apoio, sempre! Eu amo vocês! 


\section{AGRADECIMENTOS}

Inicio agradecendo a Deus. Ele esteve sempre ao meu lado durante esta caminhada, muitas vezes o caminho tornou-se tortuoso e pensei em desistir, porém, Ele me deu duas características: persistência e determinação! Contudo, não teria chegado até aqui sem a ajuda de alguns anjos, a saber:

Agradeço ao Prof. Cristoforo Scavone, para mim, é uma imensa honra e orgulho telo como orientador. Não esqueço seus ensinamentos, seus preciosos conselhos e sua inestimável confiança. Muito obrigada!

À $\mathrm{Dr}^{\mathrm{a}}$. Elisa Mitiko Kawamoto, pela infinita disponibilidade, por todos os ensinamentos e pela impecável condução deste trabalho.

À Prof ${ }^{a}$. Dr ${ }^{a}$. Tânia Markouraks, pelas sugestões pertinentes durante a construção deste trabalho.

Ainda no âmbito acadêmico, devo agradecer a $\operatorname{Prof}^{\mathrm{a}}$. $\mathrm{Dr}^{\mathrm{a}}$. Tânia Viel e ao Prof. Dr. Hudson Buck, pelo apoio incondicional, disponibilidade e ensinamentos na área de comportamento animal.

Não poderia esquecer de agradecer ao Prof. Dr. Roberto Zats e a $\mathrm{Dr}^{\mathrm{a}}$. Clarice Kazue Fujihara, que além de acreditarem nesta pesquisa, se tornaram parceiros de trabalho, dando o suporte necessário ao manuseio do modelo animal de nefrectomia.

À $\mathrm{Dr}^{\mathrm{a}}$. Carmem Tzanno Martins, um exemplo que sempre levarei comigo, como pessoa e como profissional, muito obrigada pelo auxílio com os pacientes e toda a parte clínica desta pesquisa.

Ao Dr. João Paulo Lian Branco Martins, modelo de clareza e objetividade.

À Prof ${ }^{a}$. Dr ${ }^{a}$. Carolina D. Munhoz, por gentilmente esclarecer minhas dúvidas neste meu caminhar. 
Agradeço, também, aos amigos de Lleida, na Espanha, que gentilmente me receberam e com quem tenho aprendido muito, Dr. José Manuel Valdivielso. $\mathrm{Dr}^{\mathrm{a}}$. Adriana Silva Dusso, $\mathrm{Dr}^{\mathrm{a}}$. Maria Vitoria Arcidiacono, $\mathrm{Dr}^{\mathrm{a}}$. Petya Valcheva e $\mathrm{Dr}^{\mathrm{a}}$. Milica Bozic Stanojevic. ¡Muchas gracias!

Aos colegas do Laboratório de Neurofarmacologia Molecular do ICB-USP, pela companhia no processo de pesquisa, tornando o ambiente sempre alegre e produtivo.

Aos pacientes, pela delicadeza e sensibilidade no compartilhamento deste meu aprendizado.

Agradeço também, aos amigos, Marco Antônio, Ângela, Eliana e Alexandre, que sempre me ouviram e me cederam a mão amiga nos dias em que a luz não brilhava tanto.

Agradeço a todos que fazem parte da família do Departamento de Farmacologia do ICB-USP e do Departamento de Nefrologia do HC-USP, sem a colaboração de todos, excelentes profissionais, que lutam por uma educação digna e ensino de qualidade.

Ao CNPq, CAPES e FAPESP pelo apoio financeiro.

Não poderia esquecer a secretaria do departamento, Selma e Mônica, pela paciência e pela imensa ajuda na parte burocrática do processo.

À minha família, que compreenderam as ausências e que, seguramente, são os que mais compartilham as minhas alegrias.

Divido com todos vocês, mais uma etapa de minha vida. 


\section{RESUMO}

DEGASPARI, S. Alteração na sinalização inflamatória e na proteína Klotho em pacientes com Doença Renal Crônica (DRC), em hemodiálise, na presença e ausência de déficit cognitivo e em modelo animal de DRC (nefrectomia 5/6). 2013. 107 f. Tese (Doutorado em Farmacologia) - Instituto de Ciências Biomédicas, Universidade de São Paulo, São Paulo, 2013.

DRC é a condição que descreve alteração irreversível da função renal, desencadeando alterações relacionadas a função renal, bem como 0 desenvolvimento de vários sintomas neurológicos. A DRC tem se tornado um problema de saúde pública devido ao aumento progressivo dos casos de insuficiência renal com necessidade de terapia renal substitutiva, de forma que no Brasil foi observado elevação de 10\% em sua incidência entre 2004 e 2005. Pesquisas recentes tem mostrado que o grau de deficiência cognitiva está associado ao grau de comprometimento da função renal. Acredita-se que essas alterações cognitivas estão relacionadas às alterações vasculares do Sistema Nervoso Central (SNC) decorrente tanto da DRC quanto às variações desencadeadas pelos procedimentos de hemodiálise. O Modified Mini-mental Scale (3MS) e o Kidney Disease Quality of Life (KDQOL-CF) têm sido utilizados para a avaliação do déficit cognitivo nesses pacientes, de forma, que as alterações no lobo frontal são as mais freqüentes. Muitas hipóteses são descritas como fatores desencadeantes do déficit cognitivo relacionado a DRC, dentre eles, acredita-se que o estresse oxidativo e a resposta inflamatória estão envolvidos na patogênese tanto da DRC quanto das lesões relacionadas à isquemia da Demência Vascular. Recentemente, estudos relacionando alterações na klotho sérica com o envelhecimento precoce tem sido descritos, sendo essa proteína fortemente influenciada pela função renal, considerase que a klotho também pode estar envolvida nas alterações cognitivas presentes na DRC. Assim, o objetivo deste trabalho é o de avaliar a ausência e presença de déficit cognitivo em pacientes com DRC em hemodiálise, bem como em modelo animal de $5 / 6$ de ablação renal, relacionando a concentração de citocinas (IL-1 $1 \beta$, TNF-a, IL-6, IL-10, IFN- $\gamma$ ), proteína C reativa, cortisol/corticoesterona e klotho em soro humano e de rato, em líquido céfalo-raquídeo de rato e homogenato de hipocampo, córtex frontal, amígdala e rim de rato. Os dados mostraram que os mediadores séricos pró-inflamatórios e antinflamatórios realizada nos indivíduos DRC e DRC-Cl não apresentaram diferença em relação aos indivíduos do grupo controle ou associação com a presença do declínio da função cognitiva. Alem disso no modelo animal de DRC, ainda que em condições pré-dialíticas, não encontramos correlação entre as alterações séricas de citocinas pró e anti-inflamatórias com o aparecimento do déficit cognitivo. Finalmente, os nossos dados mostraram ainda uma redução importante dos níveis séricos da proteína Klotho nos indivíduos do grupo DRC-Cl, assim como nos animais com déficit cognitivo associado ao modelo animal de DRC quando comparado com os respectivos grupos Controle e DRC sem déficit. Em conjunto, os dados sugerem que as alterações na sinalização associada a proteína Klotho desempenham um papel fundamental no desenvolvimento de alterações cognitivas associadas com insuficiência renal crônica.

Palavras-chave: Doença renal crônica. Cognição. TNF $\alpha$. Klotho. 


\section{ABSTRACT}

DEGASPARI, S. Influence of inflammatory signaling and Klotho in cognitive deficit linked to Chronic Kidney Disease (CKD) patients on hemodialysis and animal models of CKD (5/6 nephrectomy). 2013. $107 \mathrm{f}$. Tese (Doutorado em Farmacologia) - Instituto de Ciências Biomédicas, Universidade de São Paulo, São Paulo, 2013.

CKD is a condition that describes irreversible alteration of renal function by triggering changes related to renal function and development of various neurological symptoms. CKD has become a public health problem due to progressive increase in cases of renal failure requiring renal replacement therapy. In fact, it has been reported an increase of 10\% of the CKD incidence between 2004 and 2005. Recent research has shown that the degree of cognitive impairment is associated to degree of impairment of renal function. It is believed that these cognitive changes are related to vascular changes in the central nervous system (CNS) due to CKD, as well as by changes triggered by hemodialysis procedures. The Modified Mini-Mental Scale (3MS) and the Kidney Disease Quality of Life (KDQOL-CF) have been used for the assessment of cognitive impairment in this kind of patients, and most of data reported is about changes in the frontal lobe. Several hypotheses are described as triggering factors of cognitive impairment related to CKD, including the linked of oxidative stress and inflammatory response in the pathogenesis of CKD and of injuries related to vascular dementia. Recent studies have reported changes in serum klotho with aging, and levels of this protein are strongly influenced by renal function. Also, it may be involved in the cognitive impairment found in CKD. Thus, the objective of this thesis is to evaluate the presence and absence of cognitive impairment in patients with CKD on hemodialysis, as well as in a 5/6 renal ablation animal model. In parallel, we performed animal behavioral tests to evaluate the memory, as well as IL-1 $\beta$, TNF- $\alpha, \mathrm{IL}-6, \mathrm{IL}-10$, Klotho and cortisol levels in CKD patients plasma and $5 / 6$ renal ablation serum, hippocampus, frontal cortex, amigdala, kidney and cerebrospinal fluid by ELISA. The data showed no differences in serum pro-inflammatory and anti-inflammatory mediators in CKD and CKD-Cl groups when compared to the control group or association with the presence of the decline in cognitive function. In addition we found no correlation between changes in serum pro-and anti-inflammatory with the onset of cognitive impairment in the animal model of CKD, even in pre-dialysis conditions. Finally, our data also showed a significant reduction in serum levels of Klotho protein among individuals with CKD-Cl, as well as in animals with cognitive deficits associated with the animal model of CKD when compared with the respective control groups and CKD without deficit. Taken together, together, the present data suggest that changes in Klotho signaling plays a key role in the development of cognitive changes associated with chronic renal failure.

Keywords: Chronic Kidney Diseases (CKD). Cognition. TNF-a. Klotho. 


\section{LISTA DE FIGURAS}

Figura 1 - Número de procedimentos dialíticos e transplantes renais de 1976 a 2003

Figura 2 - Níveis de estrogênio sérico $(\mathrm{pg} / \mathrm{ml})$ dosados em indivíduos do sexo feminino em pacientes portadores de DRC na ausência (DRC) ou presença de déficit cognitivo (DRC-Cl).

Figura 3 - Níveis de Klotho sérico $(\mathrm{pg} / \mathrm{mL})$ em indivíduos controles, e com DRC na ausência de déficit cognitivo (DRC) e na presença de déficit cognitivo (DRC-Cl) em coletas pré e pós-diálise.

Figura 4 - Análise dos dados obtidos no Campo Aberto após 150 dias de nefrectomia 52

Figura 5 - Análise dos dados obtidos no teste de Labirinto de Barnes.

Figura 6 - Análise dos dados obtidos com o teste de esquiva inibitória nos grupos Sham e Nx durante o período de 120 dias de nefrectomia. .55

Figura 7 - Análise dos dados obtidos com o teste de reconhecimento do novo objeto nos grupos Sham e Nx após 90 dias de nefrectomia. .56

Figura 8 - Análise da esclerose glomerular no modelo animal de 5/6 de nefrectomia após 150 dias do procedimento cirúrgico.

Figura 9 - Análise da área intersticial cortical no modelo animal de 5/6 de nefrectomia após 150 dias do procedimento cirúrgico.

Figura 10 - Análise dos níveis séricos de IL-6 (pg/mL) aos 30 e 120 dias de nefrectomia, coleta 1 e 4 respectivamente.

Figura 11 - Análise dos níveis séricos de $\mathrm{IL}-1 \beta(\mathrm{pg} / \mathrm{mL})$ aos 30 e 120 dias de nefrectomia, coleta 1 e 4 respectivamente.

Figura 12 - Análise dos níveis séricos de TNF-a (pg/mL) aos 30 e 120 dias de nefrectomia, coleta 1 e 4 respectivamente.

Figura 13 - Análise dos níveis séricos de Proteína C Reativa (ng/mL) aos 30 e 120 dias de nefrectomia, coleta 1 e 4 respectivamente.

Figura 14 - Análise dos níveis séricos de IFN-Y (pg/mL) aos 30 e 120 dias de nefrectomia, coleta 1 e 4 respectivamente.

Figura 15 - Análise dos níveis séricos de IL-10 (pg/mL) aos 30 e 120 dias de nefrectomia, coleta 1 e 4 respectivamente. .63 
Figura 16 - Análise dos níveis séricos de Corticoesterona (pg/mL) aos 30 e 120 dias de nefrectomia, coleta 1 e 4 respectivamente.

Figura 17 - Análise dos níveis liquóricos de IL-6 (pg/mL) e TNF- $\alpha$ (pg/mL) após 120 dias de nefrectomia.

Figura 18 - Análise dos níveis liquóricos de Proteína C Reativa ( $\mathrm{ng} / \mathrm{mL}), \mathrm{IL}-1 \beta$ $(\mathrm{pg} / \mathrm{mL})$ e IFN-y $(\mathrm{pg} / \mathrm{mL})$ após 120 dias de nefrectomia.

Figura 19 - Análise dos níveis liquóricos de IL-10 (pg/mL) e Corticoesterona (pg/mL) após 120 dias de nefrectomia.

Figura 20 - Análise dos níveis teciduais de IL-6 (pg/mL) em diferentes regiões cerebrais e no rim, após 120 dias de nefrectomia 66

Figura 21 - Análise dos níveis teciduais de TNF- $\alpha(\mathrm{pg} / \mathrm{mL})$ em diferentes regiões cerebrais e no rim, após 120 dias de nefrectomia

Figura 22 - Análise dos níveis teciduais de IL-1ß ( $\mathrm{pg} / \mathrm{mL})$ em diferentes regiões cerebrais e no rim, após 120 dias de nefrectomia.

Figura 23 - Análise dos níveis teciduais de Proteína C Reativa $(\mathrm{ng} / \mathrm{mL})$ em diferentes regiões cerebrais, após 120 dias de nefrect.

Figura 24 - Análise dos níveis teciduais de IL-10 ( $\mathrm{pg} / \mathrm{mL})$ em diferentes regiões cerebrais e no rim, após 120 dias de nefrectomia

Figura 25 - Análise dos níveis teciduais de IFN-y ( $\mathrm{pg} / \mathrm{mL})$ em diferentes regiões cerebrais e no rim, após 120 dias de nefrectomia. .70

Figura 26 - Dosagem por ELISA da concentração sérica da proteína klotho. .71

Figura 27 - Níveis de Klotho no córtex frontal e hipocampo de ratos Sham, Nx-M e $\mathrm{Nx}-\mathrm{Cl}$ 


\section{LISTA DE TABELAS}

Tabela 1 - Caracterização demográfica dos indivíduos avaliados nessa pesquisa

Tabela 2 - Descrição dos valores usados na adequação do nível de escolaridade para o $3 \mathrm{MS}$ usado para determinar alterações na função cognitiva. 46

Tabela 3 - Descrição do valor usado na aplicação do KDQOL-SF como subescala da função cognitiva. 46

Tabela 4 - Tarefas avaliadas pelo 3MS mostrando os pontos de maior declínio da função cognitiva no grupo DRC-Cl comparado ao grupo controle e DRC. Observe a ausência de diferença significativa entre os escores do grupo controle e DRC.

Tabela 5 - Características bioquímicas dos participantes dessa pesquisa em programa de hemodiálise de acordo com os valores encontrados no 3MS. 48

Tabela 6 - Análise recíproca comparativa dos níveis de citocinas séricas, cortisol e proteína $C$ reativa em indivíduos controles, e com DRC na ausência de déficit cognitivo (DRC) e na presença de déficit cognitivo (DRC-Cl) em coletas pré e pós-diálise.

Tabela 7 - Estudo do peso corporal e pressão sanguínea aos 30 e 150 dias de nefrectomia, mostrando redução do peso corporal e hipertensão arterial no grupo $\mathrm{Nx}$.

Tabela 8 - Estudo demonstrando importante elevação da creatinina sérica no grupo Nx após 150 dias de nefrectomia em relação ao grupo Sham e ausência de anemia, verificada através da análise do hematócrito entre os grupos Nx e Sham..... 


\section{LISTA DE ABREVIATURAS E SIGLAS}

\% INT - Fração do Córtex Renal Ocupada pelo Interstício

\%EG - Porcentagem de Esclerose Glomerular

3MS - Modified Mini-mental Scale

AMPc - Monofosfato de Adenosina Ciclíco

ATP - Trifosfato de Adenosina

AVE - Acidente Vascular Encefálico

BDNF - Fator Neurotrófico Derivado do Cérebro

$\mathrm{Ca}^{++}$- Cálcio

CAMDEX - Cambridge Cognitive Examination

CAPD - Diálise Peritoneal Ambulatorial Contínua

CCSE - Cognitive Capacity Screening

CINE - Centro Integrado de Nefrologia

DA - Doença de Alzheimer

DP - Doença de Parkinson

DRC - Doença Renal Crônica

DRC-CI - Doença Renal Crônica associada ao Comprometimento Cognitivo

EEG - Eletroencefalograma

ELISA - Enzyme Linked Immunosorbent Assay

eNOS - Óxido Nítrico Sintase Endotelial

FGF21 - Fator de Crescimento Fibroblástico 21

FGF23 - Fator de Crescimento Fibroblástico 23

GMPc - Monofosfato de Guanosina Cíclico

HUVECs - Células Endoteliais de Veias do Cordão Umbilical de Humanos

ICS - Infartação Cerebral Silenciosa

IEG - Índice de Esclerose Glomerular

IFN- $\mathrm{\gamma}$ - Interferon $\mathrm{Y}$

IGF-I - Fator de Crescimento Insulin-like

IL-10 - Interleucina 10

IL-15 - Interleucina 15

IL-1 $\beta$ - Interleucina $1 \beta$

IL-2 - Interleucina 2

IL-4 - Interleucina 4

IL-6 - Interleucina 6 
IL-8 - Interleucina 8

KDOQI - Kidney Disease Outcomes Initiative

KDQOL-CF - Kidney Disease Quality of Life

LCR - Líquido Céfalo-Raquidiano

MMSE - Mini Exame do Estado Mental

NK - Natural Killer

NO - Óxido Nítrico

$\mathrm{Nx}$ - Nefrectomia

$\mathrm{Nx}-\mathrm{Cl}$ - Nefrectomia associada a Déficit Cognitivo

Nx-M - Nefrectomia não associada a Déficit Cognitivo

PBS - Tampão Fosfato-Salino

PKA - Proteína Quinase Dependente do AMPc

PKG - Proteína Quinase Dependente do GMPc

PTH - Paratormônio

SNC - Sistema Nervoso Central

SUS - Sistema Único de Saúde

TNF- $\alpha$ - Fator de Necrose Tumoral $\alpha$

$\alpha-\mathrm{KI}-\alpha-$ Klotho 


\section{SUMÁRIO}

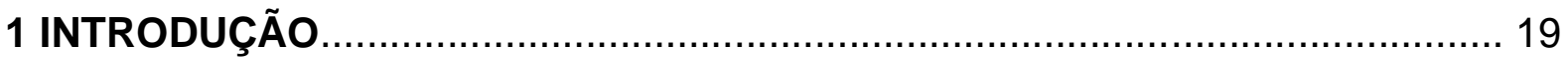

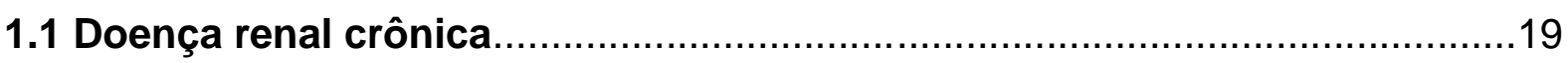

1.2 Comprometimento cognitivo em indivíduos com DRC ..............................21

1.3 Avaliação cognitiva na DRC

1.4 Biomarcadores periféricos e neurodegeneração ...........................................25

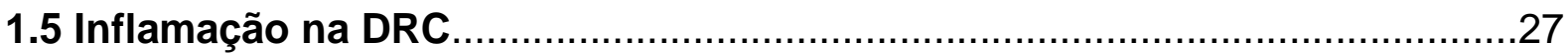

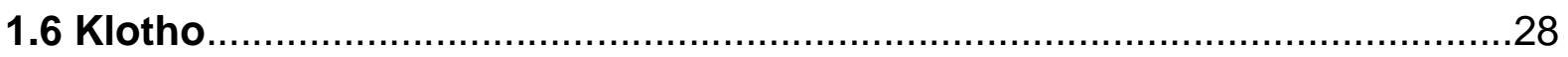

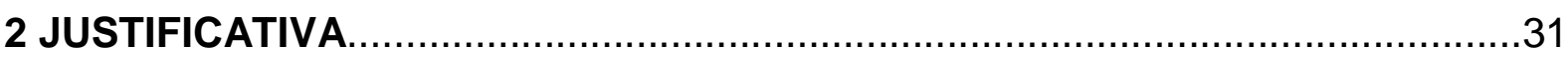

3 OBJETIVO

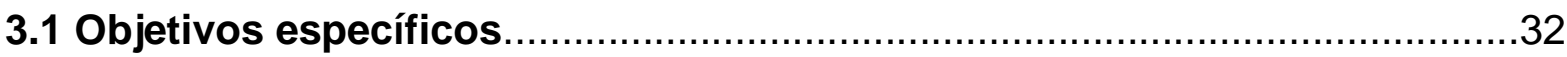

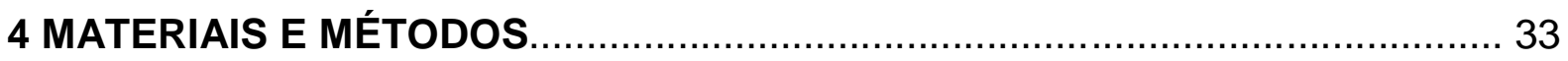

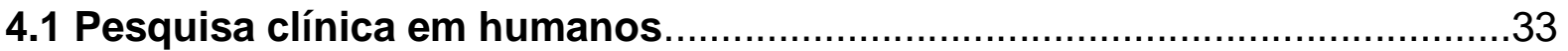

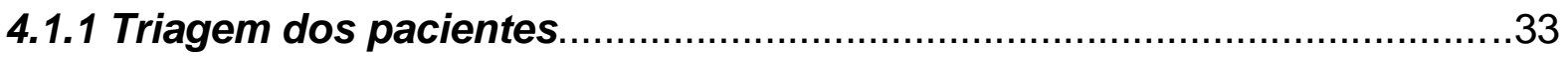

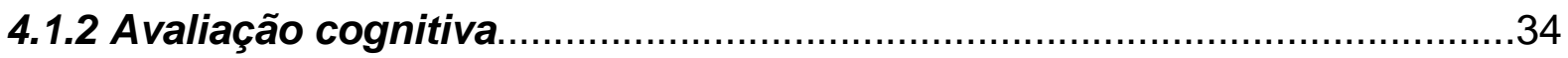

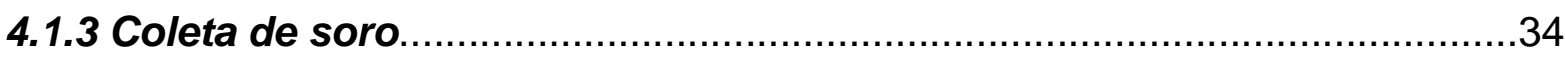

4.1.4 Ensaio de ELISA para TNF- $\alpha$, IL-1 $\beta$, IL-6, IL-10, cortisol, proteína C reativa,

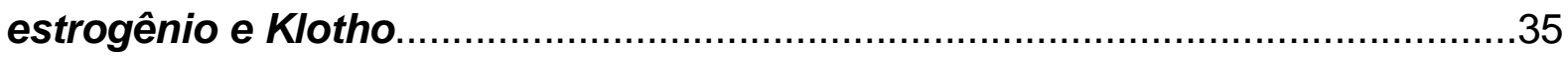

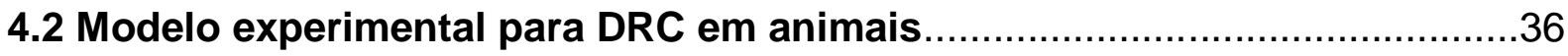

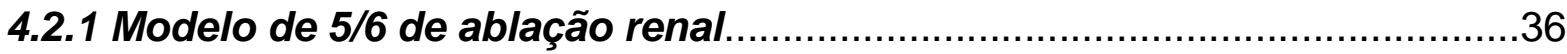

4.2.2 Teste de comportamento em animais..................................................

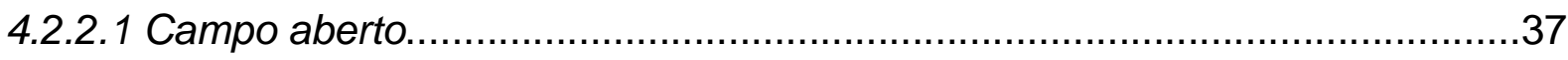

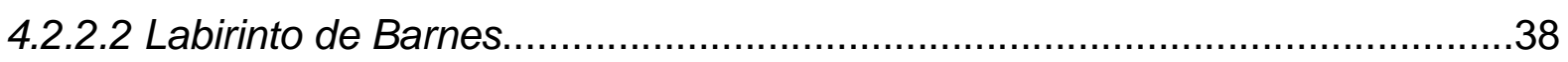

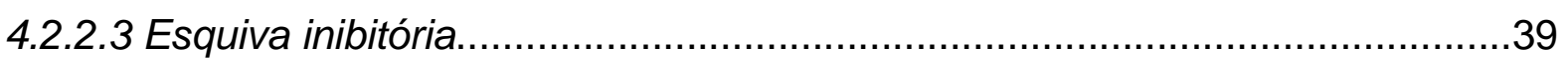

4.2.2.4 Teste de reconhecimento do novo objeto.................................................

4.2.3 Ensaio de ELISA para TNF- $\alpha$, IL-1 $\beta$, IL-6, IL-10, IFN- $y$, corticoesterona, proteína C reativa e Klotho.........................................................................

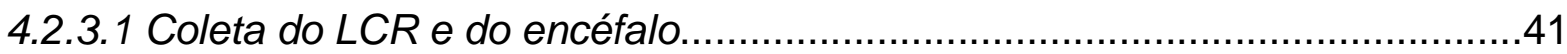

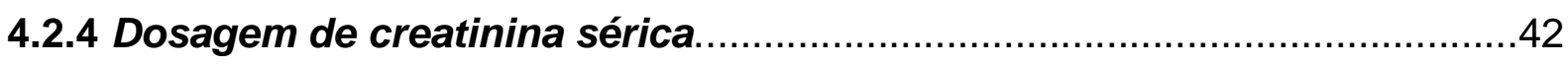

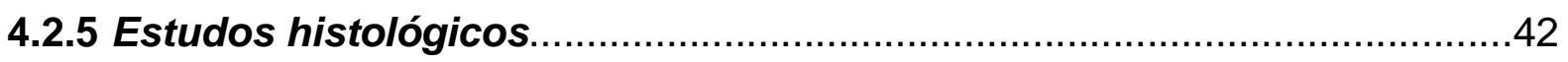

4.2.5.1 Porcentagem de esclerose glomerular...................................................

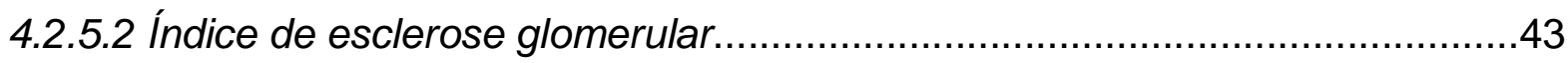

4.2.5.3 Fração do córtex renal ocupada pelo interstício.........................................43

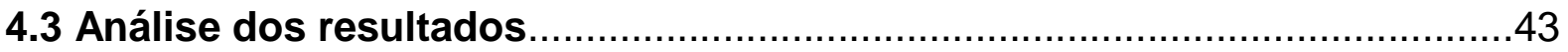




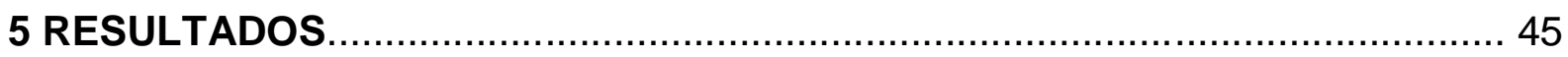

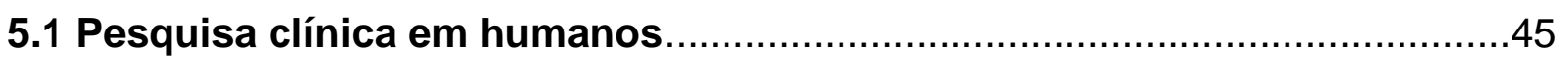

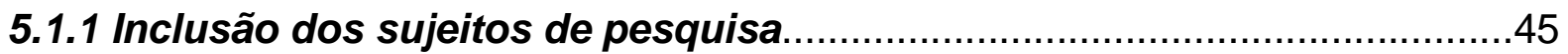

5.1.2 Parâmetros bioquímicos.....................................................................47

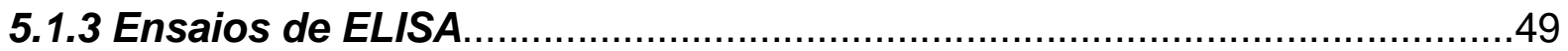

5.1.3.1 Dosagem de estrogênio sérico......................................................49

5.1.3.2 Dosagem de citocinas, cortisol e proteína $C$ reativa em soro

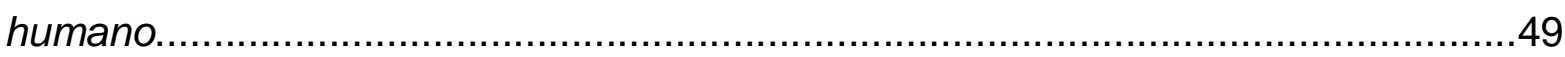

5.1.3.3 Dosagem de Klotho em soro humano..............................................51

5.2 Pesquisa no modelo animal de 5/6 de ablação renal.................................51

5.2.1 Teste de comportamento em animais................................................. 51

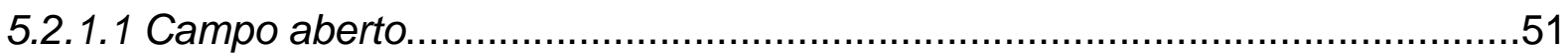

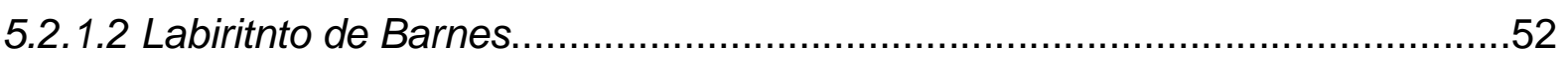

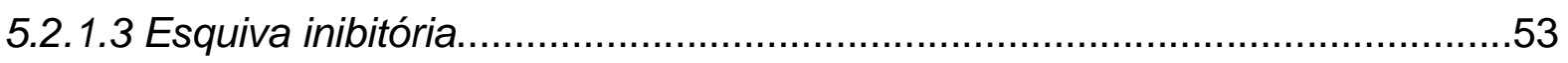

5.2.1.4 Teste de reconhecimento do novo objeto.............................................55

5.2.2 Parâmetros clínicos, bioquímicos e histológicos para caracterização da DRC no modelo de 5/6 de ablação renal.................................................57

5.2.3 Ensaios de ELISA para TNF- $\alpha, I L-1 \beta, I L-6, I L-10$, IFN- $y$, corticoesterona, proteína $C$ reativa e Klotho sérico, liquórico e em homogenato de

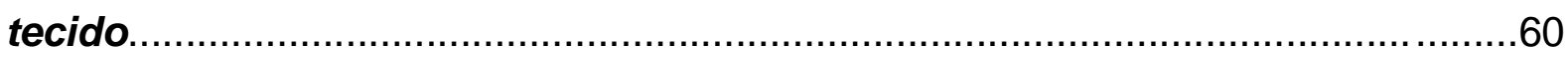

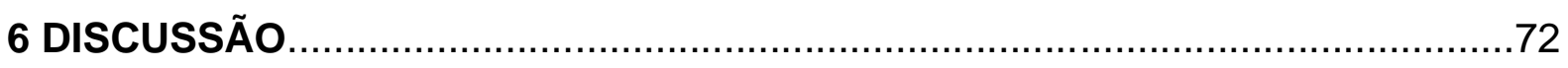

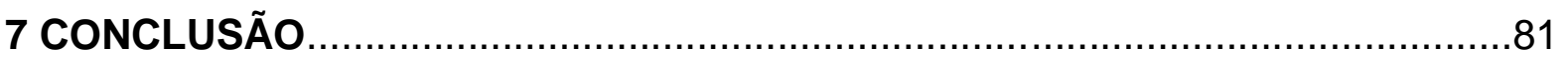

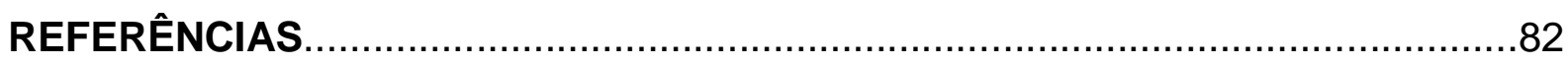

ANEXO A - Mini Exame do Estado Mental Modificado

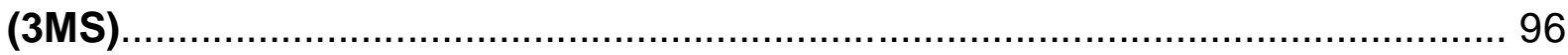

ANEXO B - Doença renal e qualidade de vida (KDQOL-SF) ...........................98

ANEXO C - Dosagem de citocinas, cortisol e proteína C reativa em soro humano (valores absolutos) .................................................................. 106 


\section{INTRODUÇÃO}

\subsection{Doença renal crônica}

DRC é uma condição que descreve extensa e irreversível alteração da função renal, sendo sua evolução clínica associada a altas taxas de morbimortalidade. Os rins são órgãos fundamentais para a manutenção da homeostase do corpo humano, assim, não é surpresa que a diminuição progressiva da função renal implique no desenvolvimento de alterações orgânicas sistêmicas, como é o caso do envolvimento do sistema cardiovascular com as alterações hidroeletrolíticas, lipídicas e de pressão sanguínea; alterações de glicemia; disfunção nutricional; anemia; alterações do metabolismo ósseo, bem como o desenvolvimento de vários sintomas neurológicos, mesmo quando o paciente é submetido a hemodiálise ou contínua diálise peritoneal ambulatorial (SITHINAMSUWAN et al., 2005; WENDY; PETER, 2007).

A DRC é um problema de saúde pública mundial. De acordo com o United States Renal Data System o número de indivíduos submetidos à terapia de hemodiálise duplicou nos Estados Unidos entre 2002 e 2010. Estudo realizado no mesmo país revela que a prevalência de DRC tem aumentado mais proeminentemente em jovens. Ainda que os indivíduos com idade de 60 anos ou mais representem agora metade de todos os novos casos de doença renal em estágio avançado, a DRC afeta amplamente indivíduos em idade avançada (KURELA et al., 2004). No Brasil, de acordo com a Sociedade Brasileira de Nefrologia e o Ministério da Saúde a prevalência de pacientes necessitando de terapia renal substitutiva (hemodiálise ou diálise peritoneal) dobrou nos últimos 5 anos (Figura 1) (BASTOS et al., 2004; CHERCHIGLIA et al., 2007). Os gastos do Sistema Único de Saúde (SUS) com os serviços de assistência prestados aos portadores de insuficiência renal cresceram acentuadamente nos últimos anos, sendo que no período de 1998 a 2002 o gasto médio nos estados brasileiros se elevou em 187\%. Em 2002, aproximadamente 71.000 indivíduos foram beneficiados com hemodiálise e diálise peritoneal, gerando um gasto anual de $R \$ 800$ milhões, ou seja, $R \$ 11.300,00$ com cada paciente com DRC, correspondendo a $13 \%$ dos gastos com procedimentos de média e alta complexidade realizados pelo SUS (GOLDBAUM; BRASIL, 2005). O SUS, em 2003, apontou um gasto médio anual de $R \$ 1$ bilhão entre os procedimentos dialíticos e 
farmacológicos, sendo a população assistida de 100 mil pacientes/ano, com previsão de crescimento maior que 10\% para o ano de 2004 (CHERCHIGLIA et al., 2007). O número projetado atualmente para pacientes em tratamento dialítico e com transplante renal no Brasil está próximo dos 120.000, a um custo de 1,4 bilhão de reais (BASTOS et al., 2011).

Figura 1 - Número de procedimentos dialíticos e transplantes renais de 1976 a 2003.

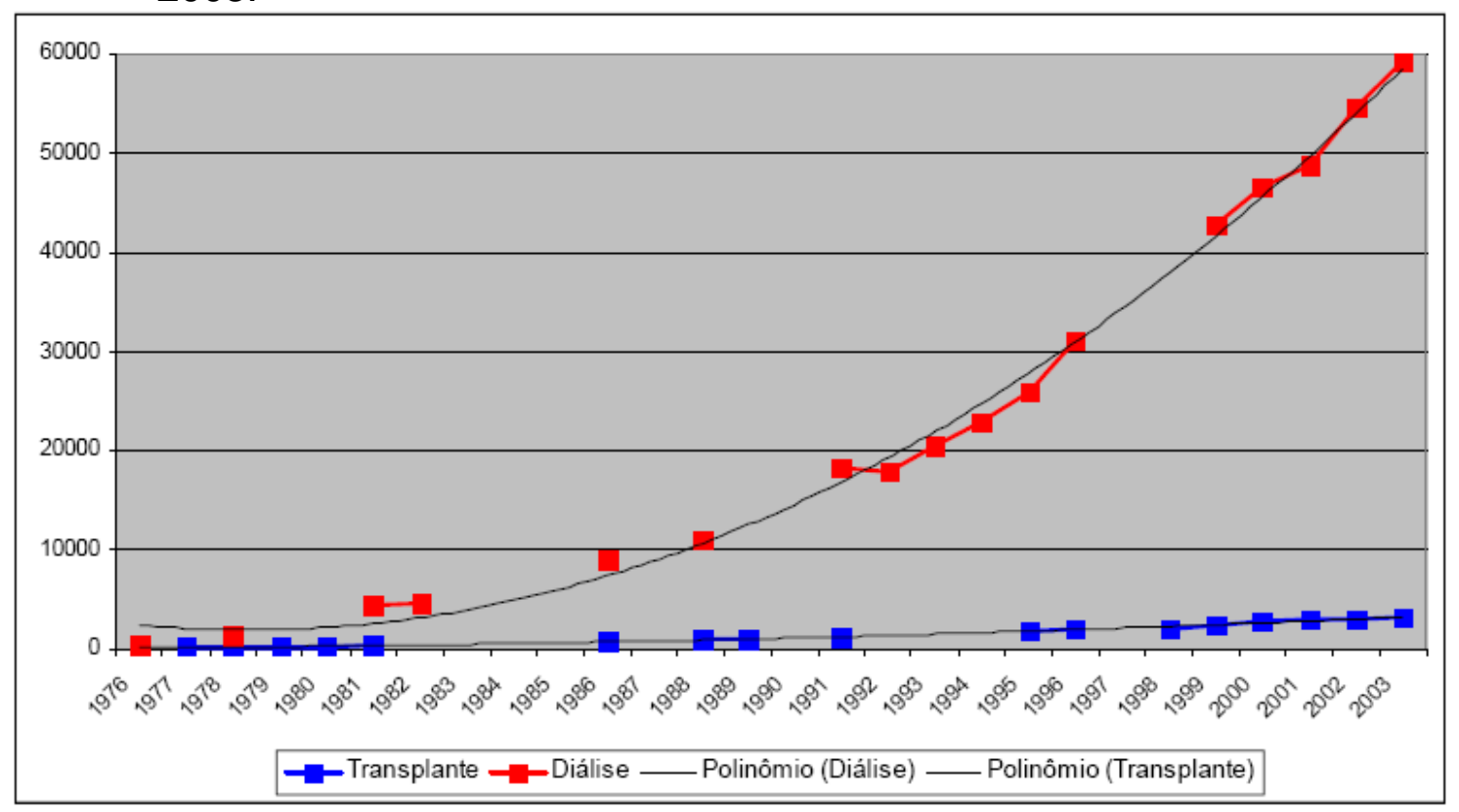

Fonte: Adaptada Coelho, 1996 (ABTO, 2004; CHERCHIGLIA et al., 2007).

Infelizmente, a DRC é subdiagnosticada e a oportunidade de implementação de prevenção primária, secundária e terciária não tem sido usados na prática clínica (BASTOS et al., 2010).

No indivíduo normal, os rins processam em média 200 litros de sangue por dia, removendo excesso de água e produtos tóxicos, produzindo eritropoetina e vitamina D. Nos indivíduos com perda da função renal a hemodiálise tem por função substituir algumas das funções renais, excetuando-se sua função de biossíntese (WENDY; PETER, 2007).

Segundo o Kidney Disease Outcomes Quality Initiative (KDOQI) a DRC pode ser classificada em estágio 1: lesão renal com média de filtração glomerular (eFGM) normal ou elevada (> $90 \mathrm{ml}$ por minuto/1,73 $\mathrm{m}^{2}$ ); estágio 2: lesão renal com pequena redução da eFGM (60-89 ml por minuto/1,73 $\mathrm{m}^{2}$ ); estágio 3: moderada redução da eFGM (30-59 ml por minuto/1,73 $\mathrm{m}^{2}$ ); estágio 4: severa diminuição da eFGM (15-29 
$\mathrm{ml}$ por minuto/1,73 $\mathrm{m}^{2}$ ); estágio 5: falência renal, com eFGM < $15 \mathrm{ml}$ por minuto/1,73 $\mathrm{m}^{2}$ ou diálise (WENDY; PETER, 2007).

\subsection{Comprometimento cognitivo em indivíduos com DRC}

Um importante determinante da qualidade de vida nos indivíduos adultos jovens é o nível de função cognitiva. Dados recentes sugerem que indivíduos em diferentes estágios da DRC apresentam elevado risco no desenvolvimento de demência e comprometimento cognitivo (MADERO et al., 2008).

A relação entre comprometimento cognitivo e a DRC em pacientes foi reconhecida recentemente, sendo relatado que o grau de deficiência cognitiva está associado ao grau de comprometimento da falência renal, de forma que apenas uma minoria dos pacientes submetidos a hemodiálise apresenta função cognitiva normal (DAHBOUR et al., 2009; MURRAY, 2008). Associa-se ao comprometimento cognitivo um decréscimo na qualidade de vida nos indivíduos com DRC em hemodiálise, bem como na adesão às recomendações da diálise, como dieta e uso de medicamentos (RAKOWSKY et al., 2006).

O comprometimento cognitivo é definido como déficit quando ocorre redução em duas áreas da função cognitiva. Isso pode incluir distúrbios de memória (aprendizado ou assimilação de nova informação), execução funcional (planejamento e reação), atenção ou velocidade de processamento de informação (concentração, rapidez de assimilação ou análise de informação), habilidade motora (integração visual, tátil ou informação auditiva associada a atividade motora) ou linguagem (dificuldade em encontrar as palavras, redução da fluência) (DAHBOUR et al., 2009; MADAN et al., 2007; MADERO et al., 2008). O termo comprometimento cognitivo médio é usado em pacientes com comprometimento cognitivo detectável por critérios clínicos e que não tenha repercussão na execução de atividades diárias simples (MADERO et al., 2008).

Sehgal et al. (1997) aplicaram o Mini Exame do Estado Mental (MMSE) em 336 pacientes em hemodiálise randomicamente selecionados, $22 \%$ dos indivíduos apresentaram comprometimento cognitivo médio (MMSE 18 - 23) não diagnosticado e $8 \%$ apresentaram comprometimento cognitivo de moderado para severo (MMSE < 18). Estudos realizados em pacientes em tratamento com hemodiálise, desconsiderando os indivíduos idosos, politraumatizados ou comorbidades severas, 
mostram que a avaliação cognitiva pelo Modified Mini-mental Scale (3MS) com complementação da subescala de função cognitiva Kidney Disease Quality of Life (KDQOL-CF) são considerados o padrão ouro na avaliação cognitiva deste perfil de pacientes.

Kurella et al. (2004), após estudo em 80 pacientes com DRC submetidos a hemodiálise, observaram que $23 \%$ dos indivíduos nos estágios 3 e 4 da DRC apresentaram comprometimento severo de execução motora funcional e $28 \%$ apresentaram perda de memória. Outros estudos relataram a relação entre a estimativa da filtração glomerular média (eFGM) e a função cognitiva, onde indivíduos com DRC e eFGM < $60 \mathrm{ml} /$ minuto/1,73m² tiveram pior desempenho em testes de execução funcional e memória verbal, sendo conhecido que a redução nos níveis de progesterona e estrogênio, em mulheres menopausadas, descreve um decréscimo de $10 \mathrm{ml} / \mathrm{min} / 1,73 \mathrm{~m}^{2}$ na eFGM, correspondendo a uma elevação de $15-25 \%$ no risco de desenvolvimento de disfunção cognitiva (KURELLA et al., 2005). Selinger et al. (2004) relataram elevação em $37 \%$ do risco de desenvolvimento de déficit cognitivo em indivíduos jovens com DRC quando comparados com indivíduos sem DRC. Esse dado, quando ajustado para idade, sexo, raça, biótipo, nível de escolaridade, doença cardíaca e coronariana, diabete, hipertensão, tabagismo e genótipo apoE permanece em $26 \%$ nos indivíduos com creatinina em 2,0 mg/dl quando comparados a indivíduos com 1,0 mg/dl de creatinina.

Murray et al. (2006) realizaram estudo em 338 indivíduos acima de 55 anos com DRC em hemodiálise. Apenas 2,9\% dos indivíduos em diálise apresentavam história de comprometimento cognitivo documentada. No entanto, após a realização dos testes de função cognitiva foi constatado que apenas $12,7 \%$ dos indivíduos em diálise apresentavam essa função normal, enquanto 13,9\% apresentavam déficit cognitivo médio, $36,1 \%$ moderado comprometimento cognitivo e 37,3\% severo comprometimento cognitivo quando comparados com indivíduos sem DRC na mesma faixa etária.

Indivíduos em contínua diálise peritoneal ambulatorial (CAPD) apresentam melhor função cognitiva quando comparados a indivíduos em hemodiálise (BUONCRISTINI et al., 1993; TILKI et al., 2004).

A maioria dos pacientes sob hemodiálise são vasculopatas, sendo elevada a incidência de hipertensão (80\%) e diabetes (60\%) nesses pacientes, de forma que níveis elevados de marcadores inflamatórios e hemocisteína, disfunção do endotélio 
vascular, alterações cardiovasculares, e aterosclerose de artérias carótidas são freqüentemente encontrados. Todos esses fatores contribuem para o comprometimento cognitivo vascular desses indivíduos (MURRAY, 2008). O fenômeno da infartação cerebral silenciosa (ICS) resultado da oclusão de pequenos vasos sanguíneos cerebrais profundos, tem sido descrito em pacientes com DRC onde a redução acentuada da eFGM eleva a ocorrência de ICS e, consequentemente o risco do surgimento de alteração de cognição (KOBAYASHI et al., 2009).

Pacientes em hemodiálise apresentam risco elevado de desenvolver doenças cerebrovasculares subclínicas, com manifestação silenciosa ou assintomática e alterações da substância branca subcortical (SELINGER et al., 2007). Atualmente, acredita-se que as lesões da substância branca subcortical do cérebro são resultado de alterações microvasculares devido à hipoperfusão crônica, sugerindo que essas alterações estejam diretamente relacionadas com o envolvimento cognitivo desse perfil de pacientes, sendo recentemente demonstrado que a eFGM está associada com lesões da substância branca encefálica (KOBAYASHI et al., 2009; MURRAY, 2008).

Os vasos sangüíneos venosos do rim e cérebro são susceptíveis às variações de pressão sangüínea e fluxo visto que funcionam em condições de baixa resistência e são passivamente perfundidos, potencializando o surgimento de lesões causadas pelo mau funcionamento desses vasos nesses órgãos (KOBAYASHI et al., 2009).

Em geral, a Doença de Alzheimer (DA) e Demência Vascular são as causas mais comuns de danos cognitivos em adultos. Apesar da falta de conhecimento do mecanismo de ação associado ao surgimento dos déficits cognitivos em pacientes com DRC, até o momento, não existem evidências sobre o aumento da prevalência de DA em pacientes com DRC, deste modo, a Demência Vascular é a causa mais provável de danos cognitivos nestes indivíduos (FUKUNISHI et al., 2002; KURELLA et al., 2004; MADERO et al., 2008; MURRAY, 2008; SMALL et al., 1997). Essa associação entre déficit cognitivo e DRC é independente das diferenças de idade, educação e etnia (KURELLA et al., 2004). Nesses indivíduos, as anormalidades no padrão do eletroencefalograma (EEG) podem preceder os sintomas clínicos da demência por período superior a 6 meses, sendo as alterações detectadas particularmente no lobo frontal (BURN; BATES, 2008). 
Dentre as hipóteses patofisiológicas para a ocorrência do déficit cognitivo e DRC aceitas na atualidade, sugere-se o acúmulo de toxinas como alumínio, ácido úrico e estanho; desidratação; e depósito de material neurofibrilar nos neurônios corticais (BURN; BATES, 2008; WILLS; SAVORY, 1985). São, também, considerados significativos os fatores de risco relacionados a hemodiálise, incluindo hipotensão arterial, microembolização e edema cerebral. Dessa forma, pode ser destacado que as vias que envolvem isquemia e reperfusão, bem como o surgimento de inflamação estão envolvidas na degeneração neuronal e vascular presentes no déficit cognitivo associado à DRC e hemodiálise (CHONG et al., 2004; MADERO et al., 2008).

Griva et al. (2006) estudaram a função cognitiva em indivíduos após 6 meses de transplante renal, onde os mesmos apresentaram melhora da memória, porém, as funções neuropsicológicas como atenção, concentração e habilidade psicomotora não mostrou melhora significativa.

Finalmente, vale citar que estudos realizados no laboratório do Dr. Mattson, onde a nossa colaboradora Dra. Elisa está realizando o seu pós-doutorado, mostraram que modelos em animais de falha renal aguda induzem inflamação e alterações funcionais no SNC, o que reforça o envolvimento da sinalização inflamatória no desenvolvimento de déficits cognitivos (LIU et al., 2008).

\subsection{Avaliação cognitiva na DRC}

A avaliação da função cognitiva pode ser efetuada usando-se métodos neurofisiológicos (EEG, potencial evocado cognitivo e potencial evocado sensorial) e neuropsicológicos, onde esse último consiste em testes de função cognitiva geral ou testes de compreensão de um domínio particular. Os vários testes neuropsicológicos incluem o Mini Exame do Estado Mental (MMSE), o 3MS, o exame cognitivo do CAMDEX - Cambridge Cognitive Examination, o Cognitive Capacity Screening Examination (CCSE) e o The Kidney Disease Quality of Life Cognitive Function subscale (KDQOL-CF) (MADERO et al., 2008).

O MMSE é um teste de avaliação cognitiva com sensibilidade de $87 \%$ e especificidade de $82 \%$, apresentando sensibilidade suficiente para a detecção de déficit cognitivo médio, porém é pouco sensível para detectar pequenas lesões subcorticais encontradas nos pacientes em hemodiálise (PEREIRA et al., 2007; TENG; CHUI, 1987; TOMBAUGH; McINTYRE, 1992). 
O 3MS é um teste de função cognitiva global com componentes de orientação, atenção, linguagem e memória, tem sensibilidade de $91 \%$ e especificidade de $97 \%$, apresenta maior sensibilidade para déficits cognitivos médios do que o MMSE (TENG; CHUY, 1987). O CCSE é um dos mais sensíveis testes de avaliação cognitiva, no entanto, devido a sua ênfase em cálculos matemáticos e abstração ele é fortemente influenciado pelo nível educacional (HERSHEY et al., 1987; MEYER et al., 2002).

O KDQOL é um questionário de saúde aplicado a qualidade de vida e usado em indivíduos com DRC, apresenta especificidade de 98\% e apenas 15\% de sensibilidade, porém, quando usado em conjunto com o 3MS é considerado o padrão ouro na indicação de alteração cognitiva nesse perfil de pacientes (HAYS et al., 1994; KURELLA et al., 2004; RAO et al., 2000).

Williams et al. (2004) estudaram a correlação entre as avaliações neuropsicológicas e o período interdialítico, encontrando que indivíduos em hemodiálise apresentam melhor função cognitiva após 1 hora de realização da diálise do que após 24 e 67 horas, talvez devido a uremia.

\subsection{Biomarcadores periféricos e neurodegeneração}

O uso de marcadores biológicos periféricos em humanos tem propiciado avanços significativos na identificação das bases moleculares associadas a alterações que ocorrem no SNC na vigência de várias doenças neuropsiquiátricas (GIBSON; HUANG, 2005; MARCOURAKIS et al., 2008; PRATICÓ, 2005). O uso desta estratégia associada a estudos de imagem tem se mostrado de grande importância no avanço dos estudos translacionais, na medida em que eles permitem validar as teorias obtidas em modelos de experimentação em animais com as prováveis alterações bioquímicas e moleculares presentes em células sanguíneas de pacientes com diferentes tipos de doenças neuropsiquiátricas, tais como depressão, doença de Parkinson (DP), DA, ou no estudo das alterações associadas ao envelhecimento. $O$ uso de biomarcadores na pesquisa clínica foi objeto de uma Reunião Científica promovida pela "Oxford University Saïd Business School" em associação com a "New York Academy of Science" em Janeiro de 2009, reunindo as maiores assumidades de diferentes países no campo das doenças neurodegenerativas, uma vez que os estudos translacionais constituem hoje objeto 
de grande interesse em vários centros de pesquisa do mundo (eventos do NYAS, janeiro de 2009 e Revista FAPESP, março de 2010).

Estudos recentes mostraram que no envelhecimento, as alterações observadas em plaquetas de idosos (KAWAMOTO et al., 2005) se correlacionam perfeitamente com os dados obtidos em plaquetas, hipocampo e córtex pré-frontal de animais de 24 meses quando comparados com animais de 4 meses, validando os nossos estudos realizados em plaquetas humanas (KAWAMOTO et al., 2013).

Estudo recente de Shadrina et al. (2010), ressalta a importância dos estudos em biomarcadores que permitam 0 diagnóstico pré-clínico de doenças neurodegenerativas como a DP. De fato, estudos em plaquetas (SCHULZ; BEAL, 1994) ou linfócitos (BARBANTI et al., 1999; PETROZZI et al., 2001) de indivíduos com DP esporádico revelaram anormalidades na biossíntese da dopamina e na função mitocondrial.

Outra evidência atual interessante foi a descrita por Calciano (2010), que estudou células mononucleares sangüíneas como biomarcador periférico em associação com parâmetros obtidos no MMSE de indivíduos com DA. Reale et al. (2004) estudaram células mononucleares de sangue periférico de pacientes com DA em tratamento com Donezepil, descrevendo redução de IL-1 $\beta$, IL-6 e TNF- $\alpha$, junto com o aumento na expressão e produção de IL-4, sugerindo que as citocinas inflamatórias periféricas são afetadas pelo tratamento com inibidores da acetilcolinesterase. Novak et al. (1998) relataram que a administração intracerebrovascular do agonista delta-opióide SNC-80 não altera a função das células natural killers (NK), linfócitos e macrófagos, porém, a administração intravenosa de SNC-80 está associada a imunopotencialização.

Finalmente poderíamos citar outros exemplos, tais como Ossa et al. (2010), que investigaram a ferritina eritrocitária e sérica como marcador periférico do estresse oxidativo e resposta inflamatória após acidente vascular encefálico (AVE) hemorrágico, sugerindo o potencial neurotóxico do ferro nos AVEs; e Pereira et al. (2007) que referem que a atividade da IL-10 reduz a produção de citocinas próinflamatórias em macrófagos estimulados em cultura pelo peptídeo WNT5a, condição freqüentemente descrita em pacientes com choque séptico. 


\subsection{Inflamação na DRC}

O processo inflamatório sistêmico, como o encontrado nos pacientes com DRC, é evidenciado pelo aumento nas concentrações plasmáticas de citocinas próinflamatórias, como a interleucina-6 (IL-6), interleucina-15 (IL-15) e interleucina-8 (IL8), sendo que as espécies reativas de oxigênio promovem a amplificação da liberação dessas citocinas, funcionando como mecanismo de retroalimentação positiva, de forma a manter um ciclo crônico e sistêmico que produz um estado próinflamatório (GIUNTA et al., 2008). Estudo com macrófagos in vitro, sugere a atenuação do efeito inflamatório pela ativação da proteína $C$ e da citocina antiinflamatória IL-10 com participação da WNT-5a na resposta inflamatória (GEORGE, 2008). Pesquisas sugerem que a inflamação persistente e o estresse oxidativo são iniciados precocemente nos processos de falência da função renal, podendo a produção de proteína $C$ reativa hepática estar associado a ocorrência de lesões vasculares (STENVINKEL, 2006).

Nas células endoteliais cerebrais, resíduos da externalização da membrana fosfolipídica promovem dano celular, desencadeando uma via celular inflamatória e trombose (CHONG; MAIESE, 2004).

No SNC, a neuroinflamação é caracterizada por infiltração de granulócitos e macrófagos/monócitos no parênquima cerebral, ativação da microglia e astrócitos, expressão de citocinas, moléculas de adesão e outros mediadores inflamatórios (LAKHAN et al., 2009). No entanto, a ativação de astrócitos e microglia não prevê o início da inflamação clássica ou da indução de imunidade adaptativa. Em vez disso, as respostas neuroimunes provocadas por doenças ou lesões podem ser consideradas como parte de um contínuo fluxo de informação entre as células do parênquima (neurônios e glia), endotélio e leucócitos circulantes (NATHAN, 2002).

Processos como a isquemia, excitotoxicidade e estresse oxidativo ativam as células da microglia e astrócitos que por sua vez reagem secretando citocinas e metaloproteases de matriz (que induzem a produção de espécies reativas de oxigênio) (LAKHAN et al., 2009).

Em situações de má perfusão cerebral, a microglia e os astrócitos podem exercer neuroproteção através da produção de moléculas neurotróficas como o fator neurotrófico derivado do cérebro (BDNF), fator de crescimento insulin - like I (IGF-I), entre outros (LAKHAN et al., 2009; PETZOLD et al., 2003). No entanto, há 
evidências de que células da glia ativadas em resposta à isquemia, têm o potencial de liberar citocinas pró-inflamatórias como o TNF- $\alpha$, IL- $1 \beta$ e IL-6, quemocinas, e outras moléculas potencialmente citotóxicas incluindo óxido nítrico (NO), espécies reativas de oxigênio e prostaglandinas (LUCAS et al., 2006). Estes mediadores inflamatórios levam a uma superexpressão de moléculas de adesão nas células endoteliais, permitindo que células sanguíneas inflamatórias, principalmente neutrófilos, infiltrem o tecido cerebral. Os neutrófilos, que também secretam citocinas, ocasionam uma maior ativação das células gliais. Este processo resulta na morte de células neuronais e aumento do dano à área isquêmica (POPOVICH; LONGBRAKE, 2008).

\subsection{Klotho}

A fosforilação de proteínas tem sido aceita como um dos mais importantes mecanismos de regulação da função celular. Há evidências de que os sinais extracelulares produzem diversos efeitos fisiológicos através da regulação do estado de fosforilação dos diversos tipos de fosfoproteínas presentes no interior da célula (NESTLER; GREENGARD, 1999). De fato, inúmeros trabalhos têm demonstrado que os nucleotídeos cíclicos (monofosfato de adenosina cíclico - AMPc - e monofosfato de guanosina cíclico - GMPc), assim como o cálcio $\left(\mathrm{Ca}^{++}\right)$, regulam uma variedade de funções, tais como transporte axoplasmático, além de síntese, liberação, geração de potenciais de ação e diferenciação celular através de proteínas quinases (por exemplo: a proteína quinase dependente de AMPc - PKA e a proteína quinase dependente de GMPc - PKG). Estas proteínas catalisam a transferência de grupos fosfato do trifosfato de adenosina (ATP) para aceptores protéicos (grupos hidroxila dos resíduos de treonina, serina ou tirosina) modulando a atividade funcional destas proteínas (FRANCIS; CORBIN, 1994; NESTLER; GREENGARD, 1999). Vale salientar que o mesmo conceito formulado para o processo de fosforilação deve ser estendido à via inversa, ou seja, aos processos envolvendo a desfosforilação de proteínas através da ação de proteínas fosfatases. Foram identificadas oito proteínas fosfatases, as quais podem ser classificadas como fosfatases do tipo fosfoserina/fosfotreonina ou do tipo fosfotirosina (NESTLER; GREENGARD, 1999). 
Klotho é uma proteína transmembrana, estando sua expressão presente nos tecidos que regulam a homeostase do $\mathrm{Ca}^{++}$, incluindo os túbulos contorcidos distais no rim, a glândula paratireoide e o epitélio do plexo coróide no cérebro (MATSUMURA et al., 1998; SOPJANI et al., 2011). O domínio extracelular da klotho pode ser clivado, permitindo sua circulação no líquido cerebroespinal e no sangue (BLOCH et al., 2009). A $\alpha-$ Klotho ( $\alpha-k l)$ foi identificada pela primeira vez como um gene relacionado ao envelhecimento e posteriormente estando envolvido como regulador do fosfato, do metabolismo da vitamina $D$ e regulando a homeostase do $\mathrm{Ca}^{++}$(KURO-O, 2011).

O gene klotho codifica a proteína klotho com um único domínio transmembrana. O domínio extracelular apresenta dois domínios homólogos com sequência similar a da $\beta$-glucosidase de bactérias e plantas (KOROSU; KURO-O, 2008). A proteína klotho tem sido descrita com um papel enzimático efetivo, ao modificar glicoproteínas na membrana celular, onde, dependendo da proteína de membrana, a atividade da klotho pode acelerar ou retardar a degradação dessas proteínas (HU et al., 2010).

Nos rins, na glândula paratireóide e no plexo coróide, $\alpha-k l$ se liga a $\mathrm{Na}^{+} / \mathrm{K}^{+}-$ ATPase, onde baixas concentrações de $\mathrm{Ca}^{++}$extracelular permitem a rápida translocação do complexo $\alpha-\mathrm{kl} / \mathrm{Na}^{+} / \mathrm{K}^{+}$-ATPase de organelas endossomais para a membrana plasmática, permitindo a secreção do paratormônio (PTH) pelas glândulas paratireoides e o transporte transepitelial de $\mathrm{Ca}^{++}$nos rins e plexo coróide (IMURA et al., 2007; NABESHIMA, 2010).

Assim, além de estar relacionada ao processo de envelhecimento e expectativa de vida (KURO, 2010), a expressão de klotho está envolvida no controle do $\mathrm{Ca}^{++}$ pelo rim, onde a estabilização do TRPV5 pelo klotho, facilita a recaptação do $\mathrm{Ca}^{++}$ no rim. Estudos demonstram que baixas concentrações de $\mathrm{Ca}^{++}$podem induzir a secreção de klotho na glândula paratireoide e no plexo coróide, bem como a klotho apresenta um importante papel mediador da atividade da $\mathrm{Na}^{+} / \mathrm{K}^{+}$-ATPase dependente do PTH (IMURA et al., 2007; RAZZAQUE, 2008; TSUJIKAWA et al., 2003). Estudos in vitro usando o plexo coróide isoladamente, mostraram rápida elevação na atividade da $\mathrm{Na}^{+} / \mathrm{K}^{+}$-ATPase após incubação com meio de cultura contendo baixa concentração de $\mathrm{Ca}^{++}$(GUPTA et al., 2004; RAZZAQUE, 2008). No entanto, a atividade da $\mathrm{Na}^{+} / \mathrm{K}^{+}$-ATPase não é alterada pelas mudanças na concentração do $\mathrm{Ca}^{++}$em camundongos klotho knockout, sugerindo que a proteína 
de membrana klotho é um fator essencial no recrutamento rápido da $\mathrm{Na}^{+} / \mathrm{K}^{+}$-ATPase da superfície celular em resposta as alterações na concentração do $\mathrm{Ca}^{++}$ extracelular (IMURA et al., 2007; RAZZAQUE, 2008).

A supressão prolongada do PTH em camundongos klotho knockout foi associada com a elevação da atividade da vitamina $D$ e hipercalemia, evidenciando uma interrelação entre a vitamina $D$ e o klotho (LANSKE; RAZZAQUE, 2007; TSUJIKAWA et al., 2003), onde a vitamina $D$ pode regular a atividade da klotho por induzir sua produção, e o klotho pode contribuir negativamente na síntese ativa da vitamina $D$, possivelmente pela supressão da expressão do gene 1-alfa-hidroxilase (YOSHIDA et al., 2002).

Tem sido descrito, também, que o klotho participa do efeito inibitório do FGF23 sobre a formação de $1,25(\mathrm{OH})_{2} \mathrm{D}_{3}$, elevando sua produção (RAZZAQUE, 2009) e a deficiência de klotho resulta em hipercalcemia, hiperfosfatemia e calcificação vascular (KURO, 2010). A restrição de vitamina $D$ parcialmente reverte o processo acelerado de envelhecimento, o déficit de crescimento e a morte prematura dos eritrócitos em camundongos klotho-knockout. Além disso, mecanismos não associados a $1,25(\mathrm{OH})_{2} \mathrm{D}_{3}$ e $\circ \mathrm{Ca}^{++}$contribuem para a redução do sal por via renal nesses animais (TSUJIKAWA et al., 2003). Estudo de Sopjani et al. (2011) demonstrou o efeito estimulatório do klotho sobre a distribuição e função da $\mathrm{Na}^{+} / \mathrm{K}^{+}$ATPase.

Estudo associando a vitamina $D$ à função cognitiva em indivíduos jovens tem sugerido seu papel neuroprotetor via mecanismos vasculares (BUELL; TUCKER, 2011). Pesquisa realizada em modelo animal sugere que a vitamina $D$ pode interferir na expressão de neurotrofinas e proteínas de ligação de $\mathrm{Ca}^{++}$necessárias para a função cerebral normal (CLEMENS et al., 1988), evidências também sugerem que a vitamina $D$ pode suprimir a expressão de citocinas inflamatórias e, dessa forma, sua deficiência pode estar relacionada às doenças inflamatórias neurodegenerativas e mecanismos das doenças vasculares (GARCION et al., 1997; GARCION et al., 1998). 


\section{JUSTIFICATIVA}

Devido a importância clínica do déficit cognitivo como comorbidade da DRC e aos poucos estudos relacionados aos mecanismos de neurotoxidade envolvidos em sua ocorrência, especialmente na neuroinflamação, torna-se relevante avaliar os parâmetros relatados acima. A Klotho é uma proteína endógena que é capaz de apresentar uma ação anti-inflamatória e protetora das células renais através da inibição da ativação de NF-KB e a subsequente produção de citocinas inflamatórias em resposta ao estímulo de TNF- $\alpha$. Portanto, este projeto pode auxiliar na busca dos mecanismos de neurotoxicidade causados durante a progressão da DRC. 


\section{OBJETIVOS}

Estudar as alterações cognitivas em pacientes com DRC submetidos a tratamento de hemodiálise, bem como o desenvolvimento de déficit cognitivo em ratos submetidos a 5/6 de ablação renal para o desenvolvimento de lesão renal. Além disso, investigar o perfil cerebral neuroinflamatório e possíveis alterações em parâmetros bioquímicos associados a neuroinflamação e a klotho.

\subsection{Objetivos específicos}

- Avaliar os níveis de citocinas e marcadores neurais em soro (humano e animal), líquor (animal) e homogenato de tecido cerebral (córtex frontal, hipocampo, amígdala e rim).

- Avaliar os níveis de klotho no soro (humano e animal) e homogenato de tecido cerebral (córtex frontal e hipocampo). 


\section{MATERIAIS E MÉTODOS}

Esta pesquisa foi realizada no Laboratório de Neurofarmacologia Molecular no Instituto de Ciências Biomédicas da Universidade de São Paulo (ICB-USP), sob orientação do Prof. Dr. Cristoforo Scavone e co-orientação da Dra. Elisa Mitiko Kawamoto, sendo dividida em duas situações distintas, uma envolvendo o estudo em seres humanos com DRC e outra envolvendo o estudo em modelo animal para DRC.

O primeiro foi desenvolvido em colaboração com o Centro Integrado de Nefrologia (CINE) e Dialysis Center - Guarulhos/SP e São Paulo/SP, respectivamente, os quais se responsabilizaram pelo acompanhamento clínico e neurológico dos pacientes, sendo aprovado pela Comissão Nacional de Ética em Pesquisa em Humanos - CONEP (parecer 869/CEP aprovado em 10 de dezembro de 2008, ICB - USP). E o segundo foi desenvolvido em colaboração com o Prof. Dr.

Roberto Zatz, chefe do Laboratório de Fisiopatologia Renal (LIM 16 - FMUSP), responsável pelo modelo animal em DRC (5/6 nefrectomia), com aprovação pela Comissão Nacional de Ética em Pesquisa Animal (registro $n^{0} .15$, fls. 099 do livro 02).

\subsection{Pesquisa clínica em humanos}

\subsubsection{Triagem dos pacientes}

A amostra foi composta por 50 indivíduos voluntários, com faixa etária entre 40 e 50 anos, sendo 10 indivíduos sem comprometimento renal ou cognitivo, e $40 \mathrm{com}$ diagnóstico de DRC submetidos à tratamento de hemodiálise por, no mínimo, 12 meses e no máximo 18 meses. Após o preenchimento do Termo de Esclarecimento Livre Consentido, os pacientes foram divididos em três grupos:

- Grupo controle: indivíduos sem alteração da função renal ou alteração da função cognitiva.

- Grupo DRC: indivíduos em programa de hemodiálise 4h/3X/semana, com fístula arteriovenosa (FAV) em membro superior, SEM alteração da função cognitiva.

- Grupo DRC-Cl: indivíduos em programa de hemodiálise 4h/3X/semana, com FAV em membro superior, COM alteração da função cognitiva. 
Foi considerado critério de exclusão os indivíduos que apresentaram diabete, infecção ou fizerem uso de vitamina D.

\subsubsection{Avaliação cognitiva}

Foi aplicado o 3MS (ANEXO A), elaborado por Teng e Chui (1987) e validado no Brasil por Melo (2008), devido sua maior sensibilidade para detectar déficits cognitivos leves. Também, foi realizado o KDQOL-SF (ANEXO B) como subscala para avaliação da função cognitiva (KURELLA et al., 2004), com validação no Brasil realizada por Duarte et al. (2003) para aumentar a confiabilidade nos testes de avaliação cognitiva em indivíduos com DRC. Atualmente, esses testes têm sido usados como instrumento para estimar a função cognitiva em indivíduos com DRC ou com doença renal em estágio final (KURELLA et al., 2004; MADERO et al., 2008).

\subsubsection{Coleta de soro}

Nos indivíduos do grupo Controle coletamos uma única amostra $3 \mathrm{~mL}$ de sangue venoso periférico e nos indivíduos com DRC coletamos duas amostras de $3 \mathrm{~mL}$ de sangue venoso periférico, sendo uma amostra pré e outra pós-hemodiálise, de cada indivíduo em tubos com gel separador.

As amostras de sangue foram centrifugadas por $10 \mathrm{~min}, 1200 \mathrm{rpm}$ a $20{ }^{\circ} \mathrm{C}$, em seguida, o sobrenadante plasmático foi coletado e armazenado em alíquotas de 500 $\mu \mathrm{L}$ a $-80{ }^{\circ} \mathrm{C}$ até a data do processamento.

Uma alíquota de $2 \mathrm{~mL}$ de sangue venoso periférico, pré-diálise e outra pósdiálise, foi coletada em tubo seco e enviada ao Laboratório Soares de Araújo, responsável pela realização dos seguintes exames laboratoriais: uréia pré-diálise, uréia pós-diálise, creatinina, $\mathrm{Ca}^{++}$iônico, fósforo, potássio, TGP, fosfatase alcalina, ferro, saturação de de transferrina, proteína total, albumina, globulina, hematócrito completo, colesterol total, LDL, HDL e triglicerídeos. 


\subsubsection{Ensaio de ELISA para TNF-a, IL-1 $\beta$, IL-6 e IL-10, cortisol, proteína C reativa, estrogênio e Klotho}

Utilizamos os kits de imunoensaio Multiplex (Millipore ${ }^{\circledR}$ ), usando a plataforma de tecnologia Lumine ${ }^{\circledR} \mathrm{xMap}^{\circledR}$, o qual envolve um processo de coloração de microesferas de látex com dois fluoróforos, que permitem a formação de combinação de cores que podem ser identificadas pelo Luminex. Solicitamos o desenvolvimeto dos kits para dosagem de TNF- $\alpha$, IL-1 $1 \beta$, IL-6 e IL-10 para soro humano, onde anticorpos de captura para cada um desses analitos estavam localizados nas microesferas através de ligações covalentes não reversíveis. Assim, quando pipetamos $25 \mu \mathrm{L}$ de soro no poço da placa, os analitos se ligam aos anticorpos de captura na superfície das esferas, essa reação foi amplificada pela adição do marcador fluorescente estreptavidina-ficoertina, sendo a emissão de luz medida em equipamento Luminex 200, que faz uso de dois feixes de laser, o primeiro classifica a microesfera (código de cor para o ensaio) e o segundo quantifica o sinal de reporte em cada microesfera. As concentrações de TNF- $\alpha$, IL$1 \beta$, IL-6 e IL-10 foram estimadas a partir de uma curva padrão e expressa em função da concentração de proteína total da amostra em pg/ug de proteína.

Para detecção do cortisol, do estrogênio e da klotho nas amostras de soro, utilizamos o método ELISA (Enzyme Linked Immunosorbent Assay) da eBioscience (San Diego, CA, EUA) de acordo com as especificações do fabricante. De maneira resumida, colocamos $100 \mu \mathrm{L}$ de anticorpo monoclonal anti-cortisol ou anti-estrogênio ou anti-klotho em cada poço de uma placa de 96 poços sendo mantido do dia para a noite a $4 \stackrel{\circ}{\circ}$. No dia seguinte, adicionamos um tampão para bloquear as ligações inespecíficas por 1 hora a temperatura ambiente, os poços foram lavados com tampão TBS-T (50 mM Tris-base, $150 \mathrm{mM} \mathrm{NaCl}, 0,05 \%$ Tween). As amostras (50 $\mu \mathrm{L})$ ou o padrão de cortisol $(50 \mu \mathrm{L})$ ou de estrogênio $(50 \mu \mathrm{L})$ ou de klotho $(50 \mu \mathrm{L})$ foram adicionados aos poços e incubados por 2 horas a $37^{\circ} \mathrm{C}$, seguindo-se com a lavagem dos poços com TBS-T. Cem microlitros de anti-imunoglobulina $Y$ da peroxidase da raiz forte (horseradish $Y$ anti-imunoglobulina) foram adicionadas aos poços e incubadas por 1 hora a $37^{\circ} \mathrm{C}$, sendo em seguida lavados e adicionados 100 $\mu \mathrm{L}$ do substrato enzimático aos poços, devendo permanecer incubados por 15 minutos, até o aparecimento da cor azul. A reação foi interrompida com $100 \mu \mathrm{L}$ de 1 $M$ de ácido fosfórico e a absorbância medida no comprimento de onda de $450 \mathrm{~nm}$. A 
concentração de cortisol e estrogênio foi estimada a partir de uma curva padrão e expressa em função da concentração de proteína total da amostra em pg/ug de proteína.

A dosagem da proteína $C$ reativa (processo inflamatório) foi realizada no Laboratório Central do Hospital Universitário da USP, pelo método de nefelometria automatizado (SILVA, 2010).

\subsection{Modelo experimental para DRC em animais}

A nefropatia crônica está relacionada a fatores como glomeruloesclerose, fibrose renal e falência renal, podendo ser iniciada por mecanismos imunes e não imunes. Considerando algumas dificuldades relacionadas aos estudos envolvendo seres humanos, modelos experimentais que permitam 0 desenvolvimento progressivo da nefropatia têm sido pesquisados por muitos anos e, após realizarmos parceria com o Prof. Dr. Roberto Zatz, acrescentamos em nossos estudos o modelo experimental de nefrectomia $5 / 6$ desenvolvido em animais, de acordo com a descrição abaixo.

\subsubsection{Modelo de 5/6 de ablação renal}

Quarenta ratos Munich-Wistar adultos, machos, pesando inicialmente entre 230 e $260 \mathrm{~g}$ foram submetidos a $5 / 6$ de nefrectomia $(\mathrm{Nx})$, realizada através de laparotomia ventral sob anestesia com pentobarbital sódico $(50 \mathrm{mg} / \mathrm{kg} / \mathrm{IP})$, sendo removido o rim direito e realizado a ligação de 2 ramos da artéria renal esquerda, resultando em infartação de $2 / 3$ do rim esquerdo, de forma que os animais $\mathrm{Nx}$ desenvolveram lesão de $5 / 6$ da massa renal total (MACHADO et al., 2012). RatosSham foram operados sob o mesmo esquema anestésico e os pedículos renais foram manipulados sem que houvesse remoção da massa renal. Após recuperação da anestesia os animais foram divididos em dois grupos:

- Sham ( $n=20)$ : animais sem alteração da função renal, usados como controle.

- $\mathrm{Nx}(\mathrm{n}=20)$ : animais com DRC.

Os animais foram mantidos no Biotério do Departamento de Fisiologia e Biofísica da Santa Casa de Misericórdia de São Paulo e acompanhados por um período de cinco meses, durante a progressão da DRC. Nesse período, foram realizados testes 
de memória e comportamento animal, bem como coleta mensal de sangue através de punção da veia caudal, pesagem dos animais e mensuração da pressão arterial pela cauda.

\subsubsection{Teste de comportamento em animais}

Estudos recentes têm apontado a relação da DRC com o declínio cognitivo em humanos. Nesse intuito, após o estabelecimento do modelo experimental em animal para DRC, selecionamos os testes de comportamento abaixo descritos, para verificar possíveis alterações da função cognitiva.

\subsubsection{Campo aberto}

O Campo Aberto é um dos testes mais amplamente utilizados nos estudos de comportamento animal, permitindo a análise de dados referentes ao comportamento exploratório e mobilidade geral (GOULD et al., 2009).

O aparato do Campo Aberto usado neste estudo é composto de uma caixa quadrada, construída em material acrílico transparente, apresentando sensores capazes de detectar o número de movimentos nos planos horizontal e vertical.

Esse experimento foi realizado após 30 e 125 dias de nefrectomia, objetivando mensurar a capacidade de deslocamento vertical e horizontal, espontânea, nos animais estudados. Assim, na data de realização do experimento, os animais foram transportados até a antessala de experimentação e mantidos ali por 2 horas, permitindo a ambientação dos mesmos. Após esse período, os animais foram testados individualmente, sendo colocados na região central do Campo Aberto e deixados por 5 minutos para explorar livremente todo o aparato, nesse período, os sensores presentes no aparato registraram o número de movimentos vertical e horizontal. Terminado o período de teste, o animal era retirado do interior do aparato e a superfície do Campo Aberto limpa com álcool $5 \%$. Ao final do experimento, os animais foram devolvidos ao biotério. 


\subsubsection{Labirinto de Barnes}

Avaliamos o aprendizado viso-espacial e a memória utilizando o Labirinto de Barnes, de acordo com Babovic et al. (2008).

O labirinto de Barnes é composto por uma prancha circular branca de 1,30 metro de diâmetro que apresenta 16 orifícios $(9,5 \mathrm{~cm}$ de diâmetro cada), dispostos radialmente e que serviram como saída de escape para os animais. Ao redor de todo perímetro da prancha foi colocada uma contenção em cor preta, contendo quatro figuras geométricas amarelas, que serviram como pistas para a orientação espacial dos animais. Esse aparato foi posicionado a um metro do chão e uma lâmpada fluorescente de $21 \mathrm{~W}$ foi posicionada de forma a permanecer centralizada em relação a prancha, não sendo mais deslocado dessa posição durante todo o período de experimentação. No labirinto de Barnes a tarefa do animal é de se orientar pelas pistas expostas no ambiente e encontrar e entrar, no menor tempo possível, na caixa de escape. Assim, previamente ao início do experimento, os animais foram randomicamente sorteados para um número correspondente a um dos orifícios de saída, onde, durante o experimento, foi colocada uma caixa de escape contendo maravalha encaixada sob o labirinto circular.

No dia de realização do experimento os animais foram deixados por 2 horas na antessala onde seriam realizados os estudos de comportamento, permitindo sua ambientação. Após esse período, iniciamos os testes no labirinto de Barnes, sendo executadas as seguintes etapas:

- Treino: limpeza da prancha com álcool $5 \%$ e posicionamento da caixa de escape sob o orifício compatível, de acordo com sorteio prévio, sendo que este permaneceu o mesmo em todos os ensaios em que o animal foi retestado. Seguiu-se com a colocação do animal no centro da arena sob uma caixa de acrílico transparente por 1 minuto, estando o animal submetido a um ruído promovido por um rádio fora de frequência e iluminação intensa, período necessário para o animal observar o ambiente. Após esse tempo, o animal foi liberado para exploração do labirinto e feito o registro do tempo que o mesmo demorou a entrar na caixa de escape, sendo o tempo máximo para exploração do ambiente de cinco minutos. Caso o animal não atravessasse o orifício para o interior da caixa de escape, era conduzido gentilmente pelo experimentador. Uma vez na caixa, a iluminação e o ruído eram retirados e o animal permanecia no interior da caixa por um minuto. Essa fase foi realizada 
apenas um dia antes de ser iniciado a próxima fase a qual foi desempenhada uma vez no período da manhã e outra no período da tarde com 3 horas de intervalo entre elas.

- Teste: realizado durante cinco dias consecutivos e nos períodos de reteste, ou seja, após 14, 30, 60, 90 e 120 dias. Após a limpeza da arena com álcool 5\%, cada animal foi colocado no centro da arena sob uma cúpula de acrílico transparente durante 1 minuto, sendo mantidos sob uma iluminação intensa e um ruído promovido por um rádio fora de freqüência. Após esse período o animal foi liberado para explorar o ambiente, por um tempo máximo de 5 minutos, até sua entrada na caixa de escape, quando a luz era apagada e o ruído cessado, permanecendo nessas condições por 1 minuto. Foi registrado o tempo que o animal demorou para encontrar a saída de escape, o tempo total necessário até sua entrada na caixa de escape e o número de erros durante a exploração do ambiente. Esse procedimento foi executado duas vezes ao dia, com intervalo de 3 horas entre eles, permitindo 0 uso das médias diárias na realização da análise estatística.

\subsubsection{Esquiva inibitória}

Avaliamos a memória contextual reforçada por estímulo aversivo através do método de esquiva inibitória, onde o equipamento (modelo Ugo Basile, Itália) consiste de uma gaiola dividida em dois compartimentos de mesmo tamanho, sendo um iluminado e o outro escuro, os quais são separados por uma porta-guilhotina. Os animais foram colocados individualmente na parte iluminada da gaiola, sendo nesse momento acionado um cronômetro para medir o tempo (em segundos) até que os mesmos passassem pela porta e atingissem o lado escuro da gaiola, de forma que o tempo máximo de latência fosse de 300 segundos. Ao atingir o lado escuro, a portaguilhotina se fecha em 2 segundos (correspondente ao tempo necessário para que o animal atravesse por inteiro) e uma corrente elétrica de 0,5 mA é acionada pelas barras metálicas da gaiola sob as patas do animal durante 2 segundos.

Para avaliarmos a memória de longo prazo, primeiramente realizamos um treino, seguindo-se com a aplicação do teste 24 horas após o treino e sessões de reteste após 30, 60 e 90 dias da fase de treino. 
Em 1950 Berlyne descreveu que ratos passavam mais tempo explorando um objeto novo do que um objeto previamente explorado, ou seja, familiar (BEVINS; BESHEER, 2006). Esse teste de reconhecimento requer a integridade de memória do objeto previamente conhecido, compondo um teste de comportamento para os processos neuronais de armazenamento e subseqüente recordação do objeto familiar (KIM et al., 1997; MUMBY, 2001).

O teste de Reconhecimento do Novo Objeto é dividido em duas fases, na primeira o animal é familiarizado com o objeto-amostra e na segunda o animal é apresentado ao novo objeto.

O procedimento executado é composto de um pré-treinamento, onde durante quatro dias consecutivos os animais foram transportados até a sala de teste e colocados um a um por 5 minutos na caixa de teste (dimensão $41 \times 34 \mathrm{~cm} ; 1 \mathrm{~m}$ ) a qual apresenta as paredes laterais na cor preta e o fundo na cor branca. Após esse período, realizamos o treinamento, onde posicionamos dois objetos-amostra (um no canto direito da caixa e outro no canto esquerdo) no interior da caixa de teste e em seguida o animal foi posicionado no centro da caixa, permitindo a exploração do ambiente por 10 minutos. Passados esse período, o animal era retirado e testado após 2 horas, onde se seguiu com o mesmo procedimento do teste, porém, um dos objetos-amostra foi substituído por um objeto novo. Essa segunda fase teve duração de 5 minutos, para que o objeto novo não se tornasse familiar. Aplicamos esse teste com 30, 60, 90 e 120 após o procedimento cirúrgico.

Durante o procedimento foram documentados os tempos de exploração do objeto-amostra, do objeto-novo, número de sibilas e tempo de grooming. A análise dos dados foi realizada de acordo com a seguinte fórmula:

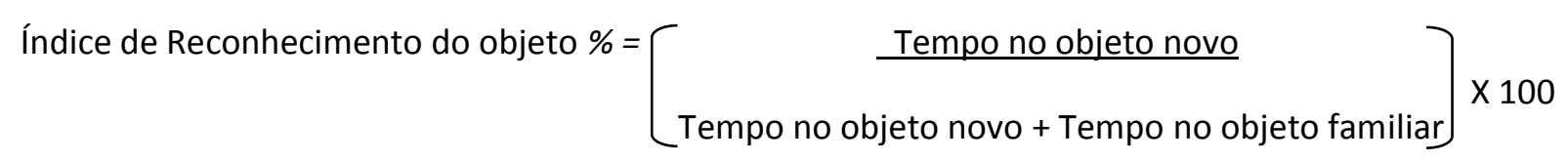




\subsubsection{Ensaio de ELISA para TNF-a, IL-1 $\beta$, IL-2, IL-4, IL-6 e IL-10, IFN- $\lambda$, proteína $C$ reativa, corticoesterona e klotho}

Durante o período de realização dos testes de comportamento, foram coletas amostras de sangue dos animais, esse procedimento foi executado mensalmente. $O$ sangue foi coletado em tubo seco através de punção da veia caudal, sendo posteriormente centrifugado a $5000 \mathrm{rpm}$ por 10 minutos a $18{ }^{\circ} \mathrm{C}$, permitindo a separação do soro, o qual foi armazenado em freezer $-80{ }^{\circ} \mathrm{C}$ até a data do processamento.

Utilizamos os kits de imunoensaio Multiplex $\left(\right.$ Millipore $^{\circledR}$ ), usando a plataforma de tecnologia Luminex ${ }^{\circledR} \mathrm{xMap}^{\circledR}$, conforme descrito acima. Solicitamos 0 desenvolvimento dos kits para dosagem de TNF- $\alpha$, IL-1 $\beta$, IL-2, IL-4, IL-6, IL-10, INF$\lambda$ e proteína $C$ reativa para soro, líquido cefalorraquidiano $(L C R)$ e macerado de tecido de rato (conforme descrito abaixo), sendo desenvolvido o mesmo procedimento que o descrito no item 4.1.4.

\subsubsection{Coleta do $L C R$ e do encéfalo}

O LCR dos animais foi coletado por punção da cisterna magna, como descrito anteriormente por Cruz Portela et al. (2002). Onde, após anestesia com isofluorano, os animais foram posicionados em equipamento estereotáxico, de forma a facilitar o acesso a região da cisterna magna. Seguiu-se com a retirada da pele e dos músculos paravertebrais na região posterior da cabeça e coluna cervical do animal, sendo, então, inserida a agulha no espaço entre a região occipital e a primeira vertebra, de forma a atingir a cisterna magna e permitir a punção do LCR.

O LCR coletado foi submetido a centrifugação $(5000 \mathrm{rpm}$, durante 5 minutos, a $18{ }^{\circ} \mathrm{C}$ ) e o sobrenadante armazenado em freezer $-80{ }^{\circ} \mathrm{C}$ até a data do processamento.

Após a retirada do LCR, os animais foram submetidos a decaptação, abrimos a calota craniana aberta, de forma a expor o encéfalo, o qual foi retirado, lavado em PBS gelado e dissecado sob superfície gelada, sendo retirado as regiões do cortex frontal, hipocampo e amígdala. Também, abrimos a cavidade abdominal dos animais e retiramos o rim esquerdo dos animais do grupo Sham e o rim remanescente dos animais Nx. Os tecidos foram armazenados em freezer $-80{ }^{\circ} \mathrm{C}$ até a data do 
processamento.

Para a realização dos ensaios de ELISA em homogenato de tecido, as estruturas foram descongeladas e homogeneizadas em tampão fosfato-salina (PBS: $\mathrm{NaCl} 137$ mM, KCl 2,68 mM, KH2PO4 1,27 mM, Na2HPO4 8,06 mM) adicionado de inibidores de proteases (PMSF 0,5 mM; ortovanadato $3 \mathrm{mM}$; leupeptina $2 \mathrm{mg} / \mathrm{mL}$; antipaína $2 \mathrm{mg} / \mathrm{mL}$ ) e EDTA 0,1 mM. Em seguida o homogenato foi centrifugado a 12.000 x g por 30 segundos a $4{ }^{\circ} \mathrm{C}$, descartando-se 0 sobrenadante. Ressuspendemos o pellet em tampão de lise (HEPES $10 \mathrm{mM} ; \mathrm{MgCl} 21,5 \mathrm{mM}$; $\mathrm{KCl}$ $10 \mathrm{mM}$; PMSF 0,5 mM; ortovanadato $3 \mathrm{mM}$; leupeptina $2 \mu \mathrm{g} / \mathrm{mL}$; antipaína $2 \mu \mathrm{g} / \mathrm{mL}$ ) e incubamos em gelo durante 10 minutos. Em seguida, foi adicionado $10 \mu \mathrm{L}$ de NP. 40 10\% com agitação vigorosa, centrifugando-se a 12.000 rpm por 30 segundos a 4 ${ }^{\circ} \mathrm{C}$, e o sobrenadante foi recolhido e a concentração de proteínas determinada, estocando as amostras a $-80^{\circ} \mathrm{C}$.

\subsubsection{Dosagem da creatinina sérica}

A concentração sérica de creatinina foi determinada na amostra de sangue coletada da aorta abdominal, na data da eutanásia, e a dosagem foi realizada através de sistema colorimétrico de kit comercialmente disponível pela Labtest Diagnóstica S.A.

\subsubsection{Estudos histológicos}

Após a perfusão in situ, os tecidos renais foram pesados, fatiados em 2-3 segmentos coronais de 4-5 mm de espessura, e pós-fixados em formaldeído a 10\%. Após a fixação os tecidos foram mantidos por 14 horas em processador automático de tecidos (Jung Histokinette 2000, Leica Instruments $\mathrm{GmbH}$, Alemanha) para desidratação, diafanização e impregnação em parafina. Os rins foram retirados do aparelho, incluídos em blocos de parafina e cortados com a espessura de $4 \mu \mathrm{m}$ através de micrótomo (Reichert Yung Supercut 2065 Leica, Nussloch, Alemanha). Os cortes histológicos foram corados pela reação de Ácido Periódico-Shiff (PAS) para quantificar os diferentes graus de lesões glomerulares e também foram corados pela reação de Tricrômio de Masson para determinar a fração da área da córtex renal ocupada por interstício. 


\subsubsection{Porcentagem de esclerose glomerular}

A quantificação da porcentagem de esclerose glomerular (\%EG) foi realizada através da contagem do número de glomérulos com esclerose, independente da extensão da lesão. Para essa avaliação foram analisados 200 glomérulos por corte, sob aumento de 200X (FUJIHARA et al., 2001).

\subsubsection{5 Índice de esclerose glomerular}

O grau de lesão glomerular de cada animal foi avaliado utilizando um número de glomérulos nunca inferior a 150 em microscópio ótico em aumento final de 200X. Para cada glomérulo foi atribuindo uma "nota" correspondente à extensão da lesão: 0 , para glomérulos intactos; 1 , para lesões acometendo $10 \%$ ou menos da superfície glomerular; 2, para lesões afetando entre $10-20 \%$ do glomérulo; 3, para lesões compreendendo entre $20-30 \%$ do glomérulo e assim por diante até a "nota" 10 correspondente à esclerose global do glomérulo. $O$ índice de esclerose glomerular (IEG) foi calculado como a média ponderada de todas as "notas" atribuídas individualmente aos glomérulos examinados (FUJIHARA et al., 2005).

\subsubsection{Fração do córtex renal ocupada pelo interstício}

Para avaliar a extensão da expansão intersticial da fração da córtex renal (\%INT), foi utilizado a coloração de tricrômio de Masson. Que foi quantificada por método de contagem de pontos em 25 campos microscópicos consecutivos, em um aumento final de 100x com uma ocular graticulada de 176 pontos (JEPSEN et al., 1979).

\subsection{Análise dos resultados}

Os dados de determinações de ELISA receberam tratamento estatístico pelo teste ANOVA seguido do pós-teste Student-Newman-Kewls, onde as diferenças foram consideradas significativas para o valor $p \leq 0,05$.

Os dados obtidos no Labirinto de Barnes foram analisados pelo tratamento estatístico ANOVA de duas vias seguido do pós-teste Bonferroni. E os dados da 
Esquiva Inibitória e Reconhecimento do Novo Objeto foram submetidos ao tratamento estatístico ANOVA de uma via não-paramétrico. Sendo as diferenças consideradas significativas para o valor $p \leq 0,05$. 


\section{RESULTADOS}

\subsection{Pesquisa clínica em humanos}

\subsubsection{Inclusão dos sujeitos de pesquisa}

Foi realizada triagem dos pacientes com DRC em hemodiálise do CINE, e 40 indivíduos entre homens e mulheres foram selecionados para participar dessa pesquisa (Tabela 1). Durante o processo de aplicação das avaliações de cognição (3MS e KDQOL), tivemos 2 indivíduos que desistiram de participar da pesquisa, 1 indivíduo que foi transferido da unidade de hemodiálise onde esse estudo foi realizado e 1 indivíduo que foi submetido a transplante renal, totalizando, portanto tivemos 36 indivíduos participantes nesse estudo.

Tabela 1 - Caracterização demográfica dos indivíduos avaliados nessa pesquisa.

\begin{tabular}{|c|c|c|c|}
\hline & $\begin{array}{l}\text { Controle } \\
(n=10)\end{array}$ & $\begin{array}{c}\text { DRC } \\
(n=21)\end{array}$ & $\begin{array}{l}\text { DRC-Cl } \\
(\mathrm{n}=15)\end{array}$ \\
\hline Idade (anos) & $45 \pm 2,8$ & $45 \pm 3,2$ & $46 \pm 2,9$ \\
\hline Sexo masculino (\%) & $40 \%$ & $62 \%$ & $40 \%$ \\
\hline Educação (anos) & $11,5 \pm 2,6$ & $11,7 \pm 3,2$ & $10,1 \pm 4,7$ \\
\hline $\begin{array}{l}\text { Anos em programa de } \\
\text { hemodiálise }\end{array}$ & & $4,3 \pm 1,5$ & $3,8 \pm 0,4$ \\
\hline \multicolumn{4}{|l|}{ Etnia (\%) } \\
\hline Afro-descendente & $20 \%$ & $44 \%$ & $31 \%$ \\
\hline Caucasiano & $80 \%$ & $66 \%$ & $62 \%$ \\
\hline Asiático & {[} & - & $7 \%$ \\
\hline Valor do 3MS & $91 \pm 5,4$ & $90 \pm 4,6$ & $71 \pm 15,1$ \\
\hline
\end{tabular}

Baseados nos valores obtidos no 3MS e KDQOL-SF e nas adaptações descritas na Tabela 2 e 3 , os indivíduos foram divididos em dois grupos experimentais:

- Grupo experimental DRC (indivíduos com lesão renal crônica em programa de hemodiálise e ausência de déficit de cognição): composto por $60 \%$ dos indivíduos avaliados $(n=21)$, sendo 13 indivíduos do sexo masculino e 8 do feminino. 
- Grupo experimental DRC-CI (indivíduos com lesão renal crônica em programa de hemodiálise e presença de déficit de cognição): composto por $40 \%$ dos indivíduos avaliados $(n=15)$, sendo 6 indivíduos são do sexo masculino e 9 do feminino.

Paralelamente, triamos indivíduos sem DRC ou qualquer outra patologia associada bem como ausência de déficit de cognição para constituir o grupo controle $(n=10)$, onde tivemos 5 indivíduos do sexo masculino e 5 do feminino.

Tabela 2 - Descrição dos valores usados na adequação do nível de escolaridade para o 3MS usado para determinar alterações na função cognitiva.

\begin{tabular}{cccc}
\hline Anos de Estudo & Valor Médio & Desvio Mínimo & Desvio Máximo \\
\hline 0 & 62 & 50 & 71 \\
1 a 2 & 82 & 78 & 91 \\
3 a 14 & 89 & 83 & 94 \\
15 ou mais & 95 & 91 & 97 \\
\hline e: Contribuições de quatro instrumentos de triagem para o diagnóstico de déficits \\
nitivos no envelhecimento no Brasil: validade de critério e normas de desempenho \\
URA, 2008).
\end{tabular}

Tabela 3 - Descrição do valor usado na aplicação do KDQOL-SF como subescala da função cognitiva

\begin{tabular}{cc}
\hline Valor obtido & Subescala da Função Cognitiva \\
\hline 0 a 50 & Abaixo do esperado \\
51 a 100 & Dentro do esperado \\
\hline
\end{tabular}

Fonte: Tradução e adaptação cultural do instrumento de avaliação de qualidade de vida para pacientes renais crônicos - KDQOL-SF (DUARTE et al., 2003).

Após compor os grupos experimentais, avaliamos os valores gerais obtidos com o 3MS, onde observamos declínio da função cognitiva presente no grupo DRCCl $(p<0,001)$ comparados ao grupo controle e DRC, sendo esse dado não observado nos indivíduos do grupo DRC quando comparados ao grupo controle. $\mathrm{O}$ estudo específico das tarefas avaliadas por este teste mostrou que o grupo DRC-Cl apresenta déficit nas áreas referentes a atenção, cálculo, fluência verbal semântica, leitura, escrita, comando verbal e evocação, correspondendo aos domínios cognitivos de memória de trabalho, processamento sintático e memória de longo 
prazo, respectivamente, quando comparados ao grupo controle (Tabela 4). No entanto, esse achado não foi observado no grupo DRC, mostrando que esses indivíduos não apresentam declínios cognitivos em relação as tarefas avaliadas pelo 3MS.

Tabela 4 - Tarefas avaliadas pelo 3MS mostrando os pontos de maior declínio da função cognitiva no grupo DRC-Cl comparado ao grupo controle e DRC. Observe a ausência de diferença significativa entre os escores do grupo controle e DRC.

\begin{tabular}{|c|c|c|c|}
\hline Habilidade Avaliada & Controle & DRC & DRC-Cl \\
\hline Recordação de Data e Local de Nascimento (max 5 pontos) & 5 & 4,95 & 4,53 \\
\hline Retenção (max 3 pontos) & 3,00 & 3,00 & 2,80 \\
\hline Orientação Temporal (max 15 pontos) & 14,87 & 14,48 & 12,47 \\
\hline Orientação Espacial (max 5 pontos) & 5,00 & 4,52 & 4,13 \\
\hline Primeira Evocação (max 9 pontos) $\left(^{*}\right)$ & 8,75 & 7,67 & 6,07 \\
\hline Atenção e Cálculo (max 2 pontos) & 1,00 & 1,29 & 0,80 \\
\hline Atenção (max 5 pontos) $\left(^{*}\right)$ & 5,00 & 4,76 & $2,00^{*}$ \\
\hline Nomeação (max 5 pontos) & 5,00 & 5,00 & 4,80 \\
\hline Fluência Verbal e Semântica (max 10 pontos) $\left(^{*}\right)$ & 9,87 & 9,33 & $7,60^{*}$ \\
\hline Similaridades (max 6 pontos) & 4,25 & 5,24 & 4,33 \\
\hline Repetição (max 5 pontos) & 4,62 & 5,00 & 4,00 \\
\hline Leitura e Compreensão (max 3 pontos) $\left(^{*}\right)$ & 2,75 & 2,57 & $1,27^{*}$ \\
\hline Escrita (max 5 pontos) $\left(^{*}\right)$ & 4,00 & 3,57 & $2,33^{*}$ \\
\hline Habilidade Viso-Construtiva (max 10 pontos) & 7,37 & 7,81 & 5,13 \\
\hline Comando Verbal (max 3 pontos) $\left({ }^{* \star}\right)$ & 2,62 & 2,81 & $2,2^{* *}$ \\
\hline Segunda Evocação (max 9 pontos) $\left(^{*}\right)$ & 7,62 & 8,10 & $5,53^{*}$ \\
\hline
\end{tabular}

$\left(^{*}\right) p<0,01$ vs Controle e DRC. $\left(^{* *}\right) p<0,05$ vs Controle e DRC. Análise não paramétrica por ANOVA de uma via, seguido do pós-teste Newman-Keuls.

\subsubsection{Parâmetros bioquímicos}

Seguindo-se a aplicação dos testes de avaliação cognitiva, amostras de sangue foram coletadas, sendo separado o soro (conforme protocolo descrito no ítem 4.1.3) para a realização de exames bioquímicos (Tabela 5). 
$\mathrm{Na}$ análise dos dados, pudemos verificar elevação no cálcio iônico nos indivíduos do grupo DRC-Cl quando comparados ao grupo DRC. No entanto, o estudo dos dados referente ao hematócrito, uréia (pré e pós diálise), creatinina, colesterol total, LDL, HDL, triglicerídeos, fósforo, potássio, proteína total, albumina, globulina e fosfatase alcalina não apresentaram diferença entre os grupos DRC e DRC-Cl.

Tabela 5 - Características bioquímicas dos participantes dessa pesquisa em programa de hemodiálise de acordo com os valores encontrados no 3MS.

\begin{tabular}{lcc}
\hline & DRC & DRC-CI \\
\hline Hematócrito & $36,51 \pm 3,9$ & $34,62 \pm 5,6$ \\
Uréia pré-diálise & $151,1 \pm 39,2$ & $160,0 \pm 50,0$ \\
Uréia pós-diálise & $55,94 \pm 22,4$ & $49,84 \pm 19,3$ \\
Creatinina & $10,64 \pm 3,7$ & $11,55 \pm 2,9$ \\
Colesterol Total & $144,3 \pm 24,9$ & $154,5 \pm 17,8$ \\
LDL & $79,5 \pm 31,3$ & $83,8 \pm 12,2$ \\
HDL & $34,1 \pm 10,3$ & $34,3 \pm 9,7$ \\
Triglicerídeos & $155,6 \pm 82,2$ & $81,7 \pm 119,5$ \\
Cálcio iônico & $1,2 \pm 0,06$ & $1,3 \pm 0,1^{*}$ \\
Fósforo & $5,9 \pm 1,5$ & $6,2 \pm 1,4$ \\
Potássio & $5,8 \pm 0,9$ & $5,9 \pm 1,1$ \\
Proteína Total & $6,8 \pm 0,5$ & $6,9 \pm 0,7$ \\
Albumina & $3,9 \pm 0,5$ & $3,8 \pm 0,3$ \\
Globulina & $2,9 \pm 0,5$ & $3,02 \pm 0,6$ \\
Fosfatase Alcalina & $79,42 \pm 26,7$ & $91,07 \pm 41,7$ \\
\hline
\end{tabular}

$\left(^{*}\right) p<0,05$ vs DRC. Teste T de Student. 


\subsubsection{Ensaios de ELISA}

\subsubsection{Dosagem do estrogênio sérico}

A análise dos escores do 3MS, considerando separadamente os sexos masculino e feminino, não mostrou predominância de declínio cognitivo entre os gêneros no grupo DRC-Cl. No entanto, realizamos a dosagem de estrogênio sérico para verificar uma possível influência hormonal na redução da função cognitiva entre as mulheres incluídas no grupo DRC e DRC-Cl.

Não verificamos diferença significativa em nossos resultados entre os grupos DRC, DRC-Cl e Controle (Figura 2), de forma que as alterações cognitivas encontradas nos indivíduos do sexo feminino do grupo experimental DRC-CI provavelmente não estão sendo associadas às variações do estrogênio.

Figura 2 - Níveis de estrogênio sérico $(\mathrm{pg} / \mathrm{ml})$ dosados em indivíduos do sexo feminino em pacientes portadores de DRC na ausência (DRC) ou presença de déficit cognitivo (DRC-Cl).

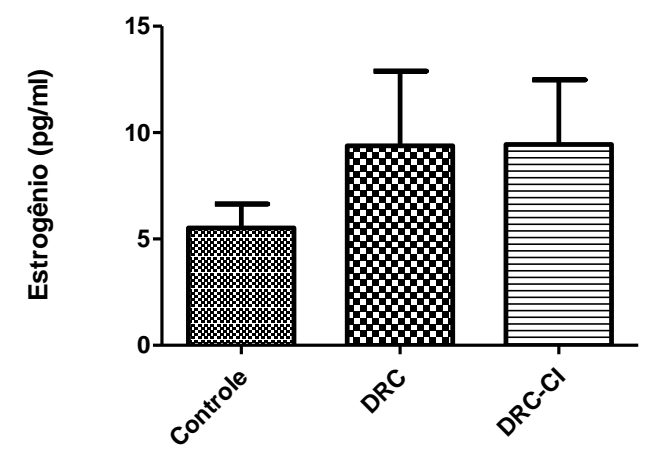

A representação gráfica demonstra a ausência de diferença significativa nos níveis de estrogênio sérico entre os grupos controle $(n=5)$, DRC $(n=8)$ e DRC-Cl $(n=9)$. ANOVA uma via, seguido do pós teste de Newman Keuls.

\subsubsection{Dosagem de citocinas, cortisol e proteína C reativa em soro humano}

Considerando a possível existência de uma conexão entre a DRC, as alterações no perfil cognitivo e o processo inflamatório, realizamos os ensaios de ELISA para dosagem de IL-1 $\beta$, IL-6, IL-10, TNF- $\alpha$, cortisol e proteína $C$ reativa.

Os testes de normalidade das amostras mostraram heterogeneidade dos erros e variâncias (no ANEXO C encontram-se os dados sem tratamento estatístico) devido aos fatores individuais de cada indivíduo avaliado, indicando a necessidade 
de transformação dos dados e a realização de todas as análises estatísticas desses parâmetros realizadas com os dados transformados. A característica de distribuição das amostras exigiu a análise recíproca (inverso ou 1/x) da variância da média como tratamento estatístico e, excetuando-se o estudo do TNF- $\alpha$, onde a amostra exigiu uma análise não-paramétrica, o comportamento de distribuição da amostras de IL$1 \beta$, IL-10, IL-6, Proteína C Reativa e cortisol permitiu uma análise paramétrica dos dados.

Assim, após as transformações estatísticas dos dados, a observação dos resultados sugeriu não haver alterações nas concentrações séricas de IL-1 $1 \beta$, IL-6, IL-10, TNF- $\alpha$, Proteína C Reativa e Cortisol entre os grupos DRC e DRC-Cl quando comparados com o grupo controle (Tabela 6), da mesma forma, o estudo das mesmas citocinas, da proteína $C$ reativa e do cortisol não foi significativa entre 0 grupo DRC e DRC-Cl. De acordo com esses dados, sugerimos não haver participação da inflamação no desenvolvimento do declínio cognitivo nos indivíduos com DRC em programa de hemodiálise.

Tabela 6 - Análise recíproca comparativa dos níveis de citocinas séricas, cortisol e proteína $\mathrm{C}$ reativa em indivíduos controles, e com DRC na ausência de déficit cognitivo (DRC) e na presença de déficit cognitivo (DRC-Cl) em coletas pré e pós-diálise.

\begin{tabular}{lccccc}
\hline Parâmetro (1/x) & $\begin{array}{c}\text { Controle } \\
(\mathrm{n}=10)\end{array}$ & $\begin{array}{c}\text { DRC-Pré } \\
(\mathrm{n}=21)\end{array}$ & $\begin{array}{c}\text { DRC-Pós } \\
(\mathrm{n}=21)\end{array}$ & $\begin{array}{c}\text { DRC-Cl-Pré } \\
(\mathrm{n}=15)\end{array}$ & $\begin{array}{c}\text { DRC-Cl-Pós } \\
(\mathrm{n}=15)\end{array}$ \\
\hline IL-1 $\beta$ & $0,13 \pm 0,05$ & $0,14 \pm 0,24$ & $0,13 \pm 0,26$ & $0,14 \pm 0,4$ & $0,13 \pm 0,16$ \\
TNF- $\alpha$ & $13,2 \pm 9,6$ & $51,7 \pm 29,8$ & $36,7 \pm 17,5$ & $24,5 \pm 15,3$ & $21,8 \pm 15,3$ \\
IL-6 & $7,3 \pm 1,3$ & $16,5 \pm 31,8$ & $28,4 \pm 86,4$ & $9,3 \pm 30,0$ & $15,5 \pm 11,0$ \\
IL-10 & $5,2 \pm 6,0$ & $7,3 \pm 4,6$ & $9,8 \pm 4,0$ & $14,8 \pm 23,7$ & $25,9 \pm 24,1$ \\
Cortisol & $1,73 \pm 1,5$ & $2,75 \pm 1,8$ & - & $2,56 \pm 3,0$ & - \\
Prot. C Reativa & $4,0 \pm 0,04$ & $4,0 \pm 0,06$ & $4,0 \pm 0,08$ & $4,5 \pm 0,09$ & $4,5 \pm 0,1$ \\
\hline
\end{tabular}

Análise recíproca paramétrica para IL1- $\beta$, IL-6, IL-10, cortisol e proteína $C$ reativa. Análise recíproca não paramétrica para TNF-a. ANOVA de uma via, seguido do pós teste de Bonferroni. 


\subsubsection{Dosagem de Klotho em soro humano}

Estudos tem demonstrado que a proteína klotho pode estar associada a DRC e sua expressão estar envolvida no controle do $\mathrm{Ca}^{++}$no rim, na glândula paratireóide e no plexo coróide.

Em relação as alterações nos níveis de klotho sérico, observamos importante redução em seus níveis nos indivíduos do grupo $\mathrm{DRC}-\mathrm{Cl}$ quando comparados aos grupos Controle e DRC (Figura 3). Há tendência de redução nos níveis séricos de klotho no grupo DRC em relação ao grupo Controle, comumente observado em indivíduos que desenvolvem DRC, no entanto, esse dado não é significativo $(p<0,08)$.

Figura 3 - Níveis de Klotho sérico (pg/mL) em indivíduos controles, e com DRC na ausência de déficit cognitivo (DRC) e na presença de déficit cognitivo (DRC-Cl) em coletas pré e pós-diálise.

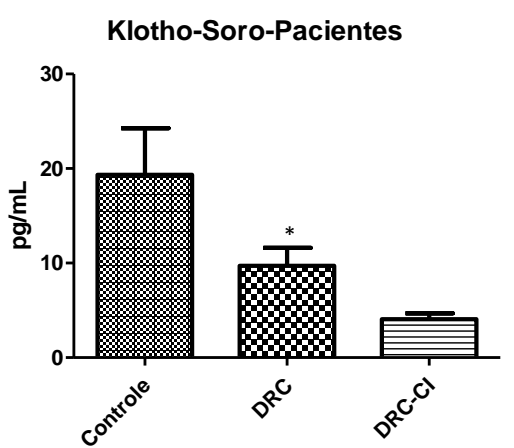

ANOVA de uma via, seguido do pós-teste Newman Keuls. $\left({ }^{*}\right)$ p $<0,05$ vs DRC-Cl.

\subsection{Modelo animal de 5/6 de ablação renal}

\subsubsection{Teste de comportamento em animais}

\subsubsection{Campo aberto}

Um indicador importante para a execução dos testes de comportamento subsequentes, se refere a capacidade locomotora dos animais, pois todos os testes realizados neste trabalho envolvem algum grau de deslocamento espontâneo. Assim, avaliamos a habilidade dos animais se deslocarem tanto horizontalmente quanto verticalmente realizando o teste do Campo Aberto durante cinco minutos. 
Esse teste foi realizado ao início do período experimental, ou seja, após 30 dias de nefrectomia e ao final do período experimental, correspondendo a 150 dias de nefrectomia.

Não encontramos alterações nos dados referentes ao deslocamento horizontal e vertical aos 150 dias entre os grupos Sham e Nx (Figura 4), onde encontramos a ausência de comprometimento locomotor, medida pelo Campo aberto, entre os grupos estudados. Esses dados nos informam que mesmo com a progressão da DRC nos animais nefrectomizados, a capacidade de deslocamento (horizontal e vertical) foi preservada durante todo o período experimental, de forma que alterações encontradas nos outros estudos comportamentais, não correspondem a alterações locomotoras.

Figura 4 - Análise dos dados obtidos no Campo Aberto após 150 dias de nefrectomia.
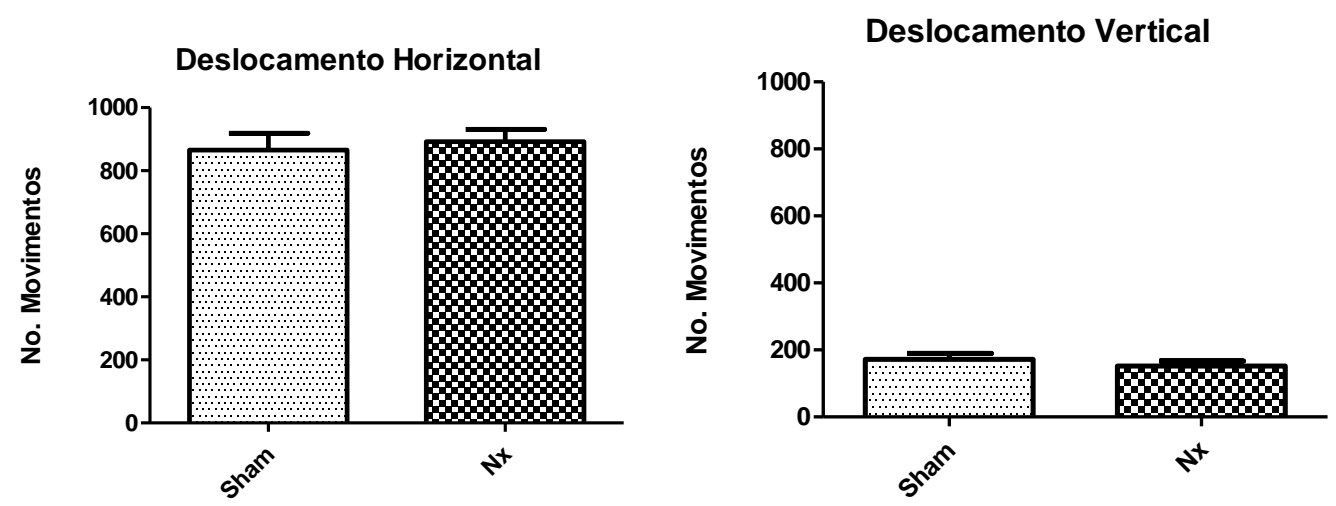

Média de deslocamento horizontal e vertical medidas durante 300 segundos, mostrando ausência de comprometimento locomotor entre os grupos Sham $(n=12)$ e $N x(n=14)$ ao final do período experimental. Teste T de Student.

\subsubsection{Labirinto de Barnes}

Trinta dias após a cirurgia de ablação renal, quando a doença renal entra em caráter de cronicidade, iniciamos o estudo da avaliação do aprendizado visoespacial, submetendo os animais ao labirinto de Barnes, e realizando sessões de reteste em intervalos de aproximadamente 30 dias entre eles por um período de cinco meses, acompanhando a progressão da DRC.

Os 5 primeiros testes, realizados em dias consecutivos, corresponde ao período de aprendizado da tarefa. Nessa etapa, não encontramos diferenças no processo de aprendizado viso-espacial entre os grupos Sham e $\mathrm{Nx}$, onde os dois 
grupos apresentaram importante redução na latência entre o primeiro e o quinto teste (Figura 5). Nas sessões de reteste, também não observamos diferença estatística significativa entre os grupos, onde os grupos Sham e Nx apresentaram latência semelhante entre as sessões de reteste aos 14, 30, 60, 90 e 120 dias quando comparados ao $5^{\circ}$ dia de teste, mostrando que apesar dos desvios encontrados, os animais do grupo Nx aprenderam a tarefa mesmo após 5 meses de nefrectomia, em semelhança ao grupo Sham, não apresentando, portanto, comprometimento da memória viso-espacial.

Figura 5 - Análise dos dados obtidos no teste de Labirinto de Barnes.

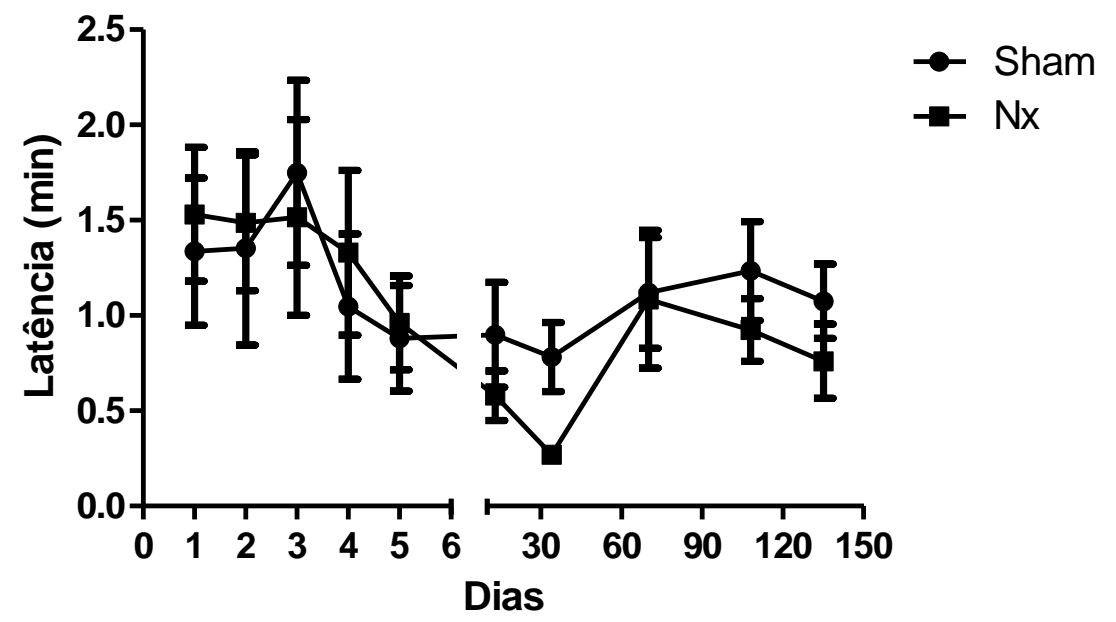

Latência média necessária para que os animais do grupo Sham $(n=12)$ e $N x \quad(n=14)$ entrassem na caixa de escape mostrando não haver diferença de aprendizado viso-motor entre os grupos durante todo o período experimental. ANOVA de duas vias, seguido do pós-teste Bonferrone.

\subsubsection{Esquiva inibitória}

No estudo dos dados obtidos na esquiva inibitória observamos que os animais do grupo controle (Sham) apresentaram melhora na latência passadas 24 horas do treino único, revelando aprendizado da tarefa. Nas sessões de reteste, observamos que a memória condicionada por reforço aversivo foi mantida por longo prazo, de forma que após 30, 60 e 90 dias após o treino, a latência permaneceu elevada (Figura 6A). Resultado diferente foi observado nos animais do grupo Nx, onde após 24 horas da sessão única de treino não encontramos redução na latência, expondo ausência de aprendizado da tarefa. Após 30 dias de execução da sessão de treino, os animais Nx mantiveram a latência diminuída, de forma que até este período, podemos afirmar que os animais não aprenderam a tarefa, mesmo sob reforço 
aversivo. Porém, aos 60 e 90 dias após a sessão treino, observamos melhora no desempenho da atividade, visualizada pelo importante aumento na latência dos animais, revelando que, neste período, os animais aprenderam a tarefa e foram capazes de manter por longo prazo esse aprendizado (Figura 6B). Acreditamos que este evento esteja relacionado ao reforço aversivo gerado pelo próprio teste ao longo do período, permitindo o desenvolvimento do aprendizado ao longo da realização dos consecutivos retestes.

Fazendo um paralelo com os achados na rotina clínica da nefrologia, onde apenas uma parcela dos pacientes com DRC desenvolvem redução da função cognitiva, analisamos isoladamente cada dado obtido no teste de esquiva inibitória, de forma a verificar se fenômeno semelhante seria encontrado no estudo realizado com os animais nefrectomizados. Assim, observamos que ao final do período de experimentação $36 \%$ dos animais $\mathrm{Nx}$ não tiveram melhora do desempenho na execução da atividade, mesmo na presença de reforço contextual aversivo (Figura 6). Desse modo, com essa análise gráfica, conseguimos dividir o grupo dos animais $\mathrm{Nx}$ em dois subgrupos, um contendo os animais $\mathrm{Nx}$ sem alteração de memória (grupo Nx-M; latência $=177,3 \pm 2,65$ ) e o outro contendo os animais $\mathrm{Nx}$ com alteração da fixação da memória detectada nesse teste (grupo $\mathrm{Nx}-\mathrm{Cl}$; latência = $23,68 \pm 6,34$ ), de forma que neste grupo, incluímos os animais com desempenho abaixo de $25 \%$ da média do grupo. Também observamos que no grupo Sham tivemos um dos animais que apresentou piora no processo de aprendizado pelo método de reforço contextual aversivo, sendo eliminado do estudo, e que dois animais, apesar de apresentarem tempo de latência entre 1 e $25 \%$ da média do grupo, a análise individual dos animais demonstrou que esses animais apresentaram melhora no tempo de latência durante o período, sendo mantidos neste estudo. 
Figura 6 - Análise dos dados obtidos com o teste de esquiva inibitória nos grupos Sham e Nx durante o período de 120 dias de nefrectomia.
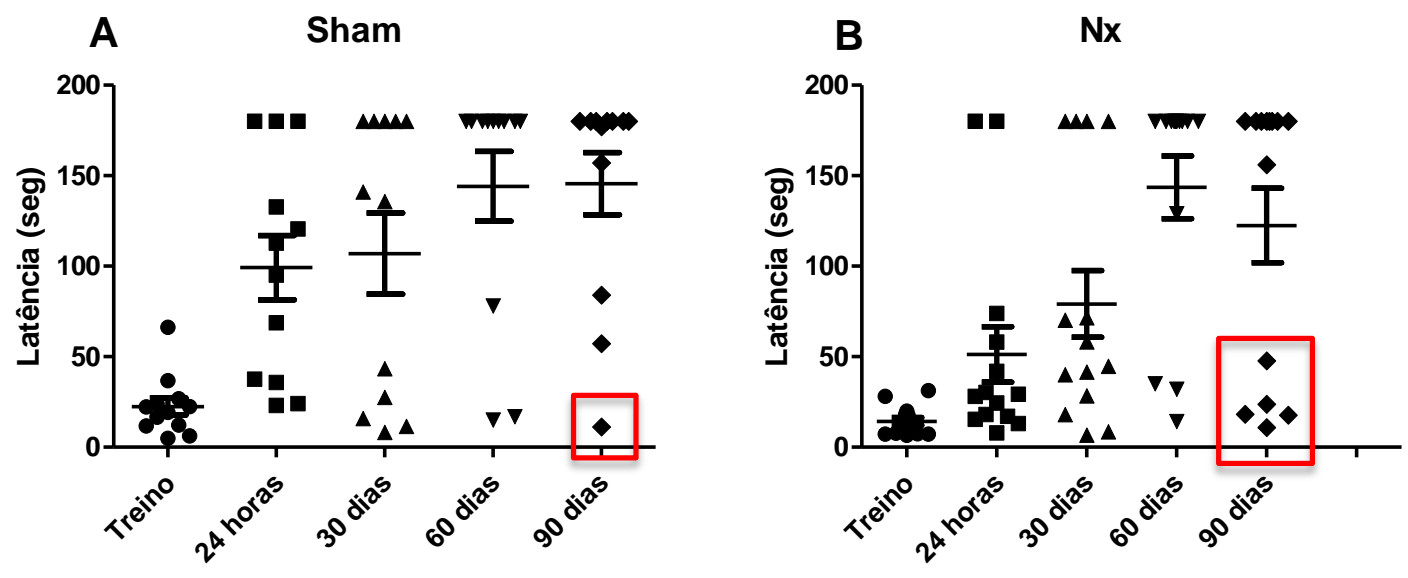

Na Figura $6 A$, observamos, no grupo Sham $(n=12)$, uma elevação na latência após 24 horas da sessão treino, mostrando que na presença de um estímulo aversivo os animais aprenderam a tarefa. Nos testes subsequentes, realizados 30,60 e 90 dias após a sessão treino os animais mostraram manutenção do aprendizado (memória de longo prazo) e até mesmo melhora na performance, apenas 1 animal do grupo Sham não apresentou melhora do desempenho (caixa vermelha), sendo excluído desse estudo. Na Figura 6B, no estudo das latências do grupo Nx $(n=14)$ observamos que o desempenho da sessão treino foi semelhante ao do grupo Sham, no entando, após 24 horas dessa sessão, os animais Nx não lembraram da tarefa aprendida durante a sessão de treino, mesmo em presença de estímulo aversivo, sendo esse resultado mantido no reteste de 30 dias após a sessão treino. Apenas nos retestes de 60 e 90 dias após a sessão treino observamos melhora no desempenho em $68 \%$ dos animais do grupo $\mathrm{Nx}$, enquanto $36 \%$ mantiveram latência semelhante a sessão treino (caixa vermelha), demonstrando que esses animais não lembraram a tarefa. Assim, considerando o reteste realizado após 90 dias da sessão treino, subdividimos o grupo $\mathrm{Nx}$ em dois subgrupos, grupo $\mathrm{Nx}-\mathrm{M}$, correspondendo aos animais que aprenderam a tarefa e grupo $\mathrm{Nx}-\mathrm{Cl}$, correspondendo aos animais que não aprenderam a tarefa (caixa vermelha). $\left(^{*}\right)$ vs sessão treino. $p<0,05$. ANOVA de uma via, seguido pelo pós-teste de Dunns.

\subsubsection{Teste de reconhecimento do novo objeto}

Realizamos o teste de reconhecimento do novo objeto após 35, 60 e 90 dias após a cirurgia de ablação renal, sendo considerada redução na memória operacional ou memória de longo prazo, quando o tempo de exploração no objeto novo tenha sido inferior a $40 \%$ do tempo de exploração total entre o objeto familiar e o objeto novo.

Aos 35 dias de nefrectomia, não observamos diferença entre os tempos de exploração do objeto novo entre os grupos Sham ( $t=60,29 \pm 4,17)$ e $N x(t=64,41 \pm$ $5,97)$. Apesar de encontrarmos uma importante redução no tempo de exploração do objeto novo pelos animais do grupo $\mathrm{Nx}(\mathrm{t}=57,81 \pm 6,42)$ em comparação com 0 grupo Sham ( $t=77,95 \pm 4,58)$ no estudo dos dados relativos ao teste realizado após 
60 dias de nefrectomia, em função do tempo de exploração no objeto novo não ser inferior a $40 \%$ do tempo de exploração total entre o objeto novo e o objeto familiar, não foi possível constatar a existência de alteração da função cognitiva nesta etapa. No entanto, após 90 dias de nefrectomia, observamos que os animais do grupo $\mathrm{Nx}$ $(t=37,70 \pm 5,93)$ exploraram por tempo estatisticamente menor o objeto novo quando comparados ao grupo Sham $(\mathrm{t}=62,11 \pm 7,81)$, sendo, portanto, nesse período identificado déficit na memória operacional e de longo prazo.

Considerando que o déficit de memória é identificado quando o animal utiliza menos do que $40 \%$ do tempo total do experimento explorando o objeto novo, após identificar uma redução importante na média deste tempo no grupo Nx (90 dias após a cirurgia de ablação renal), analisamos isoladamente os dados de cada animal, onde os animais nefrectomizados que mantiveram período de exploração do objeto novo superior a $40 \%$ foram considerados animais que não apresentaram déficit, sendo incluídos no subgrupo $\mathrm{Nx}-\mathrm{M}$, e os animais nefrectomizados que apresentaram rendimento menor que $40 \%$, foram incluídos no subgrupo $\mathrm{Nx}-\mathrm{Cl}$ (Figura 7 ). Com essa análise, após 90 dias de nefrectomia, detectamos que $58 \%$ dos ratos apresentaram redução na memória operacional e de longo prazo avaliados na ausência de estímulo aversivo.

Figura 7 - Análise dos dados obtidos com o teste de reconhecimento do objeto novo nos grupos Sham e Nx após 90 dias de nefrectomia.

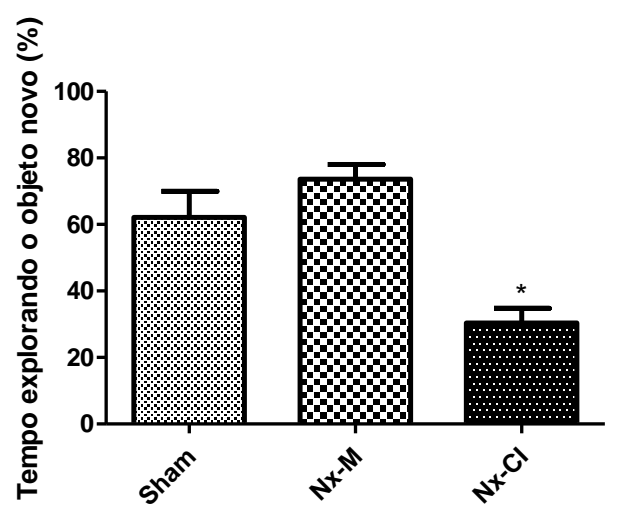

Tempo de exploração do objeto novo (\%), mostrando, que após 90 dias de nefrectomia, o grupo Nx$\mathrm{Cl}(\mathrm{n}=7)$ apresenta este tempo de exploração bastante reduzido, caracterizando comprometimento da memória operacional e de longo prazo nesses animais. Esse dado não é observado nos grupos Sham $(n=10)$ e Nx-M $(n=5) . p<0,05-^{*}$ vs Sham e Nx-M. ANOVA de uma via, seguido do pós-teste Bonferrone. 


\subsubsection{Parâmetros clínicos, bioquímicos e histológico para caracterização da DRC no modelo de 5/6 de ablação renal (ratos Munich-Wistar).}

Durante o período experimental os animais foram quinzenalmente pesados e tiveram a pressão sanguínea mensurada mensalmente. A tabela 7 sumariza os dados obtidos após 30 e 150 dias de nefrectomia, período de início e fim dos testes de comportamento, respectivamente. Observamos redução estatisticamente significante de peso corporal já presente aos 30 dias após a realização da nefrectomia, sendo esse resultado mantido até o final do período experimental (150 dias $\mathrm{Nx}$ ), onde encontramos redução de peso corporal de aproximadamente $15 \%$ em relação ao grupo Sham no mesmo período. De maneira similar, verificamos importante elevação da média da pressão sistólica nos animais nefrectomizados presente desde 30 dias após a cirurgia, tornando-se mais evidentes ao final do período experimental (150 dias $\mathrm{Nx}$ ) quando comparados aos animais Sham no mesmo período, caracterizando a ocorrência de hipertensão arterial nos animais $\mathrm{Nx}$ durante todo o período experimental.

Tabela 7 - Estudo do peso corporal e pressão sanguínea aos 30 e 150 dias de nefrectomia, mostrando redução do peso corporal e hipertensão arterial no grupo $\mathrm{Nx}$.

\begin{tabular}{lcccc}
\hline & \multicolumn{2}{c}{ Peso Corporal $(\mathbf{g})$} & \multicolumn{2}{c}{ Pressão Sangüínea $\mathbf{( m m H g )}$} \\
& 30 dias & $\mathbf{1 5 0}$ dias & 30 dias & $\mathbf{1 5 0}$ dias \\
\hline Sham $(\mathrm{n}=12)$ & $287,9 \pm 4,3$ & $296,8 \pm 5,2$ & $102 \pm 1,9$ & $116 \pm 1,9$ \\
$\mathbf{N x}(\mathrm{n}=14)$ & $240,5 \pm 4,7^{*}$ & $254,1 \pm 3,7^{*}$ & $132 \pm 3,8^{*}$ & $159 \pm 4,1^{*}$ \\
\hline
\end{tabular}

Teste T de Student. $p<0,01 .\left(^{*}\right)$ vs Sham.

Ao final do período experimental (150 dias), coletamos uma alíquota maior de sangue, possibilitando a realização dos ensaios para análise da creatinina sérica e do hematócrito, onde verificamos elevação significativa nos níveis séricos de creatinina nos animais $\mathrm{Nx}$ quando comparados aos animais Sham (Tabela 8), indicando a presença de DRC nesse grupo. Por outro lado, no estudo do hematócrito não encontramos alteração em seu nível, comparando os grupos Sham e Nx, sugerindo a ausência de anemia no grupo Nx (Tabela 8). 
Tabela 8 - Estudo demonstrando importante elevação da creatinina sérica no grupo Nx após 150 dias de nefrectomia em relação ao grupo Sham e ausência de anemia, verificada através da análise do hematócrito entre os grupos Nx e Sham.

\begin{tabular}{lcc}
\hline & Creatinina (mg/dl) & Hematócrito (\%) \\
\hline Sham $(n=12)$ & $0,65 \pm 0,05$ & $47,40 \pm 1,2$ \\
$\mathbf{N x}(n=14)$ & $1,13 \pm 0,05^{\star}$ & $45,86 \pm 0,47$ \\
\hline
\end{tabular}

Teste T de Student. $p<0,05 .\left(^{*}\right)$ vs Sham.

Estudos de análise histológica, gentilmente realizada pela Dra. Denise MAC Malheiros, revelou importante aumento na porcentagem de glomérulos esclerosados no grupo Nx quando comparado ao grupo Sham (Figura 8). Dado semelhante foi encontrado no estudo da área intersticial cortical, onde observamos uma elevação desse dado analisado no grupo Nx em relação ao grupo Sham (Figura 9). Esses dados, juntos, são compatíveis com a ocorrência de lesão glomerular renal.

Figura 8 - Análise da esclerose glomerular no modelo animal de 5/6 de nefrectomia após 150 dias do procedimento cirúrgico.
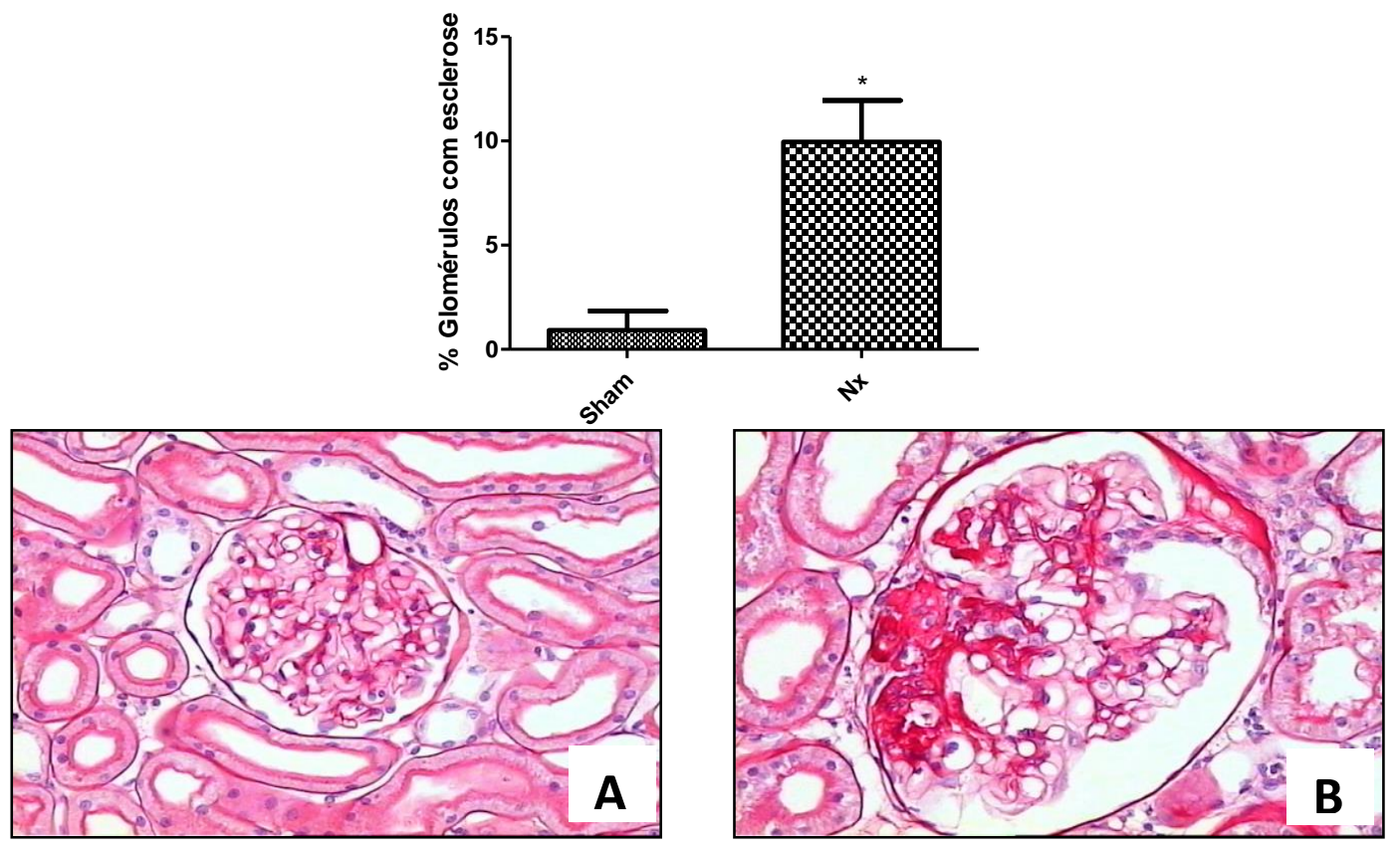

Na parte superior da figura, observe a análise gráfica evidenciando aumento significativo do número de glomérulos com esclerose no grupo $N x(B)(n=8)$ quando comparado ao grupo Sham $(A)(n=5)$. Teste $T$ de Student, $p<0,01$ - * vs Sham. As microfotografias são amostras representativas da esclerose glomerular observada nos ratos Sham e Nx. Coloração com Ácido Periódico-Shiff (PÁS). Aumento de 200X. 
Figura 9 - Análise da área intersticial cortical no modelo animal de 5/6 de nefrectomia após 150 dias do procedimento cirúrgico.
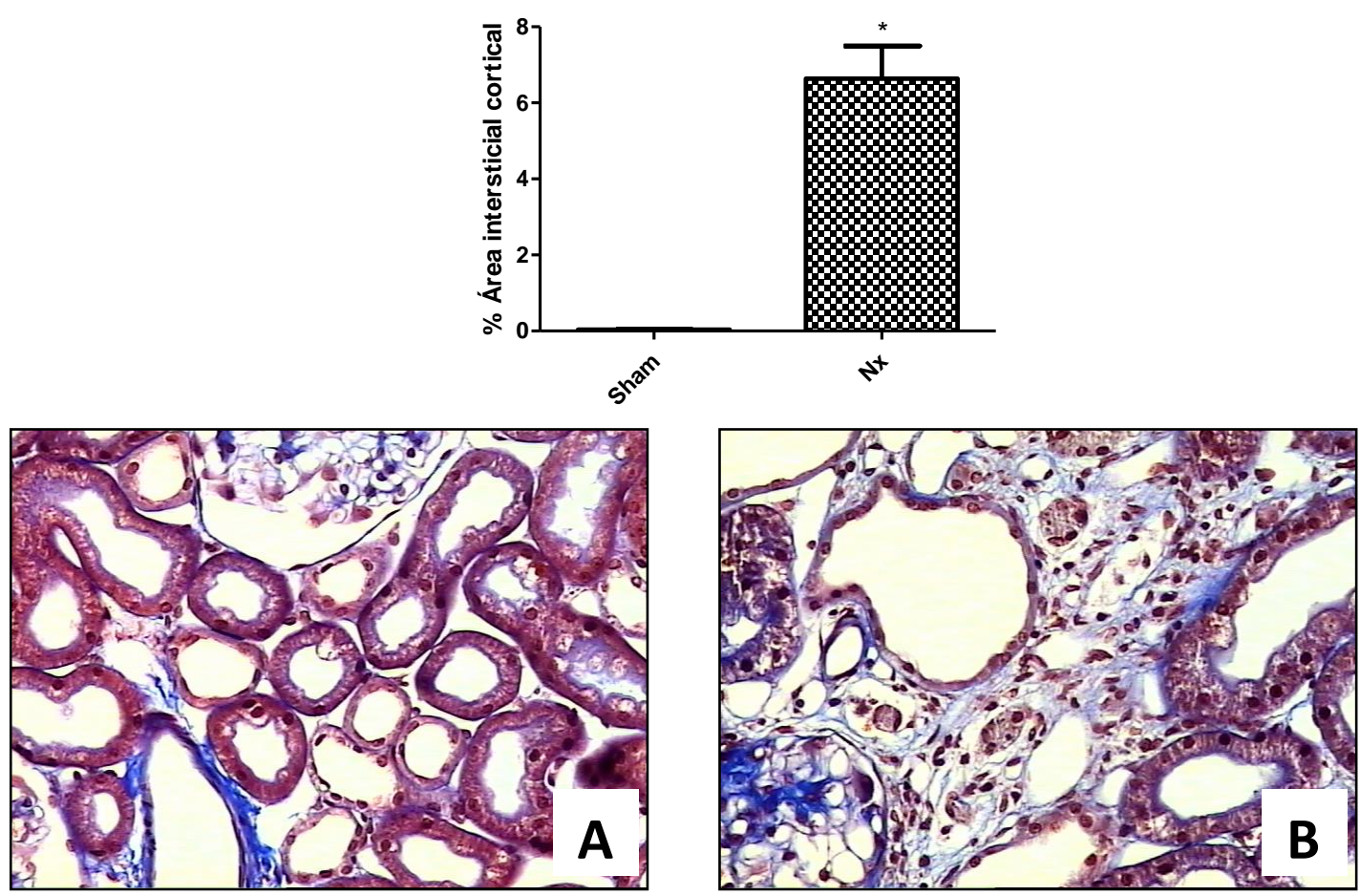

$\mathrm{Na}$ parte superior da figura, observe a análise gráfica evidenciando importante elevação na área intersticial cortical no grupo $N x(n=8)$ comparado ao grupo Sham $(n=5)$. Teste T de Student $-p<0,01$ * vs Sham. As microfotografia são amostras representativas da expansão da área intersticial observada nos ratos Sham (A) e Nx (B). Coloração com Tricômio de MassomÁcido Periódico-Shiff (PÁS). Aumento de $200 \mathrm{X}$

Considerando os dados descritos acima, podemos destacar a presença de aumento nos níveis séricos de creatinina, o elevado número de glomérulos esclerosados e a expansão da área intersticial, bem como a ocorrência de aumento da pressão sistólica, presente no grupo $\mathrm{Nx}$, o que é uma evidência marcante da presença de DRC nos animais $\mathrm{Nx}$, não sendo esses achados encontrados nos animais Sham. Interessante, que 150 dias após a cirurgia (grupo Sham), um dos animais presentes nesse grupo apresentou aumento dos glomérulos em esclerose, no entanto, não observamos elevação nem nos níveis séricos de creatinina e na área intersticial cortical neste animal. Acreditamos que essa alteração isolada seja consequência do processo natural de envelhecimento, esse animal foi excluído nas análises subsequentes. 


\subsubsection{Ensaios de ELISA para TNF- $\alpha$, IL-1 $\beta$, IL-6, IL-10, IFN- $y$, corticoesterona, Proteína C Reativa e Klotho sérico, liquórico e em homogenato de tecido}

Durante o período experimental, foram coletadas amostras de sangue pela veia caudal, para analisarmos a instalação de possível processo inflamatório sistêmico. Em princípio, comparamos os períodos de 30 dias (Coleta 1) e 120 dias (Coleta 4) após a realização da nefrectomia.

Observamos aumento significativo nos níveis séricos de IL-6 após 30 dias de nefrectomia, sendo mais pronunciado nos animais do grupo $\mathrm{Nx}-\mathrm{Cl}(1515 \pm 14,77)$ do que no grupo Nx-M (630,4 $\pm 227,9)$, quando comparados ao grupo Sham ( 150,3 \pm 37,13 ) (Figura 10). No entanto, após 120 dias de nefrectomia, essa diferença não foi observada (Sham: $51,57 \pm 13,09$; Nx-M: 53,26 $\pm 10,75$; Nx-Cl: 45,89 $\pm 7,01$ ).

Figura 10 - Análise dos níveis séricos de IL-6 (pg/mL) aos 30 e 120 dias de nefrectomia, coleta 1 e 4 respectivamente.

Coleta 1

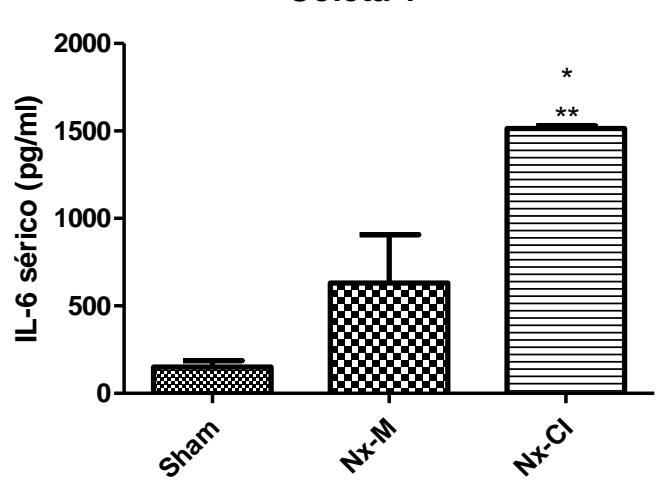

Coleta 4

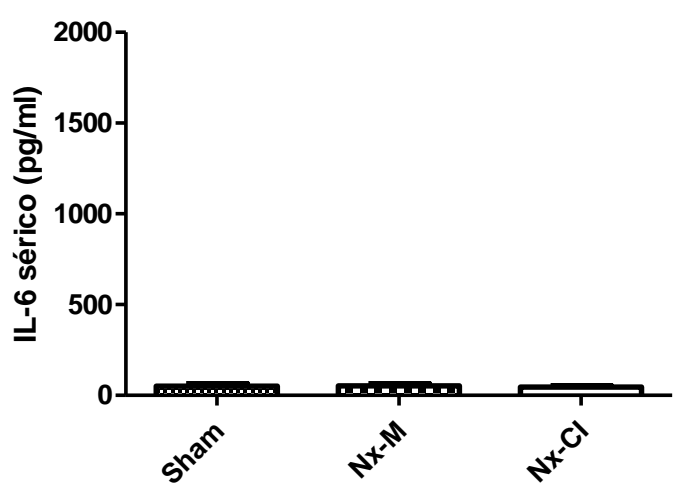

Ensaio de ELISA para IL-6: (A) observe o aumento no nível sérico da IL-6 aos 30 dias de nefrectmia nos animais do grupo $\mathrm{Nx}-\mathrm{Cl}(\mathrm{n}-10)$ em relação aos grupos Sham $(n=10)$ e $\mathrm{Nx}-\mathrm{M}(\mathrm{n}=10)$. No entanto, aos 120 dias de nefrectomia essa (B) diferença não foi encontrada, de forma a não haver mais diferenças entre os grupos Sham, Nx-M e Nx-Cl. p<0,05 - * vs Sham; ** vs Nx-M. ANOVA de uma via, seguido do pós-teste Bonferrone.

No estudo da IL-1 $\beta$, após 30 dias de nefrectomia encontramos níveis séricos dessa citocina semelhante entre os grupos (Sham: 142,4 \pm 11,46; Nx-M: 153,4 \pm 34,18; Nx-Cl: 114,6 \pm 15,53) (Figura 11). No entanto, após 120 dias de nefrectomia, observamos redução nos níveis séricos de IL-1 $\beta$ nos grupos $\mathrm{Nx}-\mathrm{M}(49,68 \pm 14,59)$ e $\mathrm{Nx}-\mathrm{Cl}(42,42 \pm 9,16)$ quando comparados ao grupo Sham $(137,5 \pm 23,86)$. Dado semelhante foi observado nos níveis séricos de TNF- $\alpha$, onde após 30 dias de nefrectomia os ratos dos grupos Nx-M $(1,35 \pm 0,25)$ e $\mathrm{Nx}-\mathrm{Cl}(1,05 \pm 0,1)$ 
apresentaram níveis semelhantes aos do grupo Sham $(1,51 \pm 0,25)$ (Figura 12), porém, após 120 dias de ablação, os níveis séricos de TNF- $\alpha$ atingiram níveis estatisticamente menores nos grupos $\mathrm{Nx}-\mathrm{M}(4,08 \pm 1,76)$ e $\mathrm{Nx}-\mathrm{Cl}(4,04 \pm 1,62)$ em relação aos animais Sham $(14,41 \pm 2,67)$.

Figura 11 - Análise dos níveis séricos de $\mathrm{IL}-1 \beta$ (pg/mL) aos 30 e 120 dias de nefrectomia, coleta 1 e 4 respectivamente.

Coleta 1

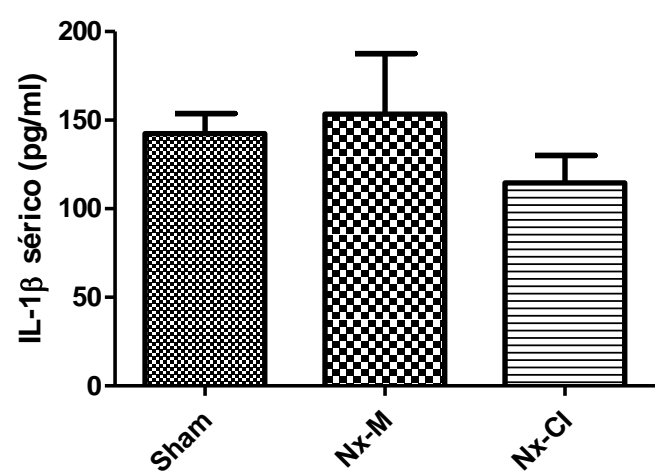

Coleta 4

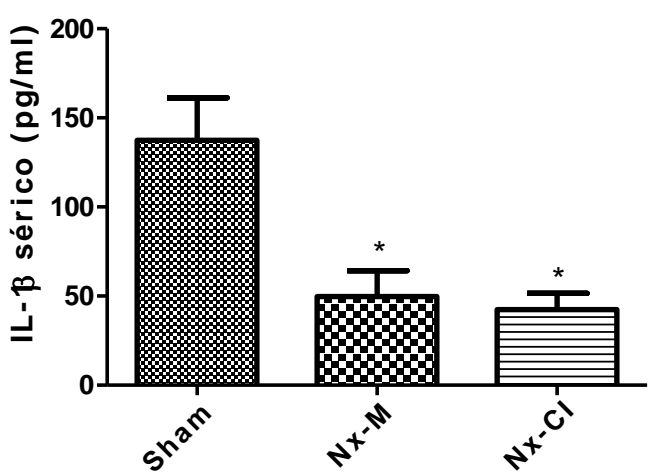

Com os dados obtidos com o ensaio de ELISA para IL-1 $1 \beta$ aos 30 dias de nefrectomia (Coleta 1) não encontramos diferença na concentração dessa proteína inflamatória entre os grupos Sham $(n=10)$, $\mathrm{Nx}-\mathrm{M}(\mathrm{n}=10)$ e $\mathrm{Nx}-\mathrm{Cl}(\mathrm{n}=10)$. Porém, note que aos 120 de nefrectomia (Coleta 4) o nível sérico da IL$1 \beta$ encontra-se diminuído nos grupos $\mathrm{Nx}-\mathrm{M}$ e $\mathrm{Nx}-\mathrm{Cl}$ em relação ao grupo Sham. $\mathrm{p}<0,05$. * vs Sham ANOVA de uma via, seguido do pós-teste Bonferrone.

Figura 12 - Análise dos níveis séricos de TNF- $\alpha(\mathrm{pg} / \mathrm{mL})$ aos 30 e 120 dias de nefrectomia, coleta 1 e 4 respectivamente.

\section{Coleta 1}

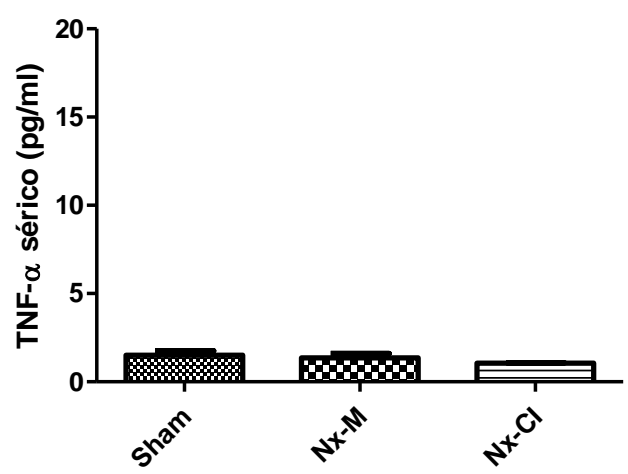

Coleta 4

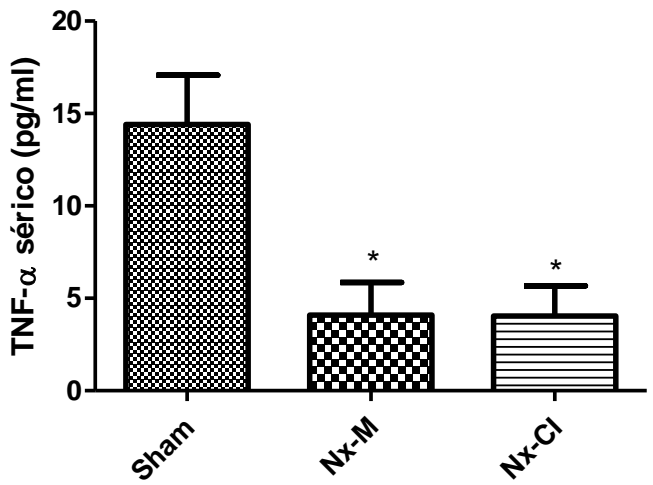

Ensaio de ELISA para TNF- $\alpha$, onde observamos não haver diferença na concentração de TNF- $\alpha$ entre os grupos estudados (Sham: $n=10 ; N x-M: n=10 ; N x-C l: n=10$ ) aos 30 dias de nefrectomia (Coleta 1), no entanto, aos 120 dias (Coleta 4) de nefrectomia encontramos diminuição na concentração sérica de TNF-a nos grupos $\mathrm{Nx}-\mathrm{M}$ e $\mathrm{Nx}-\mathrm{Cl} .\left(^{*}\right)$ vs Sham. ANOVA de uma via, seguido do pós-teste Bonferrone. 
$\mathrm{Na}$ análise da Proteína C Reativa sérica não observamos diferença entre os grupos estudados aos 30 e 120 dias de nefrectomia (Figura 13). Dado semelhante foi encontrado no estudo do IFN- $y$ sérico, onde aos 30 e 120 dias de nefrectomia os grupos estudados não apresentaram diferença entre si (Figura 14).

Figura 13 - Análise dos níveis séricos de Proteína C Reativa (ng/mL) aos 30 e 120 dias de nefrectomia, coleta 1 e 4 respectivamente.
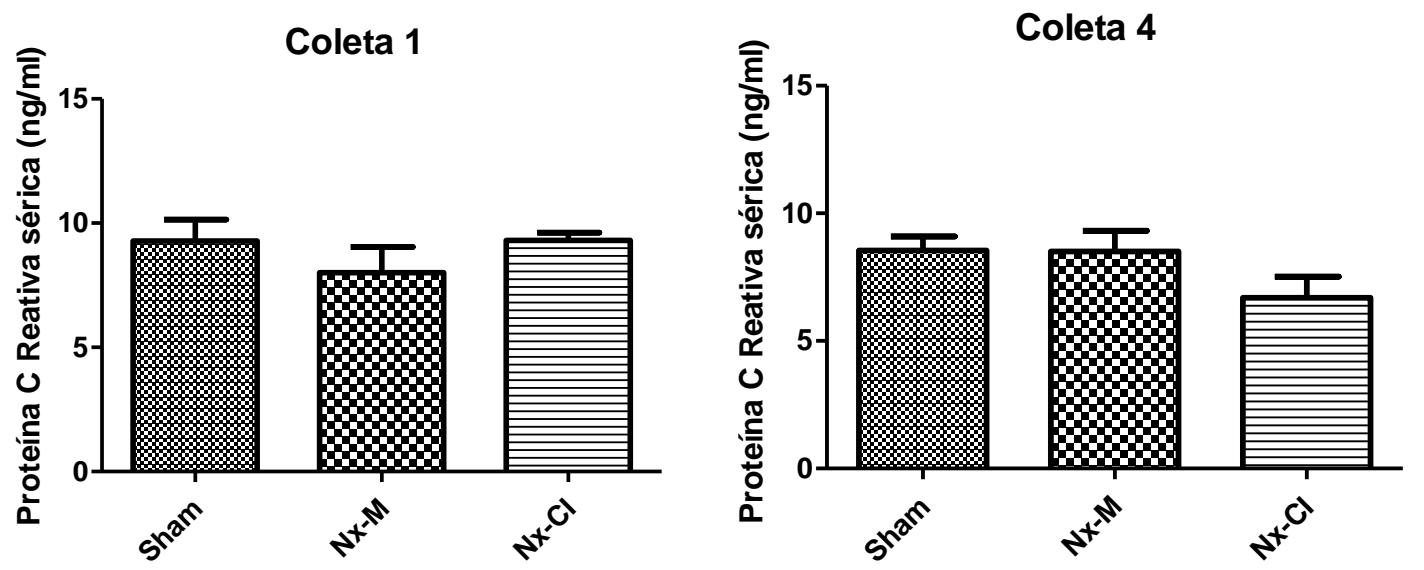

Ensaio de ELISA para Proteína C Reativa, mostrando não haver diferenças na concentração plasmática dessa proteína entre os grupos Sham ( $n=10), \mathrm{Nx}-\mathrm{M}(\mathrm{n}=10)$ e $\mathrm{Nx}-\mathrm{Cl}(\mathrm{n}=10)$ aos 30 (Coleta 1) e 120 dias (Coleta 4) de nefrectomia. ANOVA de uma via, seguido do pós-teste Bonferrone.

Figura 14 - Análise dos níveis séricos de IFN-y (pg/mL) aos 30 e 120 dias de nefrectomia, coleta 1 e 4 respectivamente.

Coleta 1

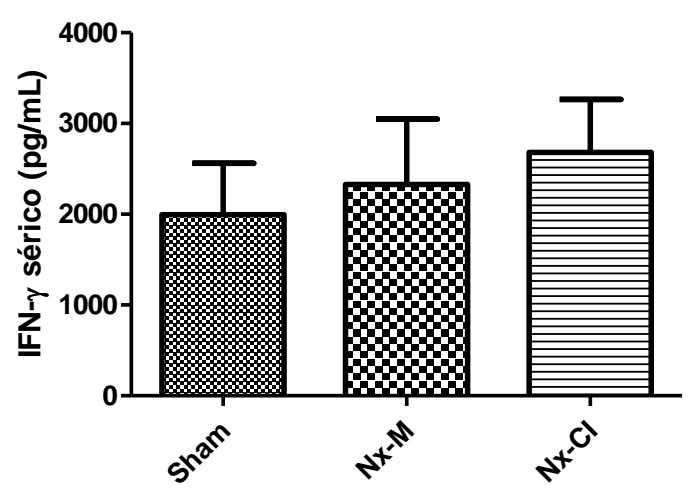

Coleta 4

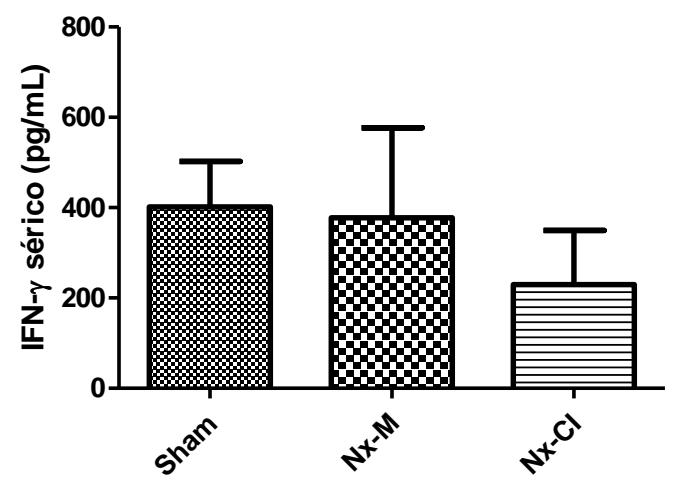

Ensaio de ELISA para IFN- $\gamma$, observe a ausência diferenças na concentração plasmática do IFN- $\gamma$ entre os grupos Sham ( $n=10), \mathrm{Nx}-\mathrm{M}(\mathrm{n}=10)$ e $\mathrm{Nx}-\mathrm{Cl}(\mathrm{n}=10)$ aos 30 (Coleta 1) e 120 dias (Coleta 4) de nefrectomia. ANOVA de uma via, seguido do pós-teste Bonferrone.

A análise dos níveis séricos de IL-10 após 30 (Sham: $3735 \pm 11,8$; Nx-M: 605,7 \pm 92,53; Nx-Cl: 909,6 \pm 9,58) e 120 (Sham: $3114 \pm$ 623,5; Nx-M: 321,3 \pm 53,52; Nx-Cl: 276,6 $\pm 65,04)$ dias de nefrectomia encontraram-se significativamente reduzidos nos animais nefrectomizados (Figura 15). 
Figura 15 - Análise dos níveis séricos de IL-10 (pg/mL) aos 30 e 120 dias de nefrectomia, coleta 1 e 4 respectivamente.
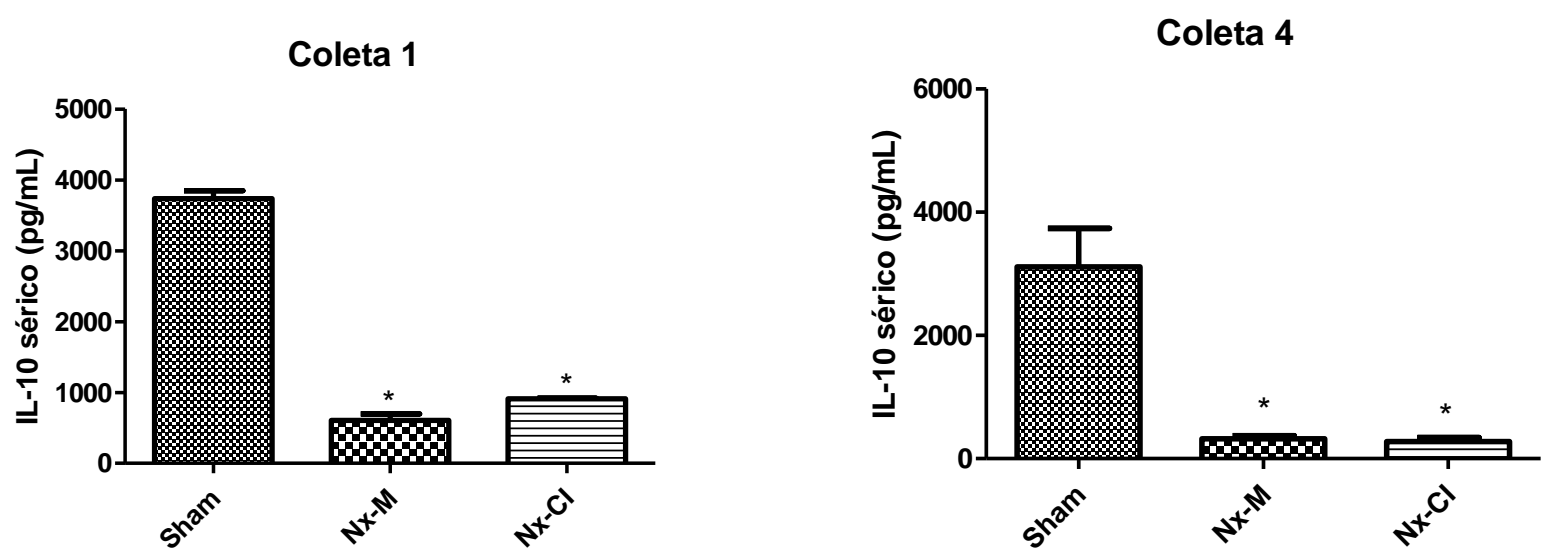

Ensaio de ELISA para IL-10, onde encontramos redução na concentração sérica de IL-10 nos grupos $\mathrm{Nx}-\mathrm{M}(\mathrm{n}=10)$ e $\mathrm{Nx}-\mathrm{Cl}(\mathrm{n}=10)$ quando comparados ao grupo Sham $(n=10)$ aos 30 (Coleta 1) e 120 dias (Coleta 4) de nefrectomia. $p<0,05-\left(^{*}\right)$ vs Sham. ANOVA de uma via, seguido do pós-teste Bonferrone.

Em contrapartida, observamos que os níveis séricos de corticoesterona aos 30 dias de nefrectomia, encontraram-se significativamente reduzidos nos animais do grupo $\mathrm{Nx}-\mathrm{Cl}(73524 \pm 107)$ quando comparados aos animais Nx-M (91647 \pm 5462$)$ e Sham (109986 \pm 7873 ), todavia, aos 120 dias de ablação, a análise dos dados mostraram um aumento significativo nos grupos Nx-M (81124 \pm 10588$)$ e Nx-Cl (81302 \pm 17451$)$ em relação aos animais Sham (38107 \pm 6214$)$ (Figura 16).

Figura 16 - Análise dos níveis séricos de Corticoesterona $(\mathrm{pg} / \mathrm{mL})$ aos 30 e 120 dias de nefrectomia, coleta 1 e 4 respectivamente.
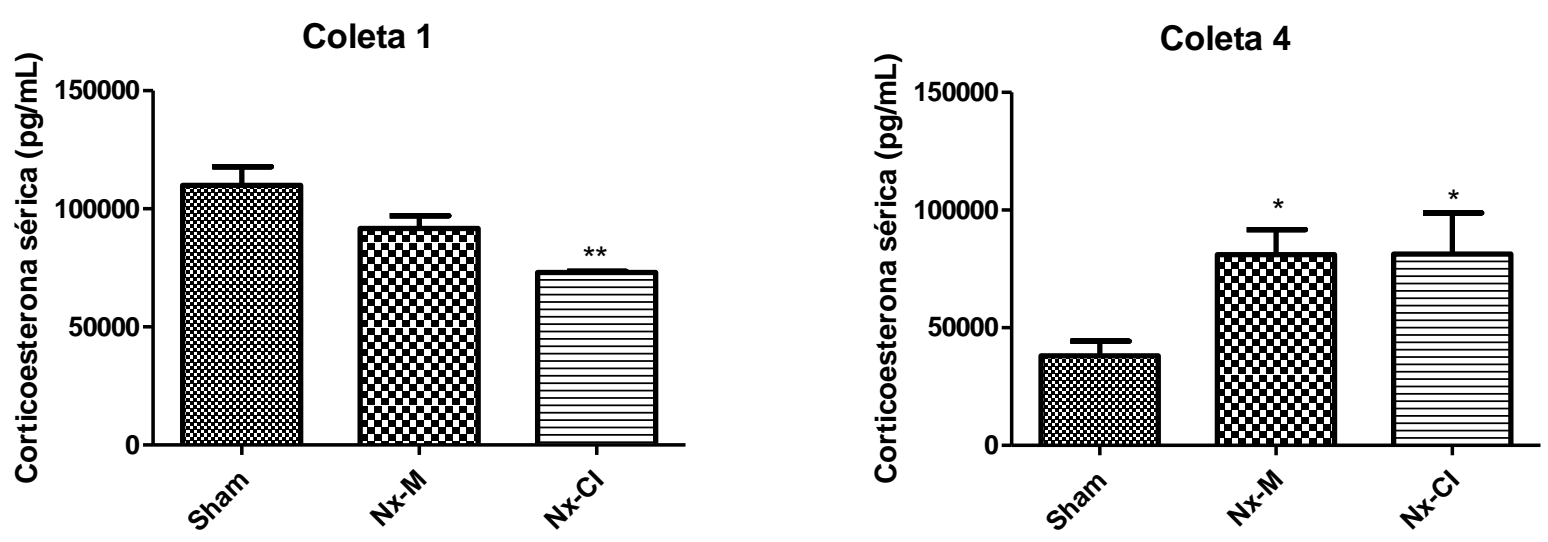

Ensaio de ELISA para corticoesterona, observe a redução na concentração sérica de corticoesterona no grupo $\mathrm{Nx}-\mathrm{Cl}$ aos 30 dias (Coleta 1) de nefrectomia quando comparado ao grupo Sham, no entanto, não encontramos diferença entre o grupo $\mathrm{Nx}-\mathrm{Cl}$ e $\mathrm{Nx}-\mathrm{M}$, bem como entre o grupo $\mathrm{Nx}-\mathrm{M}$ e Sham. Entretanto, aos 120 dias (Coleta 4) de nefrectomia, observamos nível sérico de corticoesterona elevado nos grupos $\mathrm{Nx}-\mathrm{M}$ e Nx-Cl em relação ao grupo Sham. $\mathrm{p}<0,05-{ }^{*}$ vs Sham. ANOVA de uma via, seguido do pós-teste Bonferrone. 
Aos 120 dias de nefrectomia coletamos FCR, onde não observamos diferença estatística no estudo dos níveis liquóricos de IL-6 entre os grupos analisados (Figura 17A). No entanto, encontramos uma elevação importante no nível liquórico de TNF- $\alpha$ no grupo $\mathrm{Nx}-\mathrm{Cl}$ quando comparado aos grupos Sham e Nx-M (Figura 17B).

Figura 17 - Análise dos níveis liquóricos de IL-6 (pg/mL) e TNF- $\alpha$ (pg/mL) após 120 dias de nefrectomia.
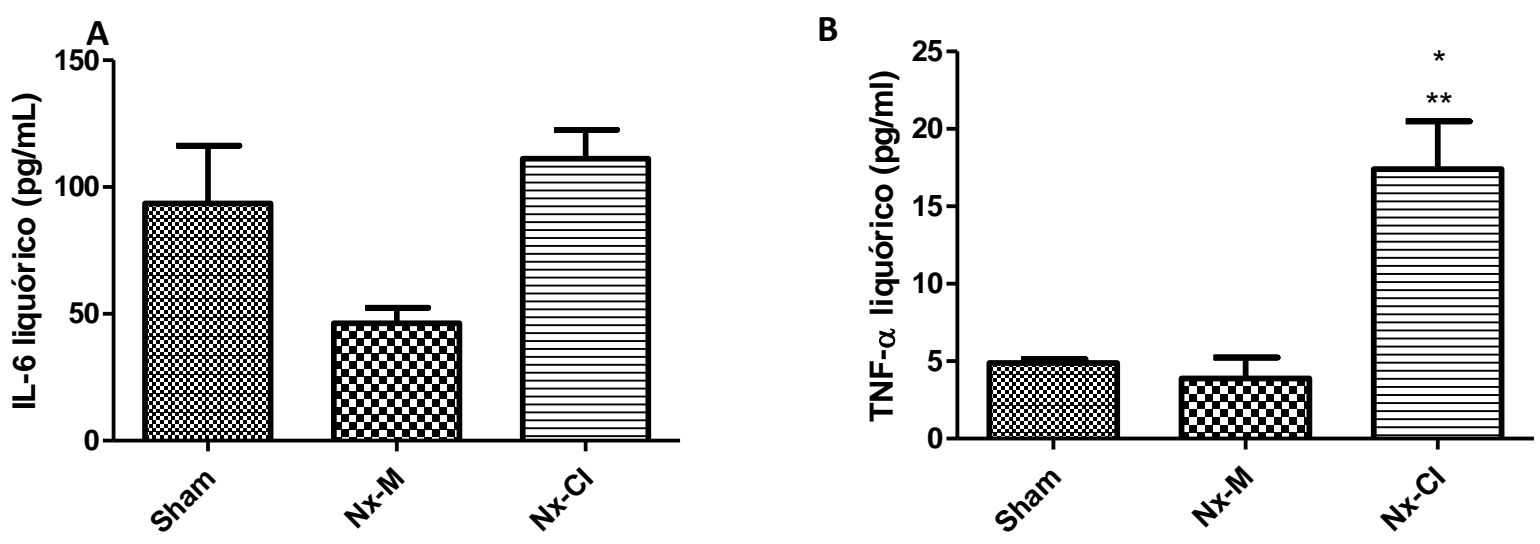

Ensaio de ELISA para dosagem de IL-6 e TNF- $\alpha$ em LCR, em 17A observe a ausência de diferença na concentração liquórica de IL-6 entre os grupos estudados (Sham: $n=5 ; \mathrm{Nx}-\mathrm{M}: \mathrm{n}=5$ e Nx-Cl: $n=5$ ). No entanto, em 17B, encontramos importante aumento na concentração liquórica de TNF-a no grupo NX-Cl quando comparado ao grupo Sham e Nx-M. p<0,05 - * vs Sham; ** vs Nx-M. ANOVA de uma via, seguido do pós-teste Bonferrone.

Observamos dado semelhante em relação a Proteína C Reativa, onde o grupo $\mathrm{Nx}-\mathrm{Cl}$ apresentou nível liquórico elevado dessa proteína quando comparado ao grupo Sham, não sendo observado diferença estatística entre o grupo Sham e Nx-M (Figura 18A). Não encontramos, porém, diferença na concentração liquórica de IL-1 $\beta$ entre os grupos estudados (Figura 18B). Todavia, encontramos importante redução na concentração liquórica de IFN-y no grupo Nx-M em relação ao grupo Sham, porém, não observamos diferença entre os grupos Sham e $\mathrm{Nx}-\mathrm{Cl}$ (Figura $18 \mathrm{C})$. 
Figura 18 - Análise dos níveis liquóricos de Proteína C Reativa $(\mathrm{ng} / \mathrm{mL}), \mathrm{IL}-1 \beta$ $(\mathrm{pg} / \mathrm{mL})$ e IFN-y $(\mathrm{pg} / \mathrm{mL})$ após 120 dias de nefrectomia.
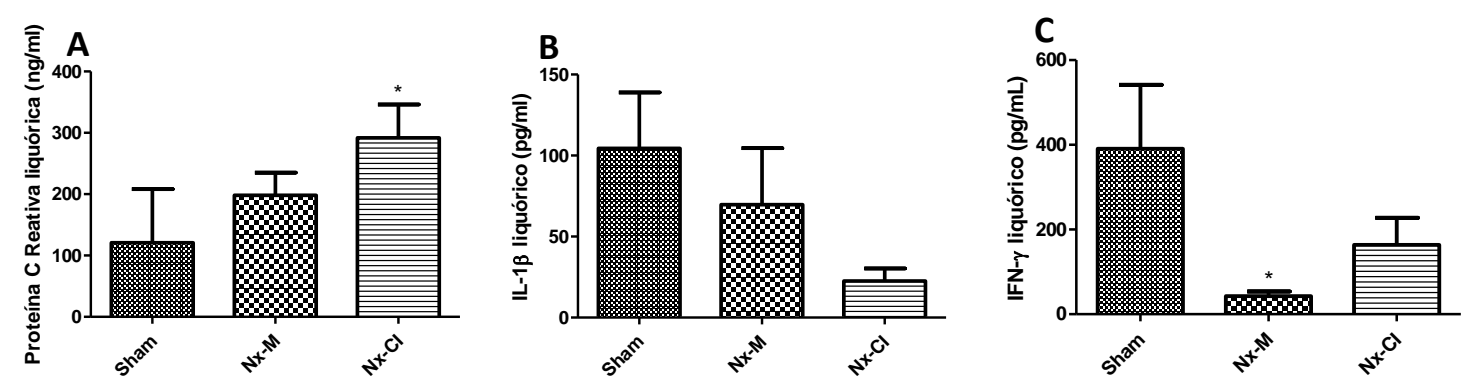

Ensaio de ELISA em FCR. Em 18A, observe a elevação na concentração liquórica de Proteína C Reativa no grupo $\mathrm{Nx}-\mathrm{Cl}(\mathrm{n}=5)$ comparado aos grupos Sham e $\mathrm{Nx}-\mathrm{M}$, porém não encontramos diferença entre os grupos Sham e Nx-M. Em 18B, a análise da concentração liquórica de IL-1 $\beta$ não identificamos diferença entre os grupos estudados. Em 18C, encontramos diminuição na concentração do IFN- $\gamma$ no grupo $\mathrm{Nx}-\mathrm{M}$ em relação ao grupo Sham e $\mathrm{Nx}-\mathrm{Cl}$. $\mathrm{p}<0,05$. ( ${ }^{*}$ ) vs Sham. ANOVA de uma via, seguido do pós-teste Bonferrone.

$\mathrm{Na}$ análise do nível liquórico de IL-10, encontramos importante redução nos grupos $\mathrm{Nx}-\mathrm{M}$ e $\mathrm{Nx}-\mathrm{Cl}$, comparados ao grupo Sham (Figura 19A). No entanto, observamos elevação significativa na concentração liquórica de corticoesterona no grupo Nx-M em relação ao grupo Sham e NX-Cl (Figura 19B).

Figura 19 - Análise dos níveis liquóricos de IL-10 (pg/mL) e Corticoesterona $(\mathrm{pg} / \mathrm{mL})$ após 120 dias de nefrectomia.
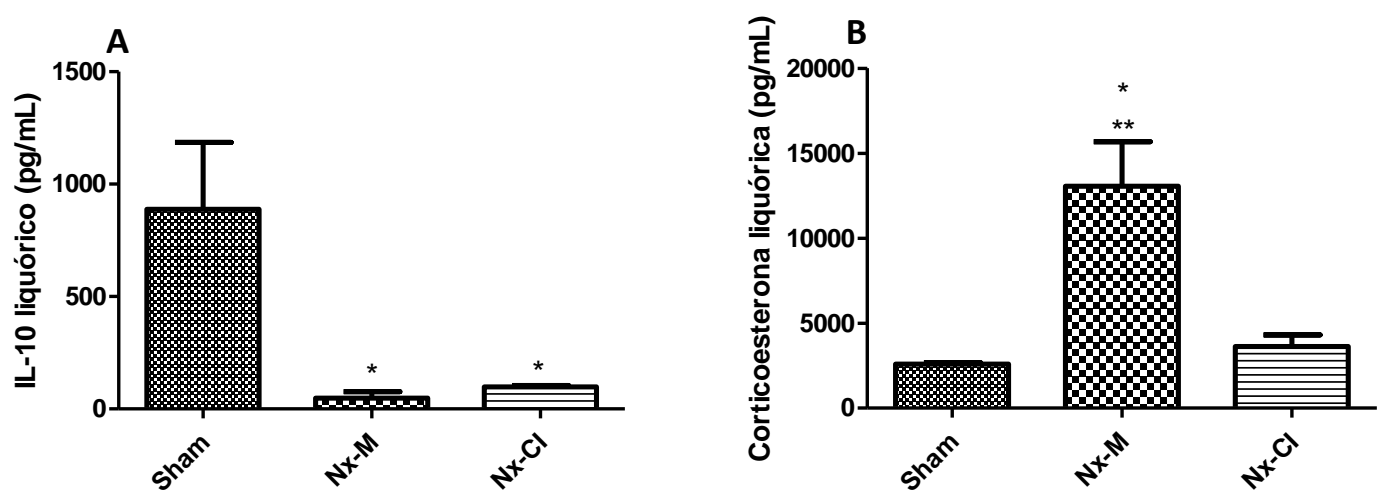

Em 19A, encontramos diminuição na concentração liquórica de IL-10 nos grupos Nx-M e Nx-Cl em relação ao grupo Sham. Em 19B, observamos aumento na concentração liquórica de Corticoesterona no grupo Nx-M em comparação com os grupos Sham e Nx-Cl. $\mathrm{p}<0,05 .\left(^{*}\right)$ vs Sham; $\left(^{* *}\right)$ vs $\mathrm{Nx}-\mathrm{Cl}$. ANOVA de uma via, seguido do pós-teste de Bonferrone.

No estudo da IL-6 em extrato tecidual observamos elevação dessa proteína inflamatória no grupo $\mathrm{Nx}-\mathrm{M}$ na região do córtex frontal, quando comparados aos grupos Sham e $\mathrm{Nx}-\mathrm{Cl}$, essa diferença não foi observada entre os grupos Sham e Nx$\mathrm{Cl}$ (Figura 20A). Na região do hipocampo e da amigdala, não encontramos dado 
semelhante, uma vez que a concentração tecidual de IL-6 observada nos respectivos extratos não apresentou diferença entre os grupos estudados (Figura 20B e 20C). No entanto, no extrato de tecido renal, encontramos importante elevação da IL-6 nos grupos Nx-M e Nx-Cl quando comparados ao grupo Sham (Figura 20D).

Figura 20 - Análise dos níveis teciduais de $\mathrm{IL}-6(\mathrm{pg} / \mathrm{mL})$ em diferentes regiões cerebrais e no rim, após 120 dias de nefrectomia.
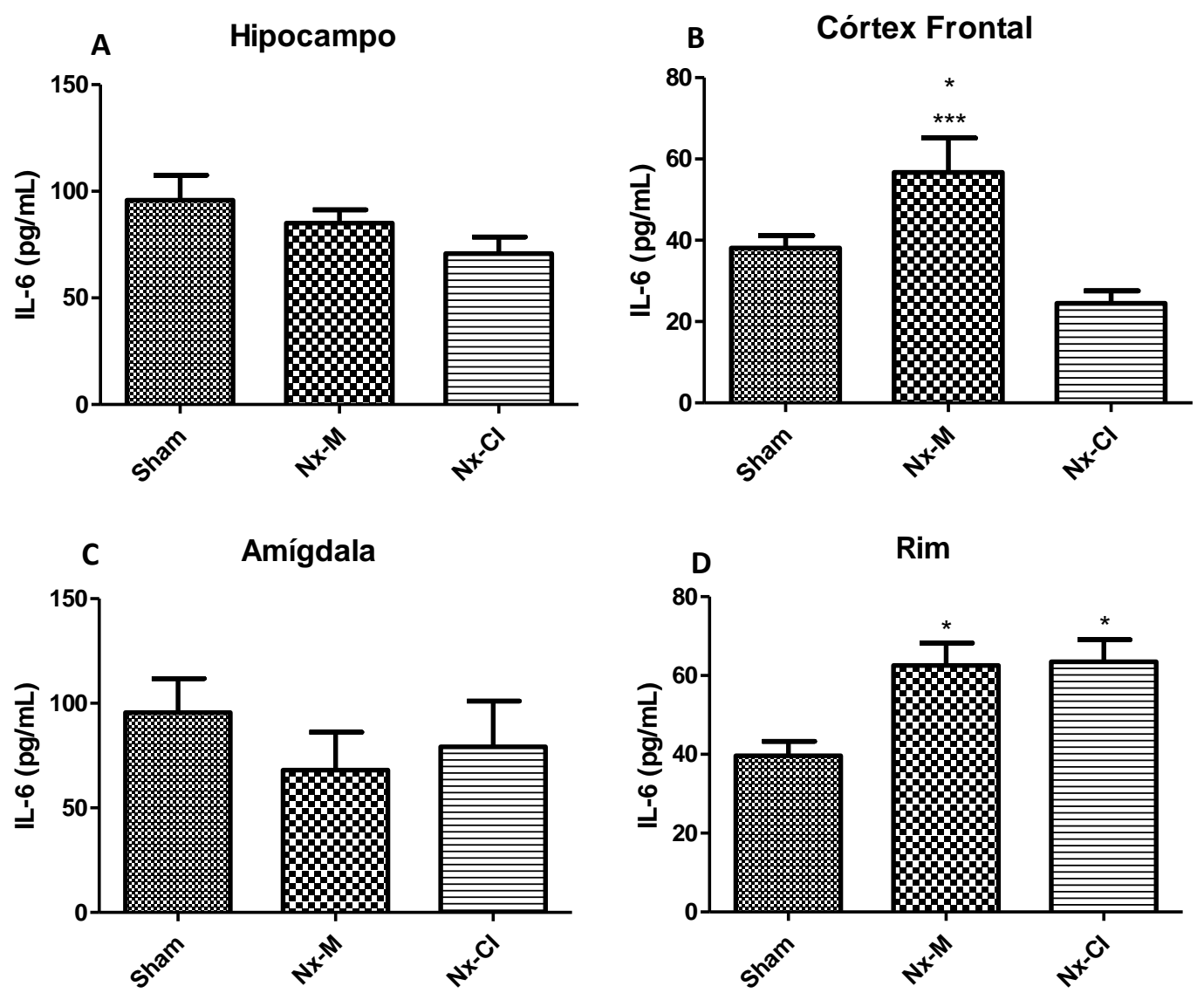

Ensaio de ELISA para IL-6. Observe a elevação da IL-6 na região do córtex frontal no grupo Nx-M $(n=6)$ em comparação com os grupos Sham $(n=6)$ e $\mathrm{Nx}-\mathrm{Cl}(n=6)$, representada em 20B. No entanto, na região do hipocampo e da amígdala, Figura 20A e 20C respectivamente, não encontramos diferença entre os grupos estudados. Em 20D, encontramos aumento na concentração tecidual de IL16 renal nos grupos $\mathrm{Nx}-\mathrm{M}$ e $\mathrm{Nx}-\mathrm{Cl}$ em relação ao grupo Sham. $\mathrm{p}<0,05 .\left(^{*}\right)$ vs Sham; $\left.{ }^{(* *}\right)$ vs $\mathrm{Nx}-\mathrm{Cl}$. ANOVA de uma via, seguido do pós-teste Bonferrone.

Observamos, no córtex frontal, elevação na concentração tecidual de TNF- $\alpha$ no grupo Nx-M em comparação aos grupos Sham e Nx-Cl (Figura 21B). Dado semelhante foi observado no tecido renal, onde o grupo Nx-M apresentou TNF- $\alpha$ elevado em relação aos grupos Sham e $\mathrm{Nx}-\mathrm{Cl}$ (Figura 21D). No entanto, não 
encontramos diferença entre os grupos na concentração tecidual de TNF-a na região do hipocampo e amígdala (Figura 21A e 21C).

Figura 21 - Análise dos níveis teciduais de TNF- $\alpha(\mathrm{pg} / \mathrm{mL})$ em diferentes regiões cerebrais e no rim, após 120 dias de nefrectomia.

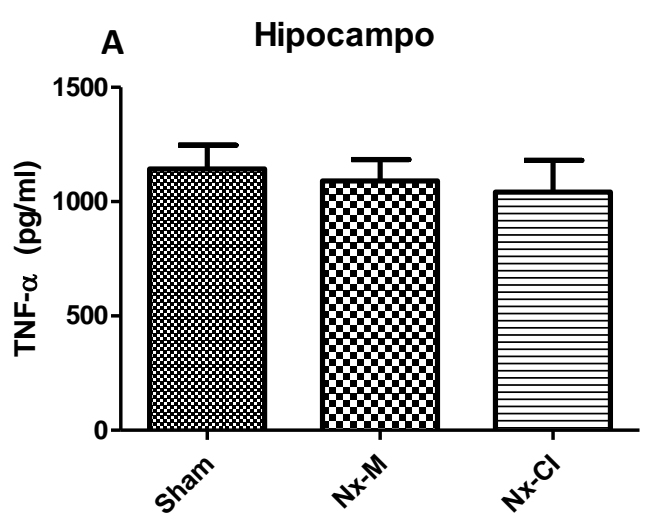

B

Córtex Frontal
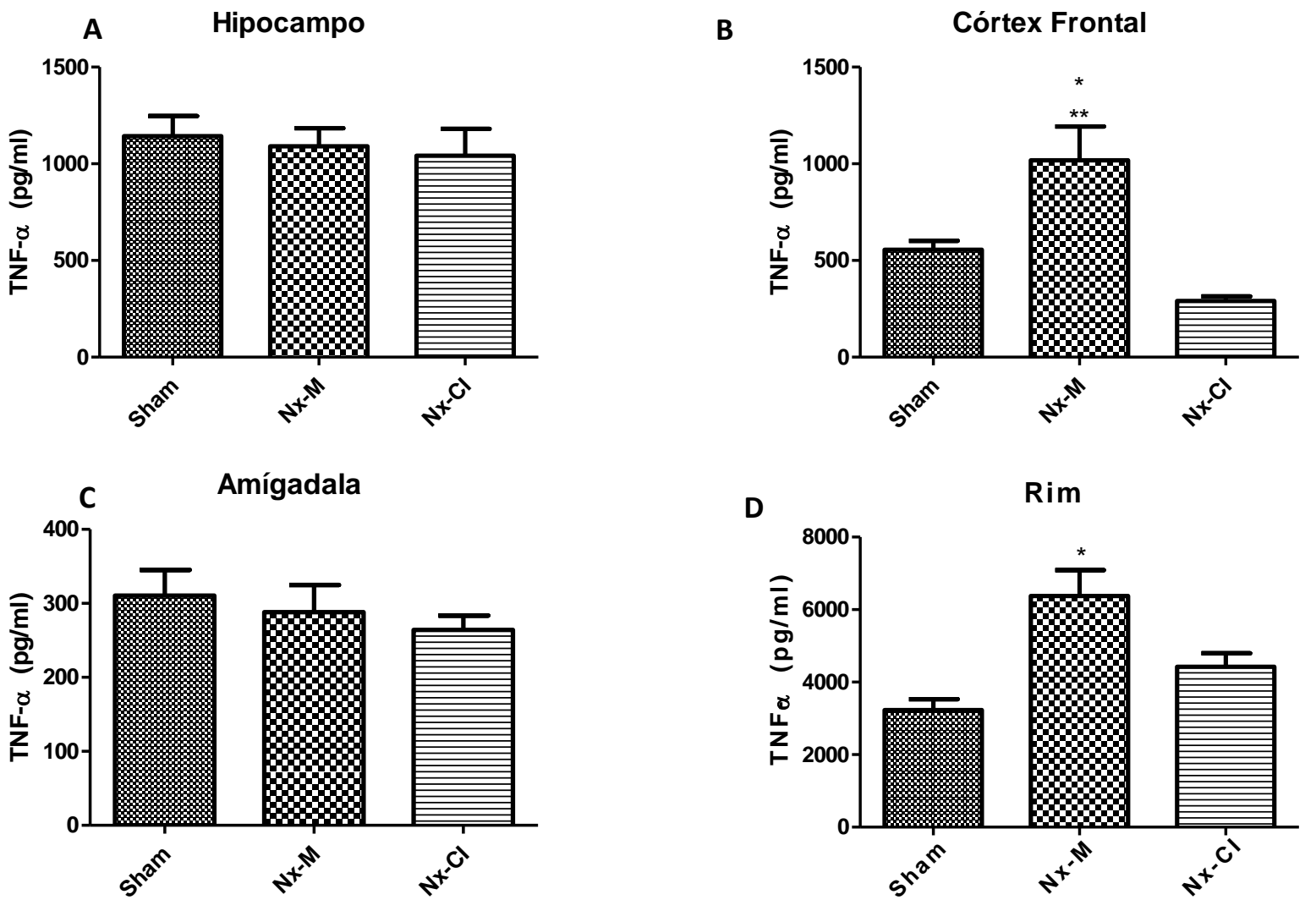

Ensaio de ELISA para TNF- $\alpha$. Em 21B, observamos elevação na concentração tecidual de TNF- $\alpha$ na região do córtex frontal presente no grupo $N x-M(n=5)$ em comparação com os grupos Sham $(n=5)$ e $\mathrm{Nx}-\mathrm{Cl}(\mathrm{n}=5)$. De mesma maneira, em 21D, tem-se a elevação na concentração tecidual de TNF- $\alpha$ renal no grupo Nx-M. Todavia, não observamos diferença na concentração tecidual do TNF- $\alpha$ nas regiões cerebrais do hipocampo e amígdala entre os grupos estudados, Figuras $21 \mathrm{~A}$ e $21 \mathrm{C}$, respectivamente. $\mathrm{p}<0,05$ - ${ }^{*}$ vs Sham; ${ }^{* *}$ vs $\mathrm{Nx}$-Cl. ANOVA de uma via, seguido do pós-teste Bonferrone.

O estudo da proteína tecidual IL-1 $\beta$ nas regiões cerebrais do hipocampo, córtex frontal e amígdala (Figuras 22A, 22B e 22C, respectivamente) e no rim (Figura 22D) mostrou ausência de diferença nas concentrações dessa proteína inflamatória entre os grupos Sham, Nx-M e Nx-Cl. Dado semelhante foi observado em relação a concentração tecidual de proteína $C$ reativa, onde não observamos diferença entre os grupos estudados nos extratos teciduais de hipocampo, córtex frontal e amígdala (Figuras 23A-C). 
Figura 22 - Análise dos níveis teciduais de $\mathrm{IL}-1 \beta(\mathrm{pg} / \mathrm{mL})$ em diferentes regiões cerebrais e no rim, após 120 dias de nefrectomia.
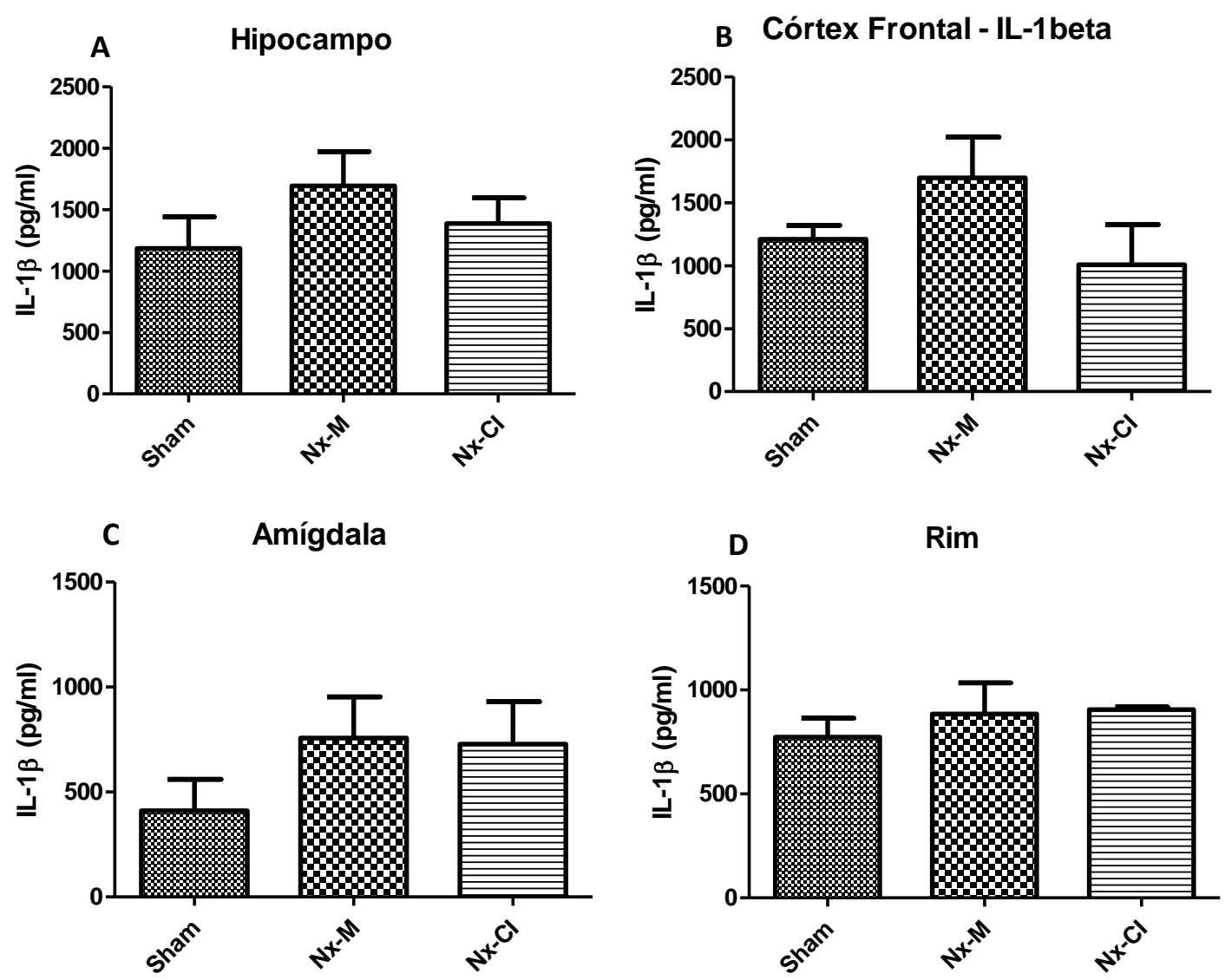

Ensaio de ELISA para IL-1 $\beta$. Encontramos ausência de diferença na concentração tecidual de IL-1 $\beta$ nas regiões do hipocampo (22A), córtex frontal (22B), amígdala (22C) e rim (22D) entre os grupos Sham $(n=5), N x-M(n=5)$ e Nx-Cl $(n=5)$. ANOVA de uma via, seguido do pós-teste Bonferrone.

Figura 23 - Análise dos níveis teciduais de Proteína C Reativa $(\mathrm{ng} / \mathrm{mL})$ em diferentes regiões cerebrais, após 120 dias de nefrectomia.
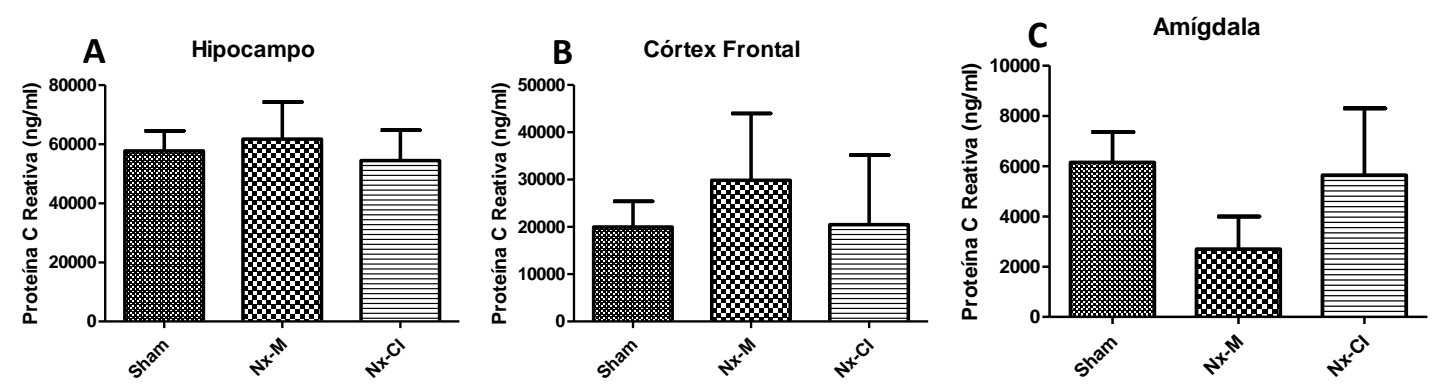

Ensaio de ELISA para Proteína C Reativa. Encontramos ausência de diferença na concentração tecidual desta proteína nas regiões do hipocampo (A), córtex frontal (B) e amígdala (C) entre os grupos Sham (n=5), Nx-M (n=5) e Nx-Cl (n=5). ANOVA de uma via, seguido do pós-teste Bonferrone.

$\mathrm{Na}$ observação da concentração tecidual de IL-10 na região do hipocampo, encontramos diminuição dessa proteína nos animais do grupo $\mathrm{Nx}-\mathrm{Cl}$, em comparação com os grupos Sham e Nx-M (Figura 24A). Dado contrário foi 
observado no tecido renal, onde encontramos elevação da IL-10 tecidual no grupo $\mathrm{Nx}-\mathrm{Cl}$ em relação aos grupos Sham e Nx-M (Figura 24D). Todavia, não encontramos diferença na concentração de IL-10 tecidual nas regiões do córtex frontal e da amígdala (Figuras 24B e 24C) entre os grupos estudados.

Figura 24 - Análise dos níveis teciduais de $\mathrm{IL}-10(\mathrm{pg} / \mathrm{mL})$ em diferentes regiões cerebrais e no rim, após 120 dias de nefrectomia.
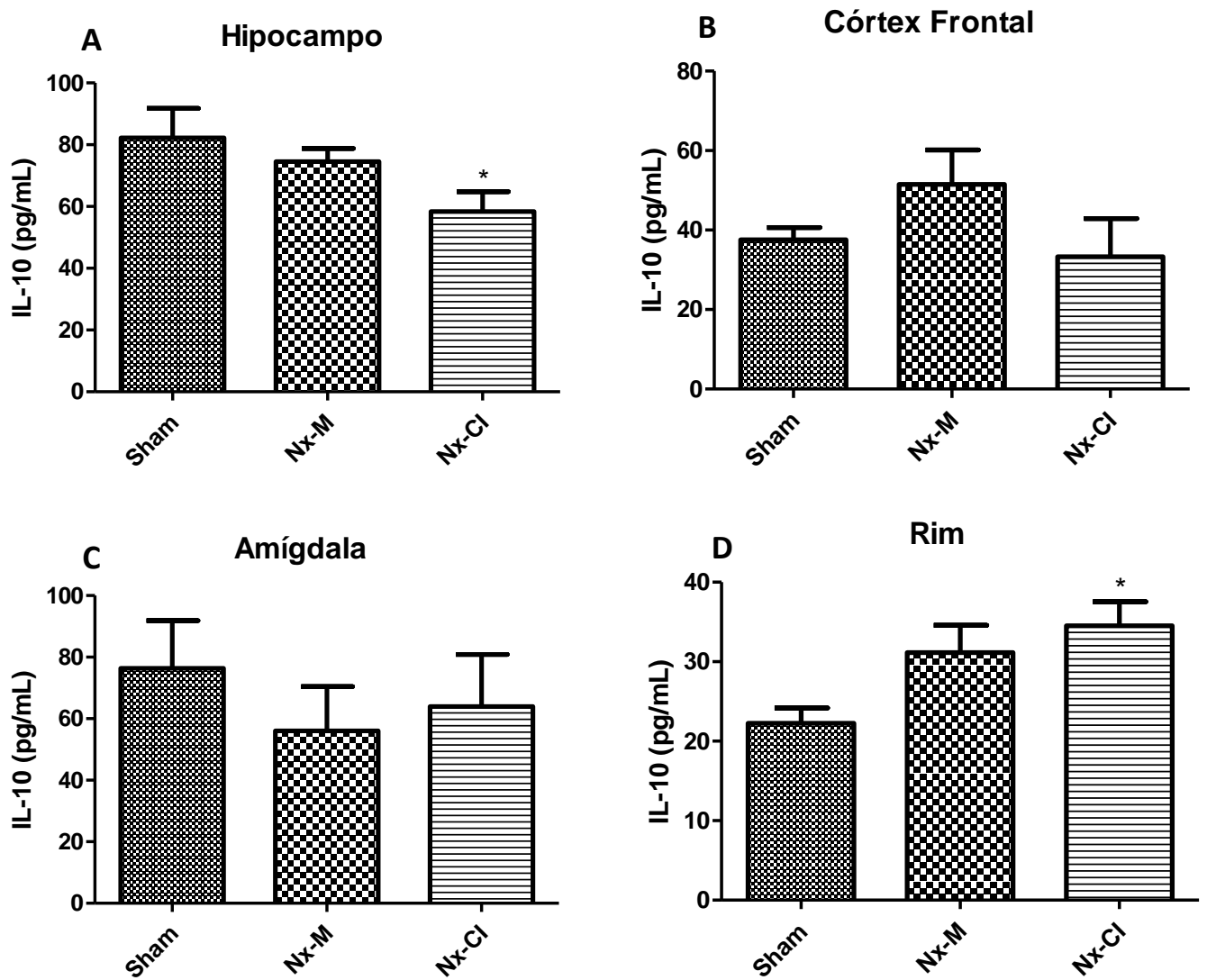

Ensaio de ELISA para IL-10. Em 24A encontramos importante redução na concentração de IL-10 na região do hipocampo no grupo $\mathrm{Nx}-\mathrm{Cl}(n=5)$ em comparação com os grupos Sham $(n=5)$ e Nx-M $(n=5)$. Esse dado não foi encontrado nas outras regiões cerebrais estudadas, córtex frontal (24B) e amígdala (24C), onde observamos ausência de diferença na concentração tecidual de IL-10 entre os grupos estudados. No entanto, detectamos um aumento significante na concentração tecidual de IL10 na região do rim (24D) presente no grupo $\mathrm{Nx}-\mathrm{Cl}$ em comparação com os grupos Sham e Nx-M.

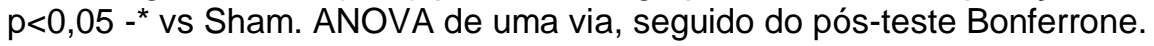

Em relação a concentração tecidual de IFN- $\gamma$, observamos que o grupo Nx-M apresentou elevação dessa proteína na região do córtex frontal quando comprados aos grupos Sham e Nx-M (Figura 25B). No entanto, esse dado não foi encontrado na região do hipocampo, amigdala e rim (Figuras 25A, C e D), onde não observamos diferença na concentração tecidual de IFN-ץ entre os grupos estudados. 
Figura 25 - Análise dos níveis teciduais de IFN-ץ (pg/mL) em diferentes regiões cerebrais e no rim, após 120 dias de nefrectomia.
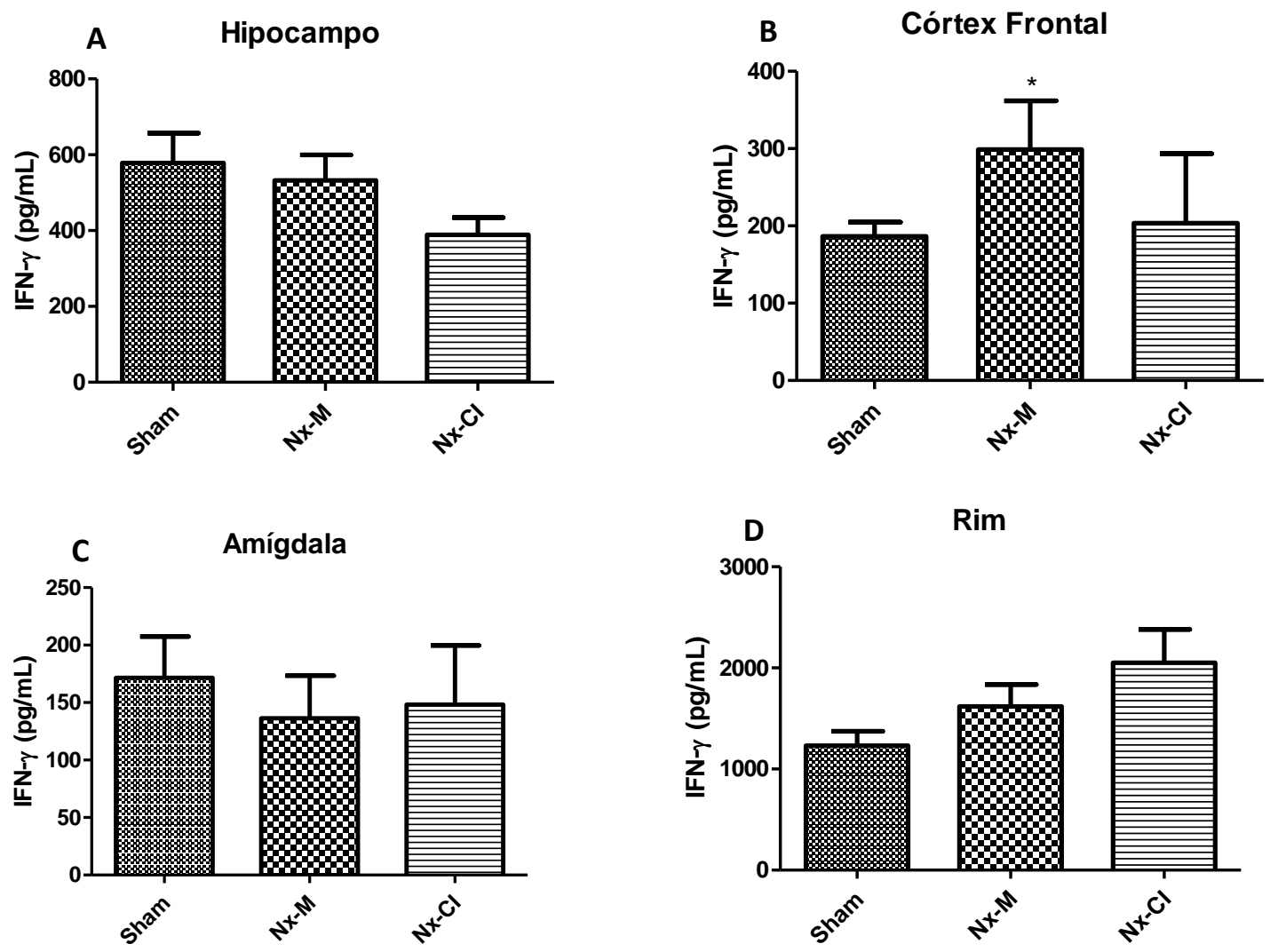

Ensaio de ELISA para IFN-ү. Em B encontramos importante elevação na concentração tecidual de IFN-y no córtex frontal dos animais do grupo Nx-M (n=5) em comparação com os grupos Sham $(n=5)$ e Nx-M (n=5). Esse dado não foi encontrado nas outras regiões cerebrais estudadas, córtex frontal (A) e amígdala (C), bem como no tecido renal (D), onde observamos ausência de diferença na concentração tecidual de IFN- $\gamma$ entre os grupos estudados. $p<0,05$ - * vs Sham. ANOVA de uma via, seguido do pós-teste Bonferrone.

Outro dado estudado neste trabalho, refere-se a concentração da proteína klotho, onde observamos, no grupo $\mathrm{Nx}-\mathrm{Cl}$, redução significativa nos níveis séricos da mesma, quando comparado aos grupos Sham e Nx-M (Figura 26). Dado semelhante foi encontrado no estudo do homogenato de córtex frontal, onde a concentração tecidual de klotho encontrou-se diminuída no grupo $\mathrm{Nx}-\mathrm{Cl}$ em relação ao grupo $\mathrm{Nx}$ $\mathrm{M}$, no entanto, essa diferença não foi observada entre os grupos $\mathrm{Nx}-\mathrm{Cl}$ e Sham (Figura 27A). 
Figura 26 - Dosagem por ELISA da concentração sérica da proteína klotho.

\section{Soro}

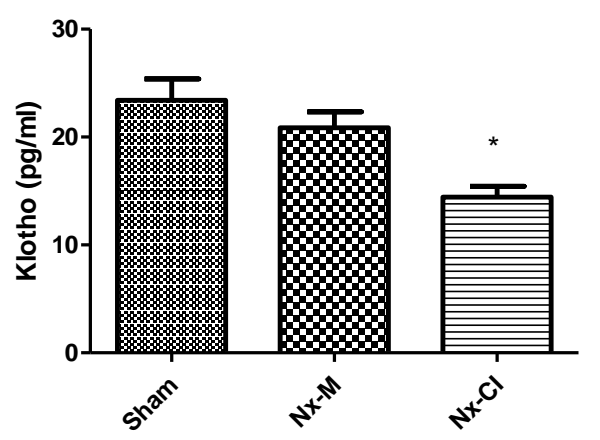

A análise gráfica mostra marcada diminuição nos níveis séricos de klotho no grupo $\mathrm{Nx}-\mathrm{Cl}(\mathrm{n}=8)$ quando comparado aos grupos Sham $(n=8)$ e Nx-M $(n=8) \cdot p<0,01-\left(^{*}\right)$ vs Sham e vs Nx-M. AVOVA de uma via, seguido pelo pós-teste Newman-Keuls.

No extrato tecidual de hipocampo, a concentração de klotho não apresenta diferença entre os grupos estudados, mostrando, que possivelmente, nesse modelo animal de DRC, a alteração da função cognitiva parece não sofrer influência importante da atividade dessa proteína (Figura 27B).

Figura 27 - Níveis de Klotho no córtex frontal e hipocampo de ratos Sham, Nx-M e $\mathrm{Nx}-\mathrm{Cl}$.
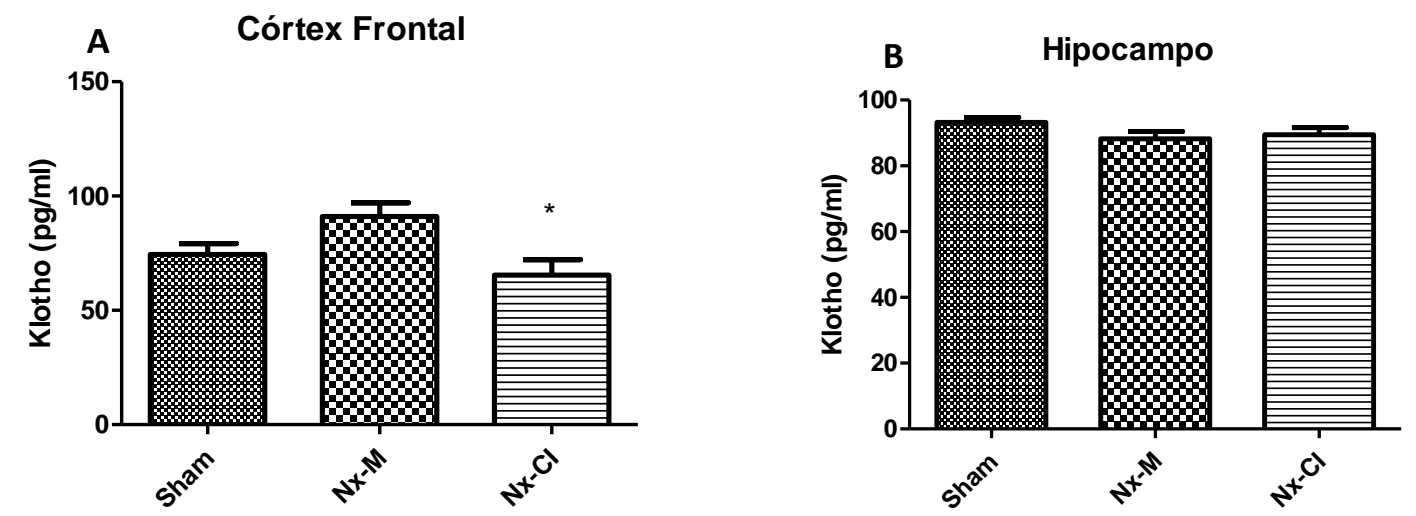

Em A, a análise gráfica mostra redução nos níveis teciduais de klotho, na região do córtex frontal, no grupo $\mathrm{Nx}-\mathrm{Cl}(\mathrm{n}=8)$ quando comparado aos grupos Sham $(n=8)$ e Nx-M $(n=8) . p<0,05-\left({ }^{*}\right)$ vs Sham e vs Nx-M. Em B, no estudo da klotho tecidual na região do hipocampo, não apresenta diferença entre os grupos estudados. AVOVA de uma via, seguido pelo pós-teste Newman-Keuls. 


\section{DISCUSSÃO}

Em nosso estudo analisamos o perfil cognitivo de indivíduos adultos com DRC em programa de hemodiálise por no mínimo 12 meses e no máximo 24 meses. Utilizamos o 3MS juntamente com o KDQOL-SF como ferramenta para avaliar a função cognitiva nesses indivíduos e, nessa condição, observamos que $40 \%$ dos pacientes com DRC apresentaram declínio da função cognitiva global, onde verificamos, no grupo $\mathrm{DRC}-\mathrm{Cl}$, que o declínio cognitivo estava concentrado nas áreas equivalentes aos domínios cognitivos de memória operacional, processamento sintático e memória de longo prazo. Paralelamente, fazendo uso de testes de comportamento animal em modelos de DRC, encontramos ocorrência semelhante, de forma que $36 \%$ dos animais submetidos a $5 / 6$ de ablação renal apresentaram declínio da memória operacional (dado obtido no teste de Esquiva Inibitória) e 40\% dos animais declínio da atenção (dado obtido no teste de reconhecimento do objeto novo).

Corroborando com nossos dados, Kurella et al. (2005) mostrou que o 3MS é um instrumento útil para detecção de déficits cognitivos globais, sendo freqüentemente encontrado alteração da função cognitiva, linguagem e memória nos indivíduos com DRC. Estudos recentes tem relatado a prevalência de declínio cognitivo entre $30-38 \%$ em pacientes submetidos à hemodiálise com freqüência de 2 vezes/semana (MADAN et al., 2007; PEREIRA et al., 2004; WANG et al., 2010), sendo descrito um aumento de aproximadamente 15 a $25 \%$ no risco para disfunção cognitiva em situações onde tem-se $10 \mathrm{~mL} / \mathrm{min} / 1,73 \mathrm{~m}^{2}$ de média de filtração glomerular (eFGM) ou menos (KURELLA et al., 2005). Em outro estudo, realizado com pacientes em estágio pré-dialítico da DRC, $20 \%$ dos indivíduos avaliados apresentaram alteração da função cognitiva, sendo encontrado nesse grupo de indivíduos eFGM de aproximadamente $10,9 \mathrm{~mL} / \mathrm{min} / 1,73 \mathrm{~m}^{2}$ (NULSEN et al., 2008).

Dahbour et al. (2009) aplicaram o MMSE em indivíduos em hemodiálise há, no mínimo 2 anos, constatando que $22 \%$ dos indivíduos apresentavam uma perda significativa da função cognitiva tanto no pré quanto no pós-hemodiálise. Esse estudo revelou ainda que os indivíduos estudados apresentam uma tendência a perda da atenção no pós-diálise apesar da orientação estar mais estabilizada na mesma condição. Teng; Chui (1987) afirmam que o declínio cognitivo pode subir para $40 \%$ quando usado o $3 \mathrm{MS}$ na avaliação da função cognitiva, provavelmente 
devido a maior sensibilidade desse teste. Encontramos dado semelhante a essas pesquisas, onde $40 \%$ dos voluntários avaliados em nosso estudo com o $3 \mathrm{MS}$ apresentaram déficit cognitivo, sendo mais marcado o declínio cognitivo médio. Embora o processo de hemodiálise seja considerado um fator de risco ao surgimento do déficit cognitivo (PEREIRA et al., 2005; YOSHIMITSU et al., 2000), a associação Kt/V (cálculo usado para adequar os tratamento de hemodiálise e CAPD, onde $\mathrm{K}$ refere-se ao clearance da uréia, $\mathrm{t}$ ao tempo de diálise e $\mathrm{V}$ ao volume de distribuição da uréia) a piora da função cognitiva não foi estabelecida, mesmo quando avaliada com diferentes testes cognitivos (MMSE, NAART, teste de reconhecimento entre outros) (AGGANIS et al., 2010), mostrando que nos indivíduos submetidos ao procedimento de hemodiálise, esse fator parece não interferir de maneira importante na alteração da função cognitiva. Ao analisarmos os dados dos testes de comportamento realizados no modelo animal de nefrectomia $5 / 6$, onde a lesão renal atinge níveis pré-dialíticos, também pudemos observar declínio da memória operacional e da atenção, indicando que a DRC, mesmo nos seus estágios mais iniciais, onde não se faz necessário o uso de terapia renal substitutiva, contribui para a ocorrência das alterações da função cognitiva.

Ainda que a DRC tenha sido recentemente reconhecida como um fator de risco independente para a ocorrência do declínio cognitivo (KURELLA et al., 2004; KURELLA et al., 2005; SELINGER et al., 2004), a patogênese das manifestações do SNC ainda não são bem estabelecidas (LIU et al., 2008; MADERO et al., 2007; PEREIRA et al., 2005). Em nossa pesquisa, com uso do 3MS como ferramenta de avaliação cognitiva, aplicado imediatamente antes do procedimento dialítico, observamos declínio da função cognitiva no grupo DRC-Cl nos domínios cognitivos memória operacional, processamento sintático e memória de longo prazo, descritos pela obtenção de valores inferiores nos itens referentes a atenção, cálculo, fluência verbal semântica, leitura, escrita, comando verbal e evocação. Similarmente, McClintock et al. (2010) apontaram redução nas funções cognitivas relacionadas a atenção global, memória e função executiva em indivíduos submetidos a bateria NEUROPSI de avaliação cognitiva, realizada 24 horas após o procedimento dialítico. Outro estudo, onde foram utilizados diferentes testes neuropsicológicos de avaliação cognitiva, como o Trail Making Test (Parte A e B), Symbol Digit Modality Test, Rey Auditory Verbal Learning Test, Benton Visual Retention Test e Grooved Pegboard, aplicados 1 hora antes da realização do procedimento dialítico, constatou declínio 
nos domínios cognitivos de atenção, concentração, função executiva, aprendizado, memória verbal, habilidade visoconstrutiva e velocidade psicomotora (GRIVA et al., 2010). Em pesquisa realizada por Kurella et al. (2005), utilizando o 3MS como ferramenta de análise cognitiva, constatou declínio das funções cognitivas mais evidente nas áreas de linguagem e memória.

Diferentes estudos apontam fatores que podem estar relacionados ao déficit cognitivo encontrado nos indivíduos com DRC, como é o caso das pesquisas relacionando valores de eFGM menores com a acentuação do declínio cognitivo (KURELLA et al., 2005), comparando os níveis séricos de creatinina, onde indivíduos com creatinina de 2,0 $\mathrm{mg} / \mathrm{dl}$ apresentam risco de desenvolver demência $37 \%$ maior que indivíduos com 1,0 mg/dl de creatinina (SELINGER et al., 2004), bem como a elevação da microalbuminúria (JOOSTEN et al., 2011).

Os nossos resultados não mostraram diferença importante nos níveis séricos de creatinina entre os grupos DRC e DRC-Cl, assim como, também, não observamos diferenças entre os níveis séricos de uréia tanto no pré-diálise como no pós-diálise entre os mesmo grupos, mostrando, que esse fator, provavelmente não está envolvido na alteração da função cognitiva nessa população estudada. A encefalopatia urêmica, em geral, evidencia alteração cognitiva nas áreas relacionadas a atenção, velocidade de processamento de informação, aprendizado e memória, no entanto, esses achados são frequentes em indivíduos que desenvolvam insuficiência renal aguda (BURN; BATES, 1998). Desta forma, a ausência da influência da uremia sobre a cognição detectada nos nossos dados pode estar associada ao fato dos pacientes incluídos neste estudo encontrarem-se num estágio crônico da insuficiência renal.

Dados da literatura comparando o desempenho cognitivo de mulheres jovens com doença renal moderada e ausência de doença renal revela a presença de comprometimento cognitivo nas voluntárias com DRC mesmo na ausência de menopausa. Os estudos de Kurella et al. (2005) relataram comprometimento cognitivo em mulheres na menopausa com DRC quando associadas a disfunção coronariana. Considerando que as mulheres incluídas em nosso estudo estavam em idade limítrofe para o desenvolvimento de menopausa e que a redução nos níveis de progesterona e estrogênio, em mulheres menopausadas, descreve um decréscimo de $10 \mathrm{ml} / \mathrm{min} / 1,73 \mathrm{~m}^{2}$ na eFGM, correspondendo a uma elevação de $15-25 \%$ no risco de desenvolvimento de disfunção cognitiva (KURELLA et al., 2005), 
analisamos os níveis séricos de estrogênio nessas voluntárias. Os dados não mostraram diferença significativa entre os grupos controle, DRC e DRC-Cl, mostrando a ausência de influência desse hormônio sobre esta pesquisa.

Ainda que não exista uma conexão direta entre os fatores de risco vascular na DRC e a função cognitiva, evidências sugerem que os elevados níveis de mediadores inflamatórios presentes nesse perfil de pacientes pode apresentar importante papel em seu surgimento (SCHMIDT et al., 2002; TEUNISSEN et al., 2003).

É sabido que processos inflamatórios periféricos podem afetar algumas funções do SNC, incluindo os processos de memória e cognição (TERRANDO et al., 2010), de forma que evidências sugerindo a participação de citocinas nos mecanismos celulares e moleculares podem estar envolvidas na complexa interação de sistemas associados aos processos cognitivos (PATANELLA et al., 2010; YIRMIYA; GOSHEN, 2010).Tanto a superexpressão como a subexpressão de citocinas tem mostrado influenciar diretamente a memória relacionada à função do hipocampo, bem como várias formas de ocorrência da plasticidade sináptica (McAFOONSE; BAUNE, 2009). Usualmente a atividade das citocinas sobre o SNC é descrito em condições patológicas associado a manifestação do comportamento doentio, resultado da liberação exacerbada de citocinas. No entanto, existem evidências sugerindo que a IL-1 $\beta$, IL-6 e TNF desempenham importante papel na ocorrência da plasticidade sináptica, neurogênese e mecanismos de aprendizado e memória em situações fisiológicas (HOPKINS; ROTHWELL, 1995; POLLMACHER et al., 2002).

Yaffe et al. (2003) defendem que a superexpressão de citocinas próinflamatórias, como a IL-6 e TNF- $\alpha$, podem promover neurodegeneração e tal elevação crônica pode estar relacionada ao declínio da função cognitiva. Sabe-se que o TNF- $\alpha$ exerce efeitos neuromodulatórios no encéfalo, tendo sido particularmente reconhecido devido seus efeitos neuromodulatórios no cérebro, tendo sido demonstrado sua participação na excitotoxicidade glutamatérgica pela inibição dos transportadores de glutamato astrocitários (MENZA et al., 2010).

Surpreendentemente, em nosso estudo, a análise de mediadores séricos próinflamatórios (IL-1 $\beta$, IL-6, TNF- $\alpha$ e proteína C reativa) e antinflamatórios (IL-10 e cortisol) realizada nos indivíduos $\mathrm{DRC}$ e DRC-CI não mostrou diferença em relação aos indivíduos do grupo controle ou associação com a presença do declínio da 
função cognitiva. Distintamente, ao considerarmos os dados obtidos no estudo dos animais submetidos a ablação de $5 / 6$ da massa renal, podemos reconhecer dois momentos distintos, o primeiro, faz referencia aos 30 dias de nefrectomia e o segundo aos 120 de nefrectomia. Assim, aos 30 dias de nefrectomia, observamos um perfil predominantemente inflamatório no grupo $\mathrm{Nx}-\mathrm{Cl}$, descrito pela elevação sérica da IL-6 e redução nos níveis séricos de IL-10 e corticoesterona quando comparados ao grupo Sham. Considerando o mesmo período, o grupo Nx-M apresentou pontualmente um declínio nos níveis séricos de IL-10, porém, não observamos elevação nos níveis séricos de citocinas pró-inflamatórias ou de proteína C reativa. Contudo, aos 120 dias de ablação renal os níveis séricos de IL-6 encontrava-se semelhante entre os grupos, e, apesar da redução nos níveis séricos de IL-10 nos grupos $\mathrm{Nx}-\mathrm{M}$ e $\mathrm{Nx}-\mathrm{Cl}$, os níveis séricos de corticoesterona encontravam-se elevados nos grupos $\mathrm{Nx}-\mathrm{M}$ e $\mathrm{Nx}-\mathrm{Cl}$. Dessa forma, podemos inferir, ainda que em condições pré-dialíticas, que a análise nos níveis séricos de citocinas pró- e antiinflamatórias nesse modelo animal de DRC, que com a cronicidade da doença renal, esse parâmetro pode não estar claramente associado ao declínio cognitivo.

Um dado que deve ser ressalvado em nossa pesquisa está relacionado a análise do líquido encéfalo-raquidiano coletado dos animais nefrectomizados ao final do período experimental, ou seja, aos 121 dias de ablação renal, onde devido a elevação no nível liquórico de TNF e redução nos níveis liquóricos de IL-10 observados no grupo NX-Cl, bem como a elevação nos níveis liquóricos de corticoesterona no grupo $\mathrm{Nx}-\mathrm{M}$, podemos inferir que existe alguma associação entre o processo inflamatório nessa região e a presença de declínio cognitivo.

Contrariamente, nosso estudo revelou a presença de elevação da IL-6, TNF- $\alpha$ e IFN-y no extrato tecidual de córtex frontal no grupo $\mathrm{Nx}-\mathrm{M}$, descrevendo um aumento da atividade inflamatória nessa região cerebral após 121 dias de ablação de $5 / 6$ da massa renal.

É descrito que a IL-6 está proporcionalmente elevada de acordo com a progressão da DRC, e embora ela seja independente da GFR, o TNF- $\alpha$ é inversamente proporcional a GFR, justificando as variações encontradas nos indivíduos com DRC (SPOTO et al., 2011). Paralelamente, usamos dois modelos de DRC em animal, onde pudemos perceber que os animais com DRC apresentavam elevação da expressão de proteínas inflamatórias como a IL-6 e o TNF-a. Assim, de 
acordo com a literatura, nossos dados em humanos e animais associam a DRC a presença de um processo inflamatório sistêmico.

Pesquisas relatam a ocorrência de infartação silenciosa cerebral na substância branca cerebral localizada principalmente no lobo frontal de indivíduos com DRC (KOBAYASHI et al., 2009). Dado similar foi encontrado em nosso estudo, onde após a realização do 3MS e KDQOL-SF nos voluntários com DRC, constatamos que esses indivíduos apresentaram declínio mais evidente em áreas relacionadas a atenção e memória de trabalho, e quando reproduzimos esse em modelos de animais com lesão renal, os testes revelaram que os animais apresentaram redução da atenção em associação com o desenvolvimento de comportamento ansioso. Esses dados mostram que a DRC pode fortemente influenciar a atividade do córtex pré-frontal, talvez devido a diferente distribuição de receptores de mediadores inflamatórios nos tecidos cerebrais, resultando em diferentes respostas celulares e moleculares, dentre elas, a da sinalização associada a proteína Klotho.

O gene Klotho codifica uma proteína de membrana do tipo I que está relacionado com $\beta$-glucuronidases. Uma diminuição na produção desta proteína foi observada em pacientes com DRC, o que pode ser um dos factores subjacentes aos processos degenerativos (por exemplo, arteriosclerose, osteoporose, atrofia da pele e deficits cognitivos) observados no curso dessa doença, enquanto que sua superexpressão aumenta por volta de $30 \%$ a expectativa de vida (KURO-O et al., 1997).

O camundongo nocaute de Klotho surge como um ótimo modelo de envelhecimento precoce (vive $~ 8$ semanas), apresentando, ainda na fase adulta (4 a 5 semanas de vida), arteriosclerose, osteoporose, atrofia da pele, infertilidade, atrofia tímica e enfisema pulmonar (KURO-O et al., 1997), déficits de retenção de memória (NAGAI, 2003), redução de sinapses no hipocampo (LI, 2004), perturbações no transporte axonal e um fenótipo neurodegenerativo no hipocampo (SHIOZAKI et al., 2008). Como parte de estudos cognitivos, há resultados que mostram declínio dos níveis de Klotho no corpo caloso de macacos rhesus idosos (DUCE et al., 2008), provavelmente devido à hipermetilação de seu promotor (KING et al., 2012), processo relacionado ao envelhecimento. Entretanto, os efeitos regulatórios de Klotho e a sua função em processos inflamatórios no SNC foram 
muito pouco estudados, sendo ainda, um campo de estudos muito desconhecido e uma das linhas de pesquisa do nosso laboratório no momento.

A Klotho apresenta papel anti-inflamatório em doenças renais, através da inibição da ativação de NF-kB e a subsequente produção de citocinas inflamatórias em resposta ao estímulo de TNF- $\alpha$ em células renais, ao inibir a kinase p38, bloqueando especificamente a fosforilação da $\operatorname{Ser}^{536}$ da RelA, sem afetar inibidores de $\mathrm{kB}$, degradação de (IKB)a ou translocação de RelA para o núcleo e sua ligação com o DNA (ZHAOet al., 2011). Através deste mecanismo postulou-se que a Klotho possui um papel renoprotetor, indicando-a como alvo terapêutico ligado ao estresse oxidativo a inflamações em diabetes tipo 2. Também, correlacionou-se a expressão de Klotho em culturas tubulares e a administração de lipopolissacarídeo (LPS), mostrando o decréscimo dos níveis de mRNA de Klotho (OHYAMA et al., 1998).

A interação entre Klotho, TNF- $\alpha, N F-k B$ e processos inflamatórios não se restringe apenas aos rins, uma vez que estudos sugerem que a disfunção endotelial observada em camundongos deficientes em Klotho, é revertida pela administração da proteína (SAITO et al., 1998; SAITO et al., 2000). A função endotelial é mediada pela regulação de óxido nítrico e é prejudicada por processos inflamatórios (MAEKAWA, 2009). Assim, a Klotho parece proteger as células endoteliais da inflamação, suprimindo o desenvolvimento de arterosclerose na vasculatura. Segundo Maekawa, a Klotho inibe a expressão de TNF- $\alpha$-induzida pela expressão de moléculas de adesão em células endoteliais de veias do cordão umbilical de

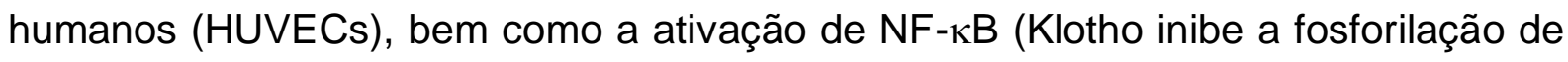
IKB) pelas HUVECs, além de promover a recuperação da fosforilação da eNOS por TNF- $\alpha$.

Além disto, a interação entre $\beta$-Klotho e o fator de crescimento fibroblasto-21 (FGF21), encontrado principalmente em tecido adiposo, confere ao FGF21 sensibilidade e habilidade de ativar cascatas de sinalização que, posteriormente levam a respostas biológicas. Há estudos que mostram que o TNF-a, agente inflamatório no tecido adiposo, inibe a expressão de $\beta$-Klotho, inviabilizando a ação do FGF-21 em adipócitos (DÍAZ-DELFIN, 2012).

No nosso estudo encontramos uma diminuição dos níveis de proteína klotho no córtex frontal e no liquor de animais $\mathrm{Nx}-\mathrm{Cl}$ quando comparados com os grupos Sham e Nx-M. Interessante é que como já citamos esse grupo também apresenta 
uma elevação importante no nível liquórico de TNF- $\alpha$ o que sugere existência de uma interação entre eles também no SNC.

Os nossos dados mostraram ainda uma redução importante dos níveis séricos da proteína Klotho nos indivíduos do grupo DRC-Cl quando comparado com grupos Controle e DRC. Interessante é que os níveis desta proteína não estavam reduzidos na vigência da DRC o que reforça a sua ação protetora tanto periférica como no SNC. Assim, diversos fatores podem tentar impedir a redução dos níveis dessa proteína com o objetivo de evitar o aparecimento dos danos cognitivos ou mesmo da perda de outras funções fisiológicas associadas a proteína klotho.

Para que possa haver um entendimento e manuseio do envelhecimento propriamente dito e de doenças com maior prevalência nesta faixa etária, há a necessidade de um amplo conhecimento das alterações funcionais e moleculares que ocorrem com a idade no SNC e periférico.

Diante disso, o estudo da Klotho (nome ligado a uma das Moiras, ou Parcas, na mitologia grega, as três irmãs que determinavam o destino, tanto dos deuses, quanto dos seres humanos) parece bem interessante na medida em existe uma correlação entre a sinalização inflamatória, klotho e envelhecimento. Uma das Morias é a Klotho, que em grego significa "fiar", segurava o fuso e tecia o fio da vida, o que pode ser justamente a ligação entre vários fatores que em conjunto determinam um estado fisiológico normal.

O envelhecimento é um processo complexo que altera as funções orgânicas em diferentes níveis de complexidade biológica. Assim, as alterações funcionais decorrentes desse processo se manifestam em nível molecular, celular e comportamental. Dentre estes mecanismos, relaciona-se ao processo de envelhecimento o mecanismo de estresse oxidativo, sendo que seu aumento está associado não apenas ao envelhecimento, mas também a graves doenças de grande prevalência na população idosa. Dentre elas, destacam-se a DA, a DP e a discinesia tardia (o principal distúrbio iatrogênico do movimento). Desta forma, um dos maiores desafios na medicina moderna é o tratamento de doenças neurodegenerativas, geralmente associadas a processos de envelhecimento.

Até o dado momento, postula-se que, em DA, DP e Esclerose Lateral Amiotrófica, as populações neuronais iniciem um processo neurodegenerativo que está associado a presença de agregados de proteína (tais como alfa-sinucleína no Parkinson ou beta-amilóide no Alzheimer) ou a alterações da fosforilação 
(hiperfosforilação da proteína Tau no Alzheimer) ou ainda de um outro fator ainda desconhecido. De perda de memória ao declínio cognitivo e fraqueza muscular, os pacientes devem enfrentar sua expectativa de vida brutalmente diminuída enquanto aguardam avanços científicos que possam trazer mais conforto e melhora em sua qualidade de vida. Diante disso, a compreensão da sinalização da proteína Klotho e das suas interações com outros mediadores inflamatórios, neurotransmissores, hormônios e fatores de crescimento no SNC pode revelar estratégias neuroprotetoras importantes para postergar 0 aparecimento das doenças neurodegenerativas. 


\section{CONCLUSÕES}

1. O declínio cognitivo observado em $40 \%$ dos pacientes com DRC estava concentrado nas áreas equivalentes aos domínios cognitivos de memoria operacional, processamento sintático e memória de longo prazo.

2. No modelo animal de DRC (5/6 de ablação renal), $36 \%$ dos animais apresentaram declíno da memória e $40 \%$ declínio de atenção.

3. Não existe diferença importante nos níveis séricos de creatinina entre os grupos DRC e DRC-Cl, assim como nos níveis séricos de uréia tanto no pré-diálise como no pós-diálise entre os mesmo grupos, o que sugere que esse fator não está envolvido na alteração da função cognitiva nessa população estudada.

4. Os níveis séricos de estrógeno não apresentaram diferença significativa entre os grupos controle, DRC e DRC-Cl, mostrando a ausência de influência desse hormônio na alteração da função cognitiva nessa população estudada.

5. A análise de mediadores séricos pró-inflamatórios (IL-1 $\beta$, IL-6, TNF- $\alpha$ e proteína $C$ reativa) e antinflamatórios (IL-10 e cortisol) realizada nos indivíduos DRC e DRC-Cl não mostrou diferença em relação aos indivíduos do grupo controle ou associação com a presença do declínio da função cognitiva o que sugere que esse não é um bom marcador para avaliar as alterações cognitivas associadas a DRC.

6. A análise nos níveis séricos de citocinas pró e antiinflamatórias no modelo animal de ablação de 5/6 da massa renal não esta claramente associada ao declínio cognitivo sugerindo que a neuroinflamação geral não é um fator diretamente associado as alterações cognitivas nessa população estudada.

7. Os níveis séricos da proteína Klotho apresenta uma redução importante nos indivíduos do grupo DRC-Cl, assim como no córtex frontal e no liquor de animais Nx$\mathrm{Cl}$ quando comparados com os grupos Sham e Nx-M.

8. O grupo DRC-Cl apresenta um aumento nos níveis liquóricos de TNF- $\alpha$ quando comparados com os grupos Sham e Nx-M, o que sugere existência de uma interação entre TNF $\alpha$ e Klotho também no SNC.

Em conjunto, os dados sugerem que as alterações na sinalização associada a proteína Klotho desempenham um papel fundamental no desenvolvimento de alterações cognitivas associadas com insuficiência renal crônica. 


\section{REFERÊNCIAS*}

AGGANIS, B. T.; WEINER, D. E.; GIANG, L. M.; SCOTT, T.; TIGHIOUART, H.; GRIFFITH, J. L.; SARNAK, M. J. Depression and cognitive function in maintenance hemodialysis patients. Am. J. Kidney Dis., v. 56, n. 4, p. 704-712, 2010.

AKIYAMA, H.; BARGER, S.; BARNUM, S.; BRADT, B.; BAUER, J.; COLE, G. M.; COOPER, N. R.; EIKELENBOOM, P.; EMMERLING, M.; FIEBICH, B. L.; FINCH, C. E.; FRAUTSCHY, S.; GRIFFIN, W. S.; HAMPEL, H.; HULL, M.; LANDRETH, G.; LUE, L.; MRAK, R.; MACKENZIE, I. R.; McGEER, P. L.; O'BANION, M. K.; PACHTER, J.; PASINETTI, G.; PLATA-SALAMAN, C.; ROGERS, J.; RYDEL, R.; SHEN, Y.; STREIT, W.; STROHMEYER, R.; TOOYOMA, I.; VAN MUISWINKEL, F. L.; VEERHUIS, R.; WALKER, D.; WEBSTER, S.; WEGRZYNIAK, B.; WENK, G.; WYSS-CORAY, T. Inflammation and Alzheimer's disease. Neurob. Aging., v. 21, n. 3, p. 383-421, 2000.

BABOVIC, D.; O'TUATHAIGH, C. M.; O'CONNOR, A. M.; O'SULLIVAN, G. J.; TIGHE, O.; CROCKE, D. T.; KARAVIORGOU, M.; GOGOS, J. A.; COTTER, D.; WADDINGTON, J. L. Phenotypic characterization of cognition and social behavior in mice with heterozygous versus homozygous deletion of catechol-Omethyltransferase. Neuroscience, v. 155, n. 4, p. 1021-1029, 2008.

BARBANTI, P.; FABBRINI, G.; RICCI, A.; CERBO, R.; BRONZETTI, E.; CARONTI, B.; CALDERARO, C.; FELICI, L.; STOCCHI, F.; MECO, G.; AMENTA, F.; LENZI, G. L. Increases expression. of dopamine receptors on lymphocytes in Parkinson's disease. Mov. Disord., v. 14, n. 5, p. 764-771, 1999.

BARNES, J. M.; BARNES, N. M.; COSTALL, B.; COUGHLAN, J.; NAYLOR, R. J.; TOMKINS, D. M.; WILLIAMS, T. J. Angiotensin-converting enzyme inhibition, angiotensin, and cognition. J. Cardiovasc. Pharmacol., v. 19, n. 6, p. 63-71, 1992.

BASTOS, M. G.; CARMO, W. B.; ABRITA, R. R.; ALMEIDA, E. C.; MAFRA, D.; COSTA, D. M.N.; GONÇALVES, J. A.; OLIVEIRA, L. A.; SANTOS, F. R.; PAULA, R. B. Doença renal crônica: problemas e soluções. NIEPEN - Núcleo Interdisciplinas de Estudos e Pesquisas em Nefrologia da Universidade Federal de Juíz de Fora - e Fundação IMEPEN. J. Bras. Nefrol., v. 26, n. 4, p. 202-215, 2004.

BASTOS, M. G.; KIRSZTAJN, G. M. Doença renal crônica: importância do diagnostic precoce, encaminhamento imediato e abordagem interdisciplinary estruturada para melhora do desfecho em pacientes ainda não submetidos à diálise. J. Bras. Nefrol., v. 33, n. 1, p. 93-108, 2011.

BEVINS, R. A.; BESHEER, J. Object recognition in rats and mice: one-trial nonmatching-to-sample learning task to study 'recognition memory'. Nature Protocols., v. 3, n. 1, p. 1306-1311, 2006. 
BLOCH, L.; SINESHCHEKOVA, O.; REICHENBACH, D.; REISS, K.; SAFTIG, P.; KURO-O, M.; KAETHER, C. Klotho is a substrate for alpha-, beta- and gammasecretase. FEBS Lett., v. 583, n. 19, p. 3221-3224, 2009.

BUELL, J. S.; TUCKER, K. L. The value of physiologic vitamin D as a biomarker of dementia. Drugs Today (Barc), v. 47, n. 3, p. 223-231, 2011.

BUONCRISTIANI, U.; ALBERTI, A.; GUBBIOTTI, G.; MAZZOTA, G.; GALLAI, V.; QUINTALIANI, G.; GABURRI, M. Better preservation of cognitive faculty in continuous ambulatory peritoneal dyalises. Perit. Dial. Int., v. 13, p. S202-S205, 1993. Suppl 2.

BURN, D. J.; BATES, D. Neurology and the kidney. J. Neurol. Neurosurg. Psychiatry, v. 65, p. 810-821, 1998.

CALCIANO, M. A.; ZHOU, W.; P. J.; EINSTEIN, R. Drug treatment of Alzheimer's disease patients leads to expression changes in peripheral blood cells. Alzheimers Dement., v. 6, n. 5, p. 386-393, 2010.

CHALAS, A.; CONWAY. E. L. No evidence for involvement of angiotensin II in spatial learning in water maze in rats. Behav. Brain Res., v. 81, n. 1-2, p. 199-205, 1996.

CHERCHIGLIA, M.; QUEIROZ, O. V.; JUNIOR, A. G. Projeto: avaliação das terapias renais substitutivas. I Ciclo de Palestras. Jornada de Economia e Saúde, 2007.

CHONG, Z. Z.; KANG, J. Q.; MAIESE, K. Essential cellular regulatory elements of oxidative stress in early and late phases of apoptosis in the central nervous system. Antiox. \& Redox Signal., v. 6, n. 2, p. 277-287, 2004.

CHONG, Z. Z.; MAIESE, K. Targeting WNT, protein kinase B, and mitochondrial membrane integrity to foster cellular survival in the nervous system. Histol. Histopathol., v.19, p. 495-504, 2004.

CLEMENS, T. L.; McGLADE, S. A.; GARRETT, K. P.; HORIUCHI, N.; HENDY, G. N. Tissue-specific regulation of avian vitamin D-dependent calcium-binding protein 28kDa mRNA by 1,25-dihydroxyvitamin D3. J. Biol. Chem., v. 263, n. 26, p. $13112-$ 13116, 1988.

COLLINO, M.; ARAGNO, M.; MASTROCOLA, R.; GALLICCHIO, M.; ROSA, A. C.; DIANZANI, C.; DANNI, O.; THIEMERMANN, C.; FANTOZZI, R. Modulation of the oxidative stress and inflamatory response by PPAR- $\lambda$ agonists in the hippocampus of rats exposed to cerebral ischemia/reperfusion. Euro. J. Pharm., v. 530, p. 70-80, 2006.

COOPER, B. G.; MIYA, D. Y.; MIZUMORI, S. J. Superior colliculus and active navigation: role os visual and non-visual cues in controlling cellular representations os space. Hypocampus, v. 8, n. 4, p. 340-372, 1998. 
CROWE, D. A.; CHAFEE, M. V.; AVERBECK, B. B.; GEORGOPOULOS, A. P. Participation of primary motor cortical neurons in a distributed network during maze solutions: representation of spatial parameters and time-course comparison with parietal area 7a. Exp. Brain Res., v. 158, p. 28-34, 2004.

CRUZ PORTELA, L. V.; OSES, J. P.; SILVEIRA, A. L. SCHMIDT, A. P.; LARA, D. R.; OLIVEIRA BATTASTINI, A. M.; RAMIREZ, G.; VINADÉ, L.; FREITAS SARKIS, J. J.; SOUZA, D. O. Guanine and adenine nucleotidase activities in rat cerebrospinal fluid. Brain Res., v. 950, n. 1-2, p. 74-78, 2002.

DAHBOUR, S. S.; WAHBEH, A. M.; HAMDAN, M. Z. Mini mental status examination (MMSE) in stable chronic renal failure patients on hemodialysis: the effects of hemodialysis on the MMSE score. A prospective study. Hem. Int., v. 13, p. 80-85, 2009.

DEMIRBILCK, M. E.; KOMUREO, N. K. H. F.; AKIN, K. O. Advanced oxidation protein products in aged with dementia. Am. J. Immun., v. 3, n. 2, p. 52-55, 2007.

DÍAZ-DELFÍN, J.; HONDARES, E.; IGLESIAS, R.; GIRALT, M.; CAELLES, C.; VILLARROYA, F. TNF- $\alpha$ represses $\beta$-Klotho expression and impairs FGF21 action in adipose cells: involvement of JNK1 in the FGF21 pathway. Endocrinology, v. 153, n. 9, p. 4238-4245, 2012.

DUARTE, P. S.; MIYAZAKI, M. C.O.S.; CICONELLI, R. M.; SESSO, R. Tradução e adaptação cultural do instrumento de avaliação de qualidade de vida para pacientes renais crônicos (KDQOL-SF). Rev. Assoc. Med. Bras., v. 49, n. 4, p. 375-381, 2003.

DUCE, J. A.; PODVIN, S.; HOLLANDER, W.; KIPLING, D.; ROSENA, D. L.; ABRAHAM, C. R. Gene profile analysis implicates Klotho as an important contributor to aging changes in brain white matter of the rhesus monkey. Glia, v. 56, n. 1, p. 106-117, 2008.

FRANCIS, S. H.; CORBIN, J. D. Structure and function of cylic nucleotide-dependent protein kinases. Annu. Rev. Physiol., v. 56, p. 237-272, 1994.

FUJIHARA, C.K.; AVANCINE, C.M.D.M.; NORONHA, I.L.; DeNUCCI, G.; ZATZ, R. Mycophenolate mofetil reduces renal injury in the chronic nitric oxide synthase inhibition model. Hypertension, v. 37, n. 1, p. 170-175, 2001.

FUJIHARA, C. K.; VELHO, M.; MALHEIROS, D. M.; ZATZ, R. An extremely high dose of losartan affords superior renoprotection in the remnant model. Kidney Int., $v$. 67, n. 5, p. 1913-1924, 2005.

FUKUNISHI I.; KITAOKA T.; SHIRAI T.; KINO, K.; KANEMATSU E.; SATO, Y. Psychiatric disorders among patients undergoing hemodialysis therapy. Nephron, v. 91, p. 344-347, 2002.

GARCION, E.; NATAF, S.; BEROD, A.; DARCY, F.; BRACHET, P. 1,25Dihydroxyvitamin D3 inhibits the expression of inducible nitric oxide synthase in rat 
central nervous system during experimental allergic encephalomyelitis. Brain Res. Mol. Brain Res., v. 45, n. 2, p. 255-267, 1997.

GARCION, E.; SINDJI, L.; MONTERO-MENEI, C.; ANDRE, C.; BRACHET, P.; DARCY, F. Expression of inducible nitric oxide synthase during rat brain inflammation: regulation by 1,25-dihydroxyvitamin D3. Glia, v. 22, n. 3, p. 282-294, 1998.

GEORGE, S. J. WNT pathway - a new role in regulation of inflammation. Aterioscler. Thromb. Vasc. Biol., v. 28, p. 400-402, 2008.

GIBSON, G. E.; HUANG, H. M. Oxidative stress in Alzheimer's disease. Neurobiol. Aging., v. 26, n. 5, p. 575-578, 2005.

GIUNTA, B.; FERNANDEZ, F.; NIKOLIC, W. V.; OBREGON, D.; RRAPO, E.; TOWN, T.; TAN, J. Inflammaging as a prodrome to Alzheimer's disease. J. Neuroinf., v. 5, p. 51-66, 2008.

GOLDBAUM, M.; BRASIL. Ministério da Saúde. Secretaria de Ciência, Tecnologia e Insumos Estratégicos. Relatório de Gestão - 2005. Brasília, 2006.

GOULD, T.; DAO, D. T.; KOVACSICS, C. E. The open field test. Neuromethods, v. 42, p. 1-20, 2009.

GRAGE-GRIEBENOW, E. D.; LORENZEN, R.; FETTING, H. D.; FLAD, A. M. E. Phenotypical and functional characterization of Fc receptor I (CD64) - negative monocytes a monir human monocyte subpopulation with high accessory and antiviral activity. Eur. J. Immunol., v. 23, p. 3126-3135, 1993.

GRIVA, K.; THOMPSON, D.; JAYASENA, D.; DAVENPORT, A.; HARRISON, M.; NEWMAN, S. P. Cognitive functioning pre-to post-kidney tranplantation-a prospective study. Nephrol. Dial. Transplant., v. 21, n. 11, p. 3275-3282, 2006.

GUPTA, S. P.; BAGARIA, P.; KUMARAN, S. A quantitative structure-activity relationship study on a series of $\mathrm{Na}^{+}, \mathrm{K}^{+}$- ATPase inhibitors. J. Enzyme Inhib. Med. Chem., v. 19, n. 5, p. 389-393, 2004.

HAYS, R. D.; KALLICH, J. D.; MAPES, D. L.; COONS, S. J.; CARTER, W. B. Development of the kidney disease quality of life (KDQOL) instrument. Qual. Life Res., v. 3, n. 5, p. 329-338, 1994.

HERSHEY, L. A.; JAFFE, D. F.; GREENOUGH, P. G.; YANG, S. L. Validation of cognitive and functional assessment instruments in vascular dementia. Int. J. Psychiatry Med., v. 17, n. 2, p. 183-192, 1987.

HOPKINS, S. J.; ROTHWELL, N. J. Cytokines and the nervous system I: expression and recognition. Trends Neurosci., v. 18, n. 2, p. 83-88, 1995.

HU, M. C.; KURO-O, M.; MOE, O. W. Klotho and kidney disease. J. Nephrol., v. 23, p. S136-S144, 2010. Suppl 16. 
IMURA, A.; TSUJI, Y.; MURATA, M.; MAEDA, R.; KUBOTA, K.; IWANO, A.; OBUSE, C.; TOGASHI, K.; TOMINAGA, M.; KITA, N.; TOMIYAMA, K.; IIJIMA, J.; NABESHIMA, Y.; FUJIOKA, M.; ASATO, R.; TANAKA, S.; KOJIMA, K.; ITO, J.; NOZAKI, K.; HASHIMOTO, N.; ITO, T.; NISHIO, T.; UCHIYAMA, T.; FUJIMORI, T.; NABESHIMA, Y. Alpha-Klotho as a regulator of calcium homeostasis. Science, v. 316, n. 5831, p. 1615-1618, 2007.

JEPSEN, F. L.; MORTENSEN, P. B. Interstitial fibrosis of the renal cortex in minimal change lesion and its correlation with renal function - a quantitative study. Virchows Arch. A. Pathol. Anat., v. 383, p. 265-270, 1979.

JOOSTEN, H.; IZAKS, G. J.; SLAETS, J. P.; de JONG, P. E.; VISSER, S. T.; BILO, H. J.; GANSEVOORT, R. T. Association of cognitive function with albuminuria and eGFR in the general population. Clin. J. Am. Soc. Nephrol., v. 6, n. 6, p. 1400-1409, 2011.

KAWAMOTO, E. M.; LEPSCH, L. B.; BOAVENTURA, M. F.; MUNHOZ, C. D.; LIMA, L. S.; YSHII, L. M.; AVELLAR, M. C.W.; CURI, R.; MATTSON, M. P.; SCAVONE, C. Amyloid beta-peptide activates nuclear factor-kappaB through an N-methyl-Daspartate signaling pathway in cultured cerebellar cells. J. Neurosci. Res., v. 8, p. 845-860, 2008.

KAWAMOTO, E. M.; MUNHOZ, C. D.; GLEZER, I.; BAHIA, V. S.; CARAMELLI, P.; NITRINI, R.; GORJAO, R.; CURI, R.; SCAVONE, C.; MARCOURAKIS, T. Oxidative state in platelets and erythrocytes in aging and Alzheimer's disease. Neurobiol. Aging., v. 26, p. 857-864, 2005.

KAWAMOTO, E. M.; VASCONCELOS, A. R.; DEGASPARI, S.; BÖHMER, A. E.; SCAVONE, C.; MARCOURAKIS, T. Age-related changes in nitric oxide activity, cyclic GMP, and TBARS levels in platelets and erythrocytes reflect the oxidative status in central nervous system. Age (Dordr), v. 35, n. 2, p. 331-342, 2013.

KIM, C. K.; KALYNCHUK, L. E.; KORNECOOK, T. J.; MUMBY, D. G.; DADGAR, N. A.; PINEL, J. P.; WEINBERG, J. Object-recognition and spatial learning and memory in rats prenatally exposed to ethanol. Behav. Neurosci., v. 111, n. 5, p. 985-995, 1997.

KING, G. D.; ROSENE, D. L.; ABRAHAM, C. R. Promoter methylation and agerelated downregulation of Klotho in rhesus monkey. Age (Dordr), v. 34, n. 6, p. 14051419, 2012.

KOBAYASHI, A.; KARLINSKI, M.; LITWIN, T.; CZLONKOWSKA. Do silent infarcts modify the effect of thrombolysis for stroke? Acta Neurol. Scand., v. 127, n. 4, p. 227-232, 2009.

KOMULAINEN, P.; LAKKA, T. A.; KIVIPELTO, M.; HASSINEN, M.; PENTTILA, I. M.; HELKALA, E. L.; GYLLING, H.; NISSINEN, A.; RAURAMAA, R. Serum high sensitivity C-reactive protein and cognitive function in elderly women. Age and Ageing, v. 36, p. 443-448, 2007. 
KUO, P.; YEN, C.; CHANG, C.; KUO, C.; CHEN, J.; SOROND, F. Relation of Creative protein to stroke, cognitive disorders, and depression in the general population: systematic review and meta-analysis. Neurology, v. 4, p. 371-380, 2005.

KURELLA, M.; CHERTOW, G. M.; LUAN, J.; YAFFE, K. Cognitive impairment in chronic kidney disease. J. Am. Geriatr. Soc., v. 52, p. 1863-1869, 2004.

KURELLA, M.; CHERTOW, G. M.; FRIED, L. F.; CUMMINGS, S. R.; HARRIS, T.; SIMONSICK, E.; SATTERFIELD, S.; AYONAYON, H.; YAFFE, K. Chronic kidney disease and cognitive impairment in the elderly: the health, aging, and body composition study. J. Am. Soc. Nephrol., v. 16, n. 7, p. 2127-2133, 2005.

KURELLA, M.; LUAN, J.; YAFFE, K.; CHERTOW, G. Validation of the Kidney Disease Quality of Life (KDQOL) cognitive function subscale. Kid. Internat., v. 66, p. 2361-2367, 2004.

KURELLA, M.; YAFFE, K.; SHLIPAK, M. G.; WENGER, N. K.; CHERTOW, G. M. Chronic kidney disease and cognitive impairment in menopausal women. Am. J. Kidney Dis., v. 45, n. 1, p. 66-76, 2005.

KURO-O, M. Klotho and aging. Biochem. et Bioph. Acta, p. 1049-1058, 2009.

KURO-O, M. Klotho. Eur. J. Physiol., v. 459, p. 333-343, 2010.

KURO-O, M. Phosphate and Klotho. Kidney Int. Suppl., v. 121, p. S20-S23, 2011.

KURO-O, M.; MATSUMURA, Y.; AIZAWA, H.; KAWAGUCHI, H. SUGA, T.; UTSUGI, T.; OHYAMA, Y.; KURABAYASHI, M.; KANAME, T.; KUME, E.; IWASAKI, H.; LIDA, A.; SHIRAKI-LIDA, T.; NISHIKAWA, S.; NAGAI, R.; NABESHIMA, Y. I. Mutation of the mouse klotho gene leads to a syndrome resembling ageing. Nature, v. 390, n. 6655, p. 45-51, 1997.

KURO, M. Klotho and the aging process. Kor. J. Int. Med., v. 26, n. 2, 2011.

KUROSU, H.; KURO-O, M. The Klotho family and the endocrine fibroblast. Curr. Opin. Nephrol. Hypertens., v. 17, p. 368-372, 2008.

LAEMMLI, U. K. Cleavage of structural proteins during the assembly of the head of bacteriophage T4. Nature, v. 227, n. 259, p. 680-685, 1970.

LAKHAN, S. E.; KIRCHGESSNER, A.; HOFER, M. Inflammatory mechanisms in ischemic stroke: therapeutic approaches. J. Transl. Med., v. 7, p. 97, 2009.

LANSKE, B.; RAZZAQUE, M. S. Vitamin D and aging: old concepts and new insights. J. Nutr. Biochem., v. 18, n. 12, p. 771-777, 2007. 
LI, S. A.; WATANABE, M.; YAMADA, H.; NAGAI, A.; KINUTA, M.; TAKEI, K. Immunohistochemical localization of klotho protein in brain, kidney, and reproductive organs of mice. Cell Struct. Funct., v. 29, n. 4, p. 91-99, 2004.

LIU, M.; LIANG,Y.; CHIGURUPATI, S.; LATHIA, J. D.; PLETNIKOV, M.; SUN, Z.; CROW, M.; ROSS, C. A.; MATTSON, M. P.; RABB, H. Acute kidney injury leads to inflammation and functional changes in the brain. J. Am. Soc. Nephrol., v. 19, n. 7, p. 1360-1370, 2008.

LUCAS, S. M.; ROTHWELL, N. J.; GIBSON, R. M. The role of inflammation in CNS injury and disease. Br. J. Pharmacol., v. 147 (Suppl 1), p. S232-S240, 2006.

MACHADO, F. G.; KURIKI, P. S.; FUJIHARA, C. K.; FANELLI, C.; ARIAS, S. C.A.; MALHEIROS, D. M.A.C.; CAMARA, N. O.S.; ZATZ, R. Chronic VEGF blockade worsens glomerular injury in the remnant kidney model. PLoS One, v. 7, n. 6, p. e39580, 2012.

MADAN, P.; KALRA, O. P.; AGARWAL, S.; TANDON, O. P. Cognitive impairment in chronic kidney disease. Nephrol. Dial. Transplant., v. 22, p. 440-444, 2007.

MADERO, M.; GUL, A.; SARNAK, M. J. Cognitive Function in Chronic Kidney Disease. Seminars in Dialysis, v. 21, p. 29-37, 2008.

MADERO, M.; SARNAK, M. J.; WANG, X.; SCEPPA, C. C.; GREENE, T.; BECK, G. J.; KUSEK, J. W.; COLLINS, A. J.; LEVEY, A. S.; MENON, V. Body mass index and mortality in CKD. Am. J. Kidney Dis., v. 50, n. 3, p. 404-411, 2007.

MAEKAWA, Y.; ISHIKAWA, K.; YASUDA, O.; OGURO, R.; HANASAKI, H.; KIDA, I.; TAKEMURA, Y.; OHISHI, M.; KATSUYA, T.; RAKUGI, H. Klotho suppresses TNFalpha-induced expression od adhesion molecules in the endothelium and attenuates NF-kappaB activation. Endocrine, v. 35, n. 3, p. 341-346, 2009.

MAIESE, K.; CHONG, Z. Z. Insights into oxidative stress and potential novel therapeutic targets for Alzheimer Disease. Restor. Neurol. Neurosci., v. 22, p. 87104, 2004.

MARCOURAKIS, T.; BAHIA, V. S.; KAWAMOTO, E. M.; MUNHOZ, C. D.; GORJÃO, R.; ARTES, R.; KOK, F.; CARAMELLI, P.; NITRINI, R.; CURI, R.; SCAVONE, C. Apoliprotein $\mathrm{E}$ genotype is related to nitric oxide production in platelets. Cell Biochem. Funct., v. 26, n. 8, p. 852-858, 2008.

MARKUS, E. J.; QIN, Y. L.; LEONARD, B.; SKAGGS, W. E.; McNAUGHTON, B. L.; BARNES, C. A. Interactions between location and task affect the spatial and directional firing of hippocampal neurons. J. Neurosci., v. 15, n. 11, p. 7079-7094, 1995.

MATSUMURA, Y.; AIZAWA, H.; SHIRAKI-LIDA, T.; NAGAI, R.; KURO-O, M.; NABESHIMA, Y. Identification of the human klotho gene and its two transcripts 
encoding membrane and secreted klotho protein. Biochem. Biophys. Res. Commun., v. 242, n. 3, p. 626-630, 1998.

McAFOOSE, J.; BAUNE, B. T. Evidence for a cytokine model of cognitive function. Neurosc. Biobeh. Rev., v. 33, p. 355-366, 2009.

McCLINTOCK, S. M.; CULLUM, M.; HUSAIN, M. M.; RUSH, A. J.; KNAPP, R. G.; MUELLER, M.; PETRIDES, G.; SAMPSON, S.; KELLNER, C. H. Evaluation of the effects of severe depression on global cognitive function and memory. CNS Spectr., v. 15, n. 5, p. 304-313, 2010.

MENZA, M.; DOBKIN, R. D.; MARIN, H.; MARK, M. H.; GARA, M.; BIENFAIT, K.; DICKE, A.; KUSNEKOV, A. The role of inflammatory cytokines in cognition and other non-motor symptoms of Parkinson's disease. Psychosomatics, v. 51, p. 474-478, 2010.

MEYER, J. S.; CHOWDHURY, M. H.; XU, G.; LI, Y. S.; QUACH, M. Donepezil treatment of vascular dementia. Ann. N. Y. Acad. Sci., v. 977, p. 482-486, 2002.

MOURA, S. M. Contribuições de quarto instrumentos de triagem para o diagnostico de deficits cognitivos no envelhecimento no Brasil: validades de critérios e normas de desempenho. Belo Horizonte: Universidade Federal de Minas Gerais, 2008.

MUMBY, D. G. Perspectives on object-recognition memory following hippocampal damage: lessons from studies in rats. Behav. Brain Res., v. 127, n. 1-2, p. 159-181, 2001.

MURRAY, A. M. Cognitive impairment in the aging dialysis and chronic kidney disease populations an occult burden. Adv. Chron. Kidney Dis., v. 15, n. 2, p. 123132, 2008.

MURRAY, A. M.; TUPPER, D. E.; KNOPMAN, D. S.; GILBERTSON, D. T.; PEDERSON, S. L.; LI, S.; SMITH, G. E.; HOCHHALTER, A. K.; COLLINS, A. J. KANE, R. L. Cognitive impairment in hemodialysis patients is common. Neurology, v. 67, n. 2, p. 216-223, 2006.

NABESHIMA, Y. Regulation of calcium homeostasis by a-Klotho and FGF23. Clin. Calcium, v. 20, n. 11, p. 1677-85, 2010.

NAGAI, T.; YAMADA, K.; KIM, H. C.; KIM, Y. S.; NODA, Y.; IMURA, A.; NABESHIMA, Y.; NABESHIMA, T. Cognition impairment in the genetic model of aging klotho gene mutant mice: a role of oxidative stress. FASEB J., v. 17, n. 1, p. 50-52, 2003.

NATHAN, C. Points of control in inflammation. Nature, v. 420, p. 846-852, 2002.

NESTLER, E. J.; GREENGARD, P. Serine and Threonine Phosphorylation. New York: Lippincott - Raven Press, 1999. 
NITA, D. A.; NITA, V.; SPULBER, S. MODOVAN, M.; POPA, D. P.; ZAGREAN, A. M.; ZAGREAN, L. Oxidative damage following cerebral ischemia depends on reperfusion - a biochemical study in rat. J. Cell. Mol. Med., v. 5, p. 163-170, 2001.

NOVAK, J. E.; GOMEZ-FLORES, R.; CALDERON, S. N.; RICE, K. C.; WEBER, R. J. Rat natural killer cell, $T$ cell and macrophage functions after intracerebroventricular injection of SNC 80. J. Pharmacol. Exp. Ther., v. 286, n. 2, p. 931-937, 1998.

NULSEN, R. S.; YAGOOB, M. M.; MAHON, A.; STOBY-FIELDS, M.; KELLY, M.; VARAGUNAM, M. Prevalence of cognitive impairment in patients attending predialysis clinic. J. Ren. Care, v. 34, n. 3, p. 121-126, 2008.

OHYAMA, Y.; KURABAYASHI, M.; MASUDA, H.; NAKAMURA, T.; AIHARA, Y.; KANAME, T.; SUGA, T.; ARAI, M.; AIZAWA, H.; MATSUMURA, Y.; KURO-O, M.; NABESHIMA, Yi; NAGAIL, R. Molecular cloning of rat klotho cDNA: markedly decreased expression of klotho by acute inflammatory stress. Biochem. Biophys. Res. Commun., v. 251, n. 3, p. 920-925, 1998.

PATANELLA, A. K.; ZINNO, M.; QUARANTA, D.; NOCITI, V.; FRISULLO, G.; GAINOTTI, G.; TONALI, P. A.; BATOCCHI, A. P.; MARRA, C. Correlations between peripheral blood mononuclear cell production of BDNF, TNF-alpha, IL-6, IL-10 and cognitive performances in multiple sclerosis patients. J. Neuroscience Res., v. 88, p. 1106-1112, 2010.

PEREIRA, A. A.; WEINER, D. E.; SCOTT, T.; CHANDRA, P.; BLUESTEIN, R.; GRIFFITH, J.; SARNAK, M. J. Subcortical cognitive impairment in dialysis patients. Hemodial. Int., v. 11, n. 3, p. 309-314, 2007.

PEREIRA, A. A.; WEINER, D. E.; SCOTT, T.; SARNAK, M. J. Cognitive function in dialysis patients. Am. J. Kidney Dis., v. 45, n. 3, p. 448-462, 2005.

PEREIRA, C.; SCHAER, D. J.; BACHLI, E. B.; KURRER, M. O.; SCHOEDON, G. WNT5a/CaMKII Signalling contributes to the inflammatory response of macrophages and is a target for the antiinflamatory action of activated protein $C$ and interleukin-10. Arterioscler. Thromb. Vasc. Biol., v. 28, p. 504-510, 2008.

PEREIRA, C. N.; MACHADO, F. R.; GUIMARÃES, H. P.; SENNA, A. P.; AMARAL, J. L. Hemodynamics and renal function during administration of low-dose dopamine in severely ill patients. São Paulo Med. J., v. 122, n. 4, p. 141-146, 2004.

PETROZZI, L.; LUCETTI, C.; GAMBACCINI, G.; BERNARDINI, S.; DEL DOTTO, P.; MIGLIORE, L.; SCARPATO, R.; BONUCCELLI, U. Cytogenetic analysis oxidative damage in lymphocytes of Parkinso's disease patients. Neurol. Sci., v. 22, n. 1, p. 83-84, 2001.

PETZOLD, A.; KEIR, G.; LIM, D.; SMITH, M.; THOMPSON, E. J. Cerebrospinal fluid (CSF) and serum S100B: release and wash-out pattern. Brain Res. Bull, v. 61, p. 281-285, 2003. 
POLLMÄCHER, T.; HAACK, M.; SCHULD, A.; REICHENBERG, A.; YIRMIYA, R. Low levels of circulation inflammatory cytokines - do they affect human brain functions? Brain Behav. Immun., v. 16, n. 5, p. 525-532, 2002.

POPOVICH, P. G.; LONGBRAKE, E. E. Can the immune system be harnessed to repair the CNS? Nat. Rev. Neurosci., v. 9, p. 481-493, 2008.

PRATICÒ, D. Peripheral biomarkers of oxidative damage in Alzheimer's disease: the road ahead. Neurobiol. Aging, v. 26, n. 5, p. 581-583, 2005.

RAKOWSKI, D. A.; CAILLARD, S.; AGODOA, L. Y.; ABBOTT, K. C. Dementia as a predictor of mortality in dialysis patients. Clin. J. Am. Soc. Nephrol., v. 1, p. 10001005, 2006.

RAO, S.; CARTER, W. B.; MAPES, D. L.; KALLICH, J. D.; KAMBERG, C. J.; SPRITZER, K. L.; HAYS, R. D. Development of subscales from the symptoms/problems and effects of kidney disease scales of the kidney quality of life instrument. Clin. Ther., v. 22, n. 9, p. 1099-1111, 2000.

RAZZAQUE, M. S. FGF23-mediated regulation of systemic phosphate homeostasis: is Klotho an essential player? Am. J. Physiol. Renal Physiol., v. 296, n. 3, p. F470F476, 2009.

RAZZAQUE, M. S. Klotho and $\mathrm{Na}^{+}, \mathrm{K}^{+}$-ATPase activity: solving the calcium metabolism dilemma? Nephrol. Dial. Transplant., v. 23, p. 459-461, 2008.

REALE, M.; IARLORI, C.; GAMBI, F.; FELICIANI, C.; SALONE, A.; TOMA, L.; DelUCA, G.; SALVATORE, M.; CONTI, P.; GAMBI, D. Treatment with an acetylcholinesterase inhibitor in Alzheimer patients modulates the expression and production of the pro-inflammatory and anti-inflammatory cytokines. $J$. Neuroimmunol., v. 148, n. 1-2, p. 162-171, 2004.

ROTHWELL, N. J.; HOPKINS, S. J. Cytokines and the nervous system II: Actions and mechanisms of action. Trends Neurosci., v. 18, n. 3, p. 130-136, 1995.

SAITO, Y.; NAKAMURA, T.; OHYAMA, Y.; SUZUKI, T.; LIDA, A,; SHIRAKI-LIDA, T.; KURO-O, M.; NABESHIMA, Y.; KURABAYASHI, M.; NAGAI, R. In vivo klotho gene delivery protects against endothelial dysfunction in multiple risk factor syndrome. Biochem. Biophys. Res. Commun., v. 276, n. 2, p. 767-772, 2000.

SAITO, Y.; YAMAGISHI, T.; NAKAMURA, T.; OHYAMA, Y.; AIZAWA, H.; SUGA, T.; MATSUMURA, Y.; MASUDA, H.; KURABAYASHI, M.; KURO-O, M.; NABESHIMA, Y.; NAGAI, R. Klotho protein protects against endothelial dysfunction. Biochem. Biophys. Res. Commun., v. 248, n. 2, p. 324-329, 1998.

SANTANA, A. C.; DEGASPARI, S.; CATANOZI, S.; DELLÊ, H.; de SÁ LIMA, L.; SILVA, C.; BLANCO, P.; SOLEZ, K.; SCAVONE, C.; NORONHA, I. L. Thalidomide 
suppresses inflammation in adenine-induced CKD with uraemia in mice. Nephrol. Dial. Transplant., v. 28, n. 5, p. 1140-1149, 2013.

SCAVONE, C.; MUNHOZ, C. D.; KAWAMOTO, E. M.; GLEZER, I.; DE SÁ LIMA, L.; MARCOURAKIS, T.; MARKUS, R. P. Age-related changes in cyclic GMP and PKGstimulated cerebellar Na,K-ATPase. Neurobiology of Aging, v. 26, n. 6, p. 907-916, 2005.

SCHMIDT, R.; FAZENKAS, F.; ENZINGER, C.; ROPELE, S.; KAPELLER, P.; SCHMIDT, H. Risk factors and progression of small vessel disease-related cerebral abnormalities. J. Neural. Transm. Suppl., v. 62, p. 47-52, 2002.

SCHULZ, J. B.; BEAL, M. F. Mitochondrial dysfunction in movement disorders. Curr. Opin. Neurol., v. 7, n. 4, p. 333-339, 1994.

SEHGAL, A. R.; GREY, S. F.; DeOREO, P. B.; WHITEHOUSE, P. J. Prevalence, recognition, and implications of mental impairment among hemodialysis patients. Am. J. Kidney Dis., v. 30, n. 1, p. 41-49, 1997.

SELIGER, S. L.; SARNAK, M. J. Subclinical vascular disease of the brain in dialysis patients. Am. J. Kidney Dis., v. 50, p. 8-10, 2007.

SELINGER, S. L.; SISCOVICK, D. S.; STEHMAN-BREEN, C. O.; GILLEN, D. L.; FITZPATRICK, A.; BLEYER, A.; KULLER, L. H. Moderate renal impairment and risk of dementia among older adults: the cardiovascular health cognition study. J. Am. Soc. Nephrol., v. 15, p. 1904-1911, 2004.

SHADRINA, M. I.; SLOMINSKY, P. A.; LIMBORSKA, S. A.; Molecular mechanisms of pathogenesis of Parkinson's disease. Int. Rev. Cell Mol. Biol., v. 281, p. 229-266, 2010.

SHIOZAKI, M.; YOSHIMURA, K.; SHIBATA, M.; KOIKE, M.; MATSUURA, N.; UCHIYAMA, Y.; GOTOW, T. Morphological and biochemical signs of age-related neurodegenerative changes in klotho mutant mice. Neuroscience, v. 152, n. 4, p. 924-941, 2008.

SILVA, R. P. Método analítico, análise química, amostragem e estatística. Química analítica quantitative. Departamento de química e biologia. Centro de Estudos Superiores de Caxias, 2010.

SIMONIAN, N. A.; COYLE, J. T. A Oxidative stress in neurodegenerative diseases. Annu. Rev. Pharmacol. Toxicol., v. 36, p. 83-106, 1996.

SITHINAMSUWAN, P.; NIYASOM, S.; NIDHINANDANA, S.; SUPASYNDH, O. Dementia and depression in end stage renal disease: comparison between hemodialysis and continuous ambulatory peritoneal dialisysis. J. Med. Assoc. Thai., v. 88, p. S141-S147, 2005. Suppl. 3. 
SMALL, G. W.; RABINS, P. V.; BARRY, P. P.; BUCKHOLTZ, N. S.; DeKOSKY, S. T.;FERRIS, S. H.; FINKEL, S. I.; GWYTHER, L. P.; KHACHATURIAN, Z. S.; LEBOWITZ, B. D.; McRAE, T. D.; MORRIS, J. C.; OAKLEY, F.; SCHNEIDER, L. S.; STREIM, J. E.; SUNDERLAND, T.; TERI, L. A.; TUNE, L. E. Diagnosis and treatment o Alzheimer disease and related disorders. Consensus statement of the American Association for Geriatric Psychiatry, the Alzheimer's Association, and the American Geriatrics Society. JAMA, v. 278, p. 1363-1371, 1997.

SMITS, H. A.; BEELEN, A. J.V.; de VOS, N. M.; RIJSMUS, A.; BRUGGEN, T. V.D.; VERHOEF, J.; MUISWINKEL, F. L.V.; NOTTET, H. S.L.M. Activation of Human Macrophages by Amyloid- $\beta$ is attenuated by astrocytes. The J. Immunol., v. 166, p. 6869-6876, 2001.

SOPJANI, M.; ALESUTAN, I.; DËRMAKU-SOPJANI, M.; GU, S.; ZELENAK, C.; MUNOZ, C.; VELIC, A.; FÖLLER, M.; ROSENBLATT, K. P.; KURO-O, M.; LANG, F. Regulation of the $\mathrm{Na}^{+} / \mathrm{K}^{+}$ATPase by Klotho. FEBS Let., v. 585, n. 12, p. 1759-1764, 2011.

SPOTO, B.; LEONARDIS, D.; PARLONGO, R. M.; PIZZINI, P.; PISANO, A.; CUTRUPI, S.; TESTA, A.; TRIPEPI, G.; ZOCCALI, C.; MALLAMACI, F. Plasma cytokines, glomerular filtration rate and adipose tissue cytokines gene expression in chronic kidney disease (CKD) patients. Nutr. Metab. Cardiovasc. Dis., v. 22, n. 11, p. 981-988, 2011.

STENVINKEL, P. Inflamation in end-stage renal disease: the hidden enemy. Nephrology, v. 11, p. 36-41, 2006.

TAMURA, M. K.; WADLEY, V.; YAFFE, K.; McCLURE, L. A.; HOWARD, G.; GO, R.; ALLMAN, R. M.; WARNOCK, D. G.; McCLELLAN, W. Kidney function and cognitive impairment in US adults: the reasons for geographic and racial differences in stroke (REGARDS) study. Am. J. Kidney Dis., v. 52, n. 2, p. 227-234, 2008.

TENG, E. L.; CHUI, H. C. The modified mini-mental state (3MS) examination. J. Clin. Psych., v. 48, p. 314-318, 1987.

TERRANDO, N.; MONACO, C.; MA, D.; FOXWELL, B. M.J.; FELDMANN, M.; MAZE, $M$. Tumor necrosis factor- $\alpha$ triggers a cytokine cascade yelding postoperative cognitive decline. PNAS., v. 107, n. 47, p. 20518-20522, 2010.

TEUNISSEN, C. E.; BLOM, A. H.; Van BOXTEL, M. P.; BOSMA, H.; de BRUIJIN, C.; JOLLES, J.; WAUTERS, B. A.; STEINBUSCH, H. W.; de VENTE, J. Homocysteine: a marker for cognitive performance? A longitudinal follow-up study. J. Nutr. Health Aging, v. 7, n. 3, p. 153-159, 2003.

TEUNISSEN, C. E.; Van BOXTEL, M. P.; BOSMA, H.; BOSMANS, E.; DELANGHE, J.; De BRUIJN, C.; WAUTERS, A.; MAES, M.; JOLLES, J.; STEINBUSCH, H. W.; de VENTE, J. Inflammation markers in relation to cognition in healthy aging population. J. Neuroimmunol., v. 134, n. 1-2, p. 142-150, 2003. 
TILKI, H. E.; AKPOLAT, T.; TUNALI, G.; KARA, A.; ONAR, M. K. Effects of haemodialysis and continuous dialysis on $\mathrm{P} 300$ cognitive potentials in uraemic patients. Ups. J. Med. Sci., v. 109, n. 1, p. 43-48, 2004.

TOMBAUGH, T. N.; McINTYRE, N. J. The mini-mental state examination: a comprehensive review. J. Am. Geriatr. Soc., v. 40, n. 9, p. 922-935, 1992.

TSUJIKAWA, H.; KUROTAKI, Y.; FUJIMORI, T.; NABESHIMA, Y. Klotho, a gene related to a syndrome resembling human premature aging, functions in a negative regulatory circuit of vitamin D endocrine system. Mol. Endocrinol., v. 17, n. 12, p. 2393-2403, 2003.

VAZIRI, N. D. Oxidative stress in uremia: nature, mechanisms, and potencial consequences. J. Sem. Nephrol., v. 24, p. 469-473, 2004.

VEROUTI, S. N.; TSOUPRAS, A. B.; ALEVIZOPOULOU, F.; DEMOPOULOS, C. A.; IATROU, C. Paricalcitol effects on activities and metabolism of platelet activating factor and on inflammatory cytokines in hemodialysis patients. Int. J. Artif. Organs., 2013.

WENDY, L.; PETER, St. Introduction: chronic kidney disease: a burgeoning health epidemic. J. Manag. Care Pharm., v. 13, n. 9, p. S2-S5, 2007.

WERSCHING, H.; DUNING, T.; LOHMANN, H.; MOHAMMADI, S.; STEHLING, C.; FOBKER, M.; CONTY, M.; MINNERUP, J.; RINGELSTEIN, E. B.; BERGER, K.; DEPPE, M.; KNECHT, S. Serum C-reactive protein is linked to cerebral microstructural integrity and cognitive function. Neurology. v. 74, n. 13, p. 10221029, 2010.

WILLIAMS, M. A.; SKLAR, A. H.; BURRIGHT, R. G.; DONOVICK, P. J. Temporal effects of dialysis on cognitive functioning in patients with ESRD. Am. J. Kidney Dis., v. 43, n. 4, p. 705-711, 2004.

WILLS, M. R.; SAVORY, J. Water content of aluminum, dialysis dementia, and osteomalacia. Env. Health Perspect., v. 63, p. 141-147, 1985.

YAFFE, K.; LINDQUIST, K.; PENNINX, B. W.; SIMONSICK, E. M.; PAHOR, M.; KRITCHEVSKY, S.; LAUNER, L.; KULLER, L.; RUBIN, S.; HARRIS, T. Inflamatory markers and cognition in well-functioning African-American and white elders. Neurology, v. 61, p. 76-80, 2003.

YANO, Y.; MATSUDA, S.; HATAKEYAMA, K.; SATO, Y.; IMAMURA, T.; SHIMADA, K.; KODAMA, T.; KARIO, K.; ASADA, Y. Plasma pentraxin 3, but not high-sensitive C-reactive protein, is a useful inflammatory biomarker for predicting cognitive impairment in elderly hypertensive patients. J. Gerontol. A. Biol. Sci. Med. Sci., v. 65A, n. 5, p. 547-552, 2010.

YIRMAIYA, R.; GOSHEN, I. Immune modulation of learning, memory, neural plasticity and neurogenesis. Brain, Behavior, and Immunity, v. 25, p. 181-213, 2011. 
YOSHIDA, T.; FUJIMORI, T.; NABESHIMA, Y. Mediatin of unusually high concentration of 1,25-dihydroxyvitamin $D$ in homozygous klotho mutant mice by increased expression of renal 1alpha-hydroxylase gene. Endocrinology, v. 143, n. 2, p. 683-689, 2002.

YOSHIMITSU, T.; HIRATA, H.; FUJII, K.; KANAI, H.; HIRAKATA, E.; HIGASHI, H.; KUBO, M.; TANAKA, H.; SHINOZAKI, M.; KATAFUCHI, R.; YOKOMIZO, Y.; OH, Y.; TOMOOKA, S.; FUJIMI, S.; FUJISHIMA, M. Cerebral ischemia as a causative mechanism for rapid progression of brain atrophy in chronic hemodialysis patients. Clin. Nephrol., v. 53, n. 6, p. 445-451, 2000.

ZHAO, Y.; BANERJEE, S.; DEY, N.; LeJEUNE, W. S.; SARKAR, P. S.; BROBEY, R.; ROSENBLATT, K. P.; TILTON, R. G.; CHOUDHARY, S. Klotho depletion contributes to increase inflammation in kidney of the $\mathrm{db} / \mathrm{db}$ mouse model of diabetes via RelA (serine) 536 phosphorylation. Diabetes, v. 60, n. 7, p. 1907-1916, 2011. 
ANEXO A - Mini Exame do Estado Mental Modificado (3MS)

NOME: Data da aplicação:

Escolaridade: Idade:

Clínica: ( ) CINE ( ) HOME / Turno:

Tempo de HD: Possui Diabetes? Se SIM, qual tipo? ( )

SIM ( ) NÃO. Tipo:

Está com infecção? ( ) SIM ( ) NÃO / Qual tipo de acesso? ( ) FAV （） Cateter ( ) Permcath

1) a) Data de nascimento:

b) Cidade e estado de nascimento:

2) Repetir as seguintes palavras

CARRO Tentativa: 12 VASO Tentativa: 12 TIJOLO Tentativa: 12

3) a) $\mathrm{O}$ ano em que estamos:

b) O semestre ou estação:

c) O mês:

d) O dia do mês:

e) Dia da semana:

4) a) Qual pais estamos:

b) $O$ estado:

c) A cidade:

d) O bairro:

e) O local (instituição/domícilio):

5) Evocação:

CARRO Sugestão: Carro, caminhão ou canoa. VASO Tentativa: Vaso, vasilha ou vasilhame. TIJOLO Tentativa: Tijolo, telha ou tinta.

6) a) $100-7=$ ?

b) $93-7=$ ?

c) $86-7=$ ? 
d) $79-7=?$

e) $72-7=$ ?

7) Soletrar a palavra MUNDO de trás pra frente

8) Nomear objetos e partes do corpo:
a) Caneta (ou lápis):
b) Relógio (ou livro):
c) Testa:
d) Queixo:
e) Cotovelo:

9) Nomear 10 animais: Quantidade no primeiro estímulo:
a) 0 a $30 \mathrm{seg}-$
b) 30 a $60 \mathrm{seg}-$

10) Repetir a frase: "Nem aqui, nem ali, nem lá" ou "Eu quero ir pra casa agora".

11) Ler a seguinte frase: "Feche os olhos", e executar a ação.

12) Escrever uma frase:

13) Desenhar a figura abaixo

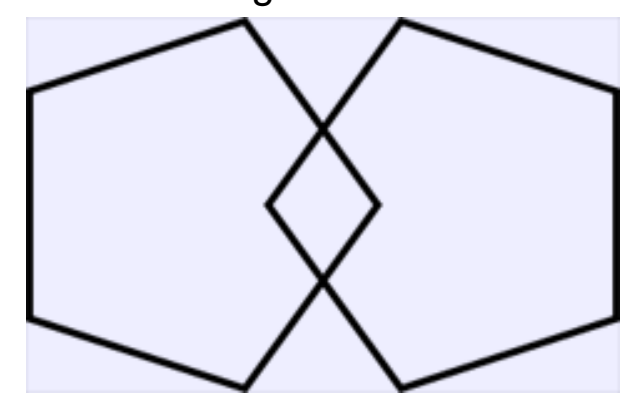

14) Ler a instrução e executa-lá:
a) Pegue este papel com a mão direita
b) Dobre este papel com as duas mãos
c) Coloque o papel no chão

15) Evocação:

CARRO Sugestão: Carro, caminhão ou canoa. VASO Tentativa: Vaso, vasilha ou vasilhame.

TIJOLO Tentativa: Tijolo, telha ou tinta. 


\section{ANEXO B - Doença renal e qualidade de vida (KDQOL-SF)}

1.Em geral, você diria que sua saúde é: [Marque um $\bigotimes$ na caixa que descreve da melhor forma a sua resposta.]

\begin{tabular}{|ccccc|}
\hline Excelente & Muito Boa & Boa & Regular & Ruim \\
$\tau$ & $\tau$ & $\tau$ & $\tau$ & $\tau$ \\
$\square 1$ & $\square 2$ & $\square 3$ & $\square 4$ & $\square 5$
\end{tabular}

2.Comparada há um ano atrás, como você avaliaria sua saúde em geral agora?

\begin{tabular}{|c|c|c|c|c|}
\hline $\begin{array}{l}\text { Muito melhor } \\
\text { agora do que há } \\
\text { um ano atrás }\end{array}$ & $\begin{array}{l}\text { Um pouco } \\
\text { melhor agora do } \\
\text { que há um ano } \\
\text { atrás }\end{array}$ & $\begin{array}{l}\text { Aproximadamente igual há } \\
\text { um ano atrás }\end{array}$ & $\begin{array}{l}\text { Um pouco pior } \\
\text { agora do que há } \\
\text { um ano atrás }\end{array}$ & $\begin{array}{l}\text { Muito pior agora do } \\
\text { que há um ano atrás }\end{array}$ \\
\hline
\end{tabular}
$\tau$
$\tau 2$
$\square^{\tau} 3$
$\square^{\tau} 4$
$\square 5$

3. Os itens seguintes são sobre atividades que você pode realizar durante um dia normal. Seu estado de saúde atual o dificulta a realizar estas atividades? Se sim, quanto? [Marque um $\triangle \mathrm{em}$ em cada linha.]

a Atividades que requerem muito esforço, como corrida, levantar objetos pesados, participar de esportes que requerem muito esforço .

\begin{tabular}{|ccc|}
\hline $\begin{array}{c}\text { Sim, } \\
\text { dificulta } \\
\text { muito }\end{array}$ & $\begin{array}{c}\text { Sim, } \\
\text { dificulta } \\
\text { um pouco }\end{array}$ & $\begin{array}{c}\text { Não, não } \\
\text { dificulta } \\
\text { nada } \\
\tau\end{array}$ \\
& & $\tau$ \\
& & \\
& & \\
& &
\end{tabular}

b Atividades moderadas, tais como mover uma mesa, varrer o chão, jogar boliche, ou caminhar mais de uma hora

c Levantar ou carregar compras de supermercado......

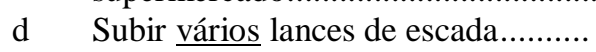

e Subir um lance de escada....

f Inclinar-se, ajoelhar-se, ou curvar-se

g Caminhar mais do que um quilômetro

h Caminhar vários quarteirões

i Caminhar um quarteirão

j Tomar banho ou vestir-se
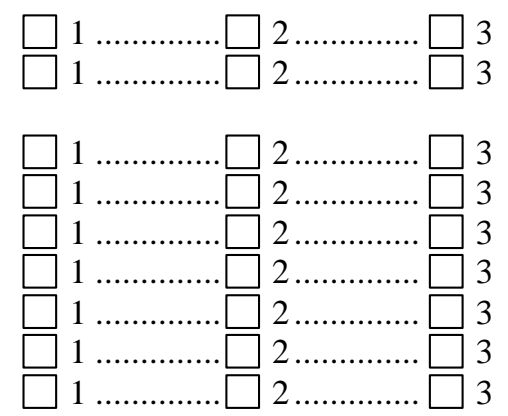

4. Durante as 4 últimas semanas, você tem tido algum dos problemas seguintes com seu trabalho ou outras atividades habituais, devido a sua saúde física?

a Você reduziu a quantidade de tempo que passa trabalhando ou em outras atividades

b Fez menos coisas do que gostaria

c Sentiu dificuldade no tipo de trabalho que realiza ou outras atividades

d Teve dificuldade para trabalhar ou para realizar outras atividades (p.ex, precisou fazer mais esforço)...

\begin{tabular}{cc|}
$\operatorname{Sim}$ & Não \\
$\tau$ & $\tau$
\end{tabular}

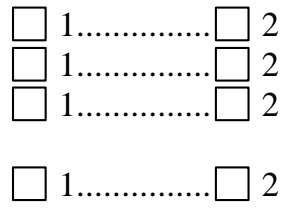


5. Durante as 4 últimas semanas, você tem tido algum dos problemas abaixo com seu trabalho ou outras atividades de vida diária devido a alguns problemas emocionais (tais como sentir-se deprimido ou ansioso)?

Reduziu a quantidade de tempo que passa trabalhando ou em outras atividades

b $\quad$ Fez menos coisas do que gostaria

c Trabalhou ou realizou outras atividades com menos atenção do que de costume.

\begin{tabular}{cc|}
\hline $\operatorname{Sim}$ & Não \\
$\tau$ & $\tau$
\end{tabular}

6. Durante as 4 últimas semanas, até que ponto os problemas com sua saúde física ou emocional interferiram com atividades sociais normais com família, amigos, vizinhos, ou grupos?

\begin{tabular}{|ccccc|}
\hline Nada & Um pouco & Moderadamente & Bastante & Extremamente \\
$\tau$ & $\tau$ & $\tau$ & $\tau$ & $\tau$ \\
$\square 1$ & $\square 2$ & $\square 3$ & $\square 4$ & $\square 5$
\end{tabular}

7.Quanta dor no corpo você sentiu durante as 4 últimas semanas?

\begin{tabular}{|cccccc|}
\hline Nenhuma & $\begin{array}{c}\text { Muito } \\
\text { leve }\end{array}$ & Leve & Moderada & Intensa & Muito Intensa \\
$\tau$ & $\tau$ & $\tau$ & $\tau$ & $\tau$ & $\tau$ \\
$\square$ & $\square$ & $\square$ & $\square$ & $\square$ & $\square$
\end{tabular}

8.Durante as $\underline{4 \text { últimas semanas, }}$ quanto a dor interferiu com seu trabalho habitual (incluindo o trabalho fora de casa e o trabalho em casa)?

\begin{tabular}{ccccc|}
\hline Nada & Um pouco & Moderado & Bastante & Extremamente \\
$\tau$ & $\tau$ & $\tau$ & $\tau$ & $\square$ \\
$\square 1$ & $\square 2$ & $\square 3$ & $\square 4$ & $\square 5$
\end{tabular}


9. Estas questões são sobre como você se sente e como as coisas tem acontecido com você durante as 4 últimas semanas. Para cada questão, por favor dê uma resposta que mais se aproxime da forma como você tem se sentido .

Durante as $\underline{4}$ últimas semanas, quanto tempo...

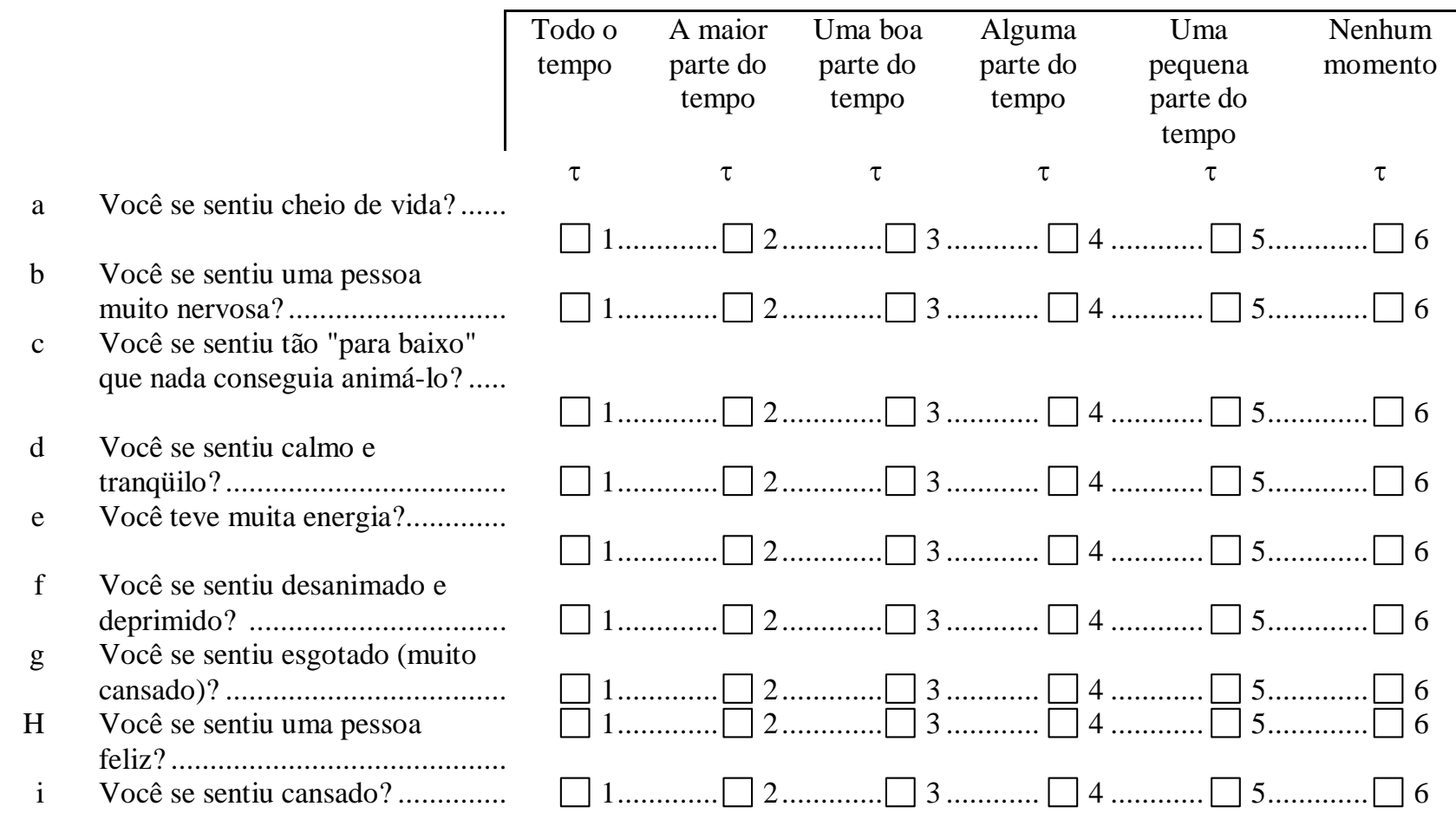

10. Durante as 4 últimas semanas, por quanto tempo os problemas de sua saúde física ou emocional interferiram com suas atividades sociais (como visitar seus amigos, parentes, etc.)?

$\begin{array}{ccccc}\text { Todo o tempo } & \begin{array}{c}\text { A maior parte do } \\ \text { tempo }\end{array} & \begin{array}{c}\text { Alguma parte do } \\ \text { tempo }\end{array} & \begin{array}{c}\text { Uma pequena parte } \\ \text { do tempo }\end{array} & \begin{array}{c}\text { Nenhum } \\ \text { momento }\end{array} \\ \tau & \tau & \tau & \tau & \tau \\ \square 1 & \square 2 & \square 3 & \square 4 & \square 5\end{array}$

11. Por favor, escolha a resposta que melhor descreve até que ponto cada uma das seguintes declarações é verdadeira ou falsa.

\begin{tabular}{|ccccc|}
\hline $\begin{array}{c}\text { Sem dúvida } \\
\text { verdadeiro }\end{array}$ & $\begin{array}{c}\text { Geralmente } \\
\text { verdadeiro }\end{array}$ & Não & Geralmente falso & Sem dúvida \\
falso
\end{tabular}

a Parece que eu fico

$\tau$

$\tau$

$\tau$

$\tau$

doente com mais

facilidade do que outras

$\square 1$

$\square 2$.

$\square 3$.

$4 \ldots$ $\square 5$

pessoas

$\square 1$

2 .

3.

4.

5

saudável quanto

qualquer pessoa que conheço.

c Acredito que minha

saúde vai piorar

d Minha saúde está

excelente

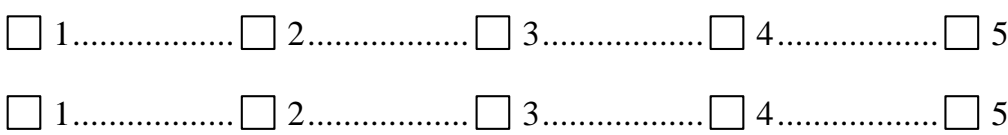


12. Até que ponto cada uma das seguintes declarações é verdadeira ou falsa para você?
a Minha doença renal
interfere demais com a
minha vida Sem dúvida
Geralmente
verdadeiro
Não
Geralmente
falso
Sem dúvida
$\tau$
$\tau$
$\tau$
$\tau$
$\tau$
b Muito do meu tempo é
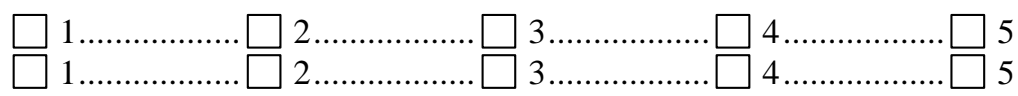 gasto com minha doença renal
c Eu me sinto decepcionado ao lidar com minha doença renal...
d Eu me sinto um peso para minha família...
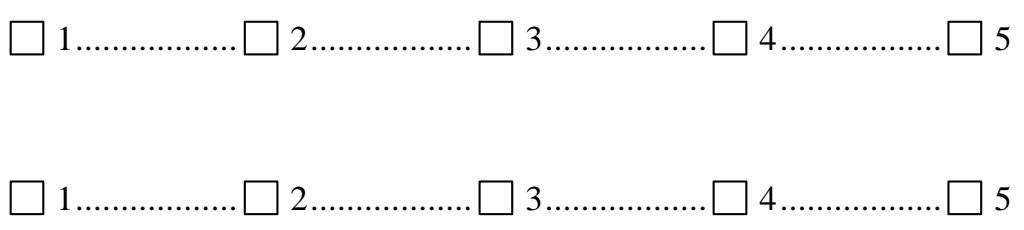

13. Estas questões são sobre como você se sente e como tem sido sua vida nas 4 últimas semanas. Para cada questão, por favor assinale a resposta que mais se aproxima de como você tem se sentido. Quanto tempo durante as 4 últimas semanas...

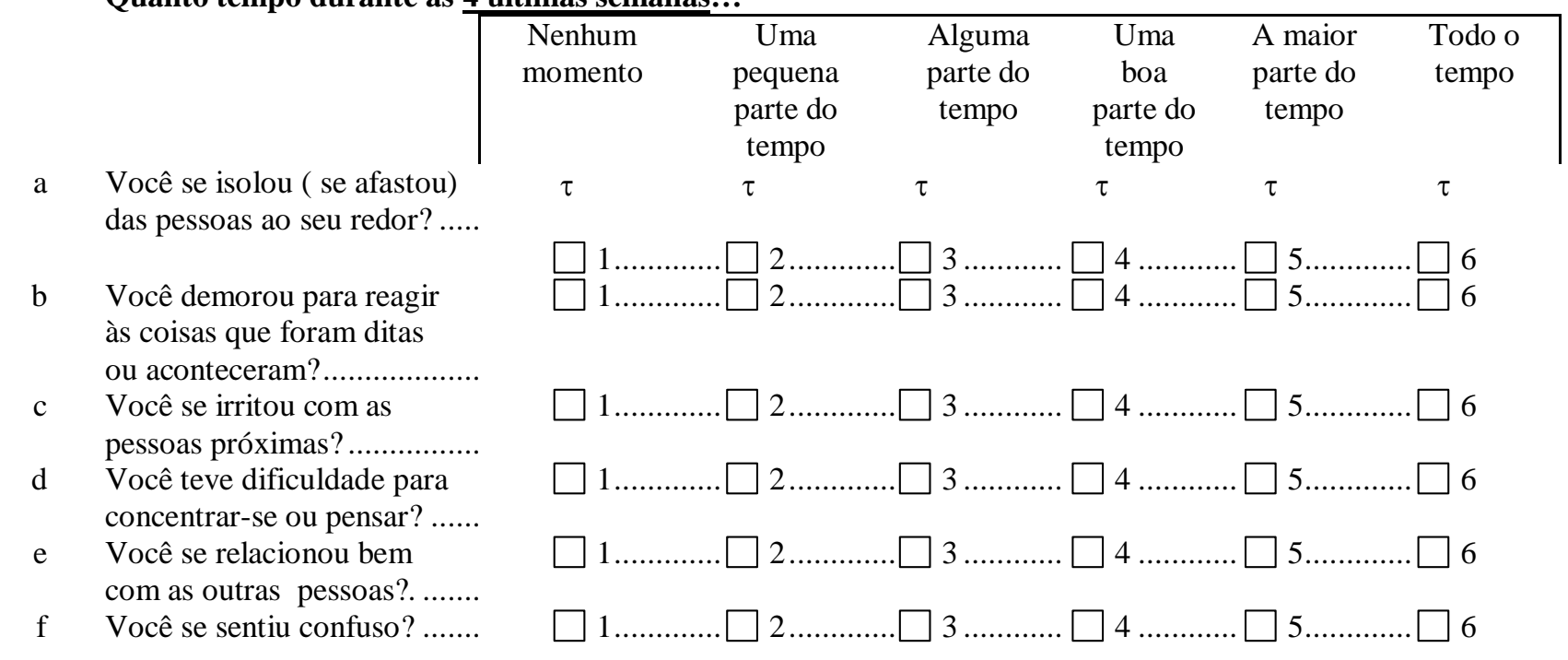

14. Durante as $\underline{4}$ últimas semanas, quanto você se incomodou com cada um dos seguintes problemas?

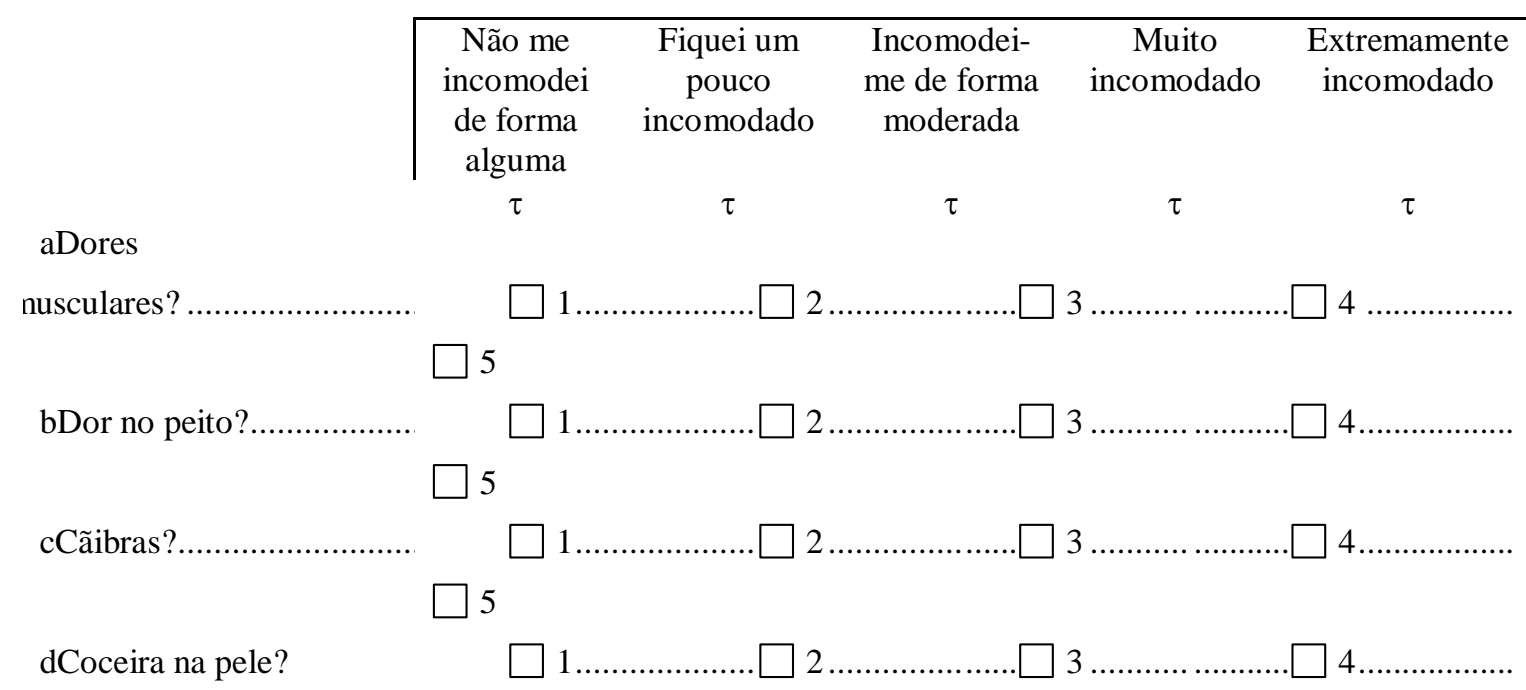


ePele seca?

$\square 1$

$\square 2$

$\square 3$

4.

5

fFalta de ar?

a

2

3.

4

5

gFraqueza ou tontura? .....

$\square 1$.

2

4

5

hFalta de apetite?

$\square 1$

2

4.

5

iEsgotamento (muito

cansaço)?

1

2 …................ $\square$

3 …….............. $\square 4$

$\square 5$

jDormência nas mãos ou

$\square$ 1..................... $\square$

$2 \ldots \ldots \ldots \ldots \ldots$

3 ……............. $\square 4$

pés?

5

kVontade de vomitar ou

indisposição estomacal? ..

$\square 1 \ldots \ldots \ldots \ldots \ldots \ldots \ldots$

3

$\square 4$

5

1(Somente paciente em hemodiálise)

Problemas com sua via de acesso (fístula ou cateter)?..

1

3.

4

$\mathrm{m}$ (Somente paciente em diálise peritoneal)

Problemas com seu

catéter?

$\square 1$

2.

3.

4 
15.Algumas pessoas ficam incomodadas com os efeitos da doença renal em suas vidas diárias, enquanto outras não. Até que ponto a doença renal lhe incomoda em cada uma das seguintes áreas?

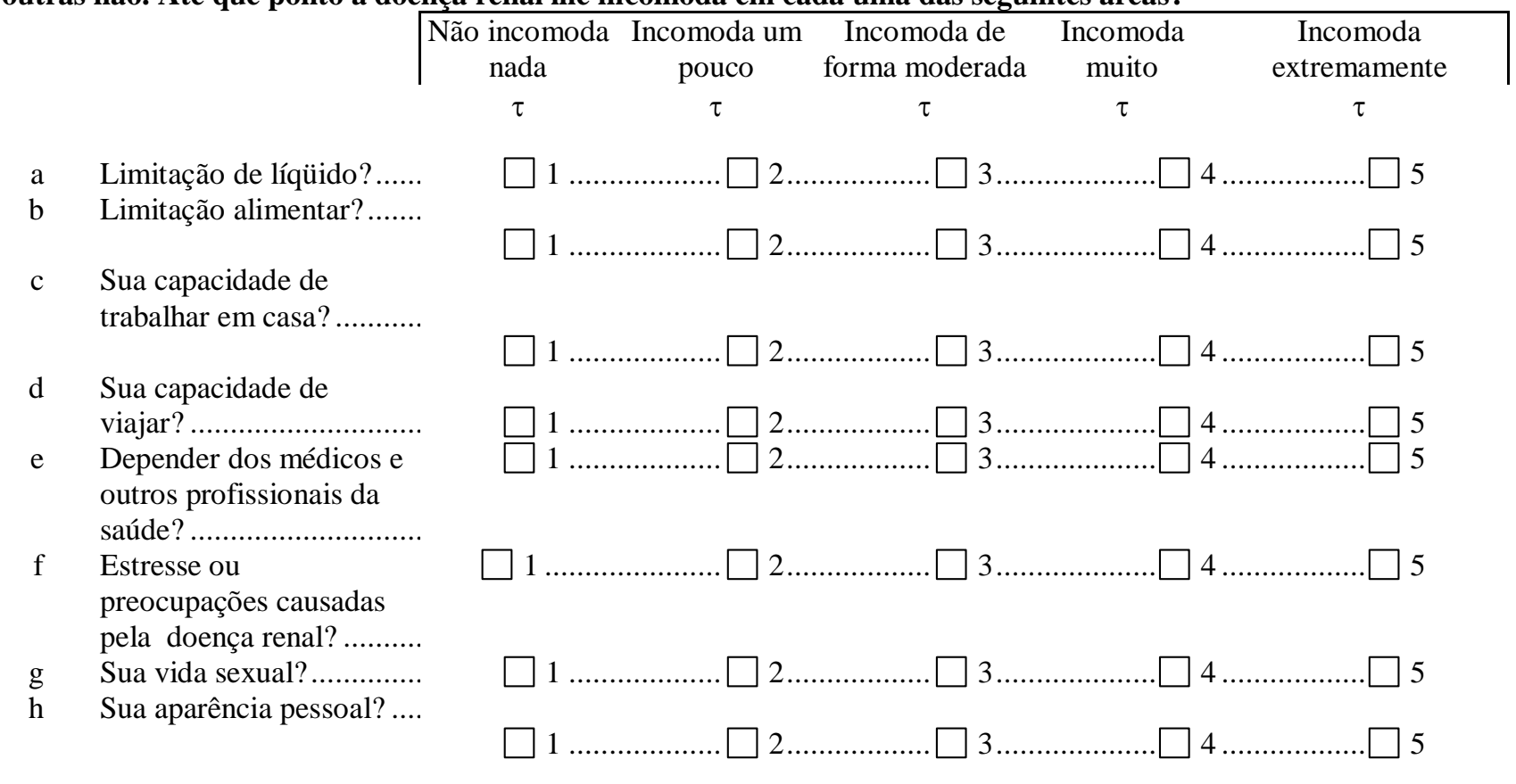

As próximas três questões são pessoais e estão relacionadas à sua atividade sexual, mas suas respostas são importantes para o entendimento do impacto da doença renal na vida das pessoas.

16. Você teve alguma atividade sexual nas 4 últimas semanas?

(Circule Um Número)

Não

Sim

2

Nas últimas 4 semanas você teve problema em:

\section{$\rightarrow$ Se respondeu não, por favor pule bara a Questão 17}

$\begin{array}{cc}\text { Um problema } & \begin{array}{c}\text { Muito } \\ \text { problema }\end{array}\end{array}$

$\tau$

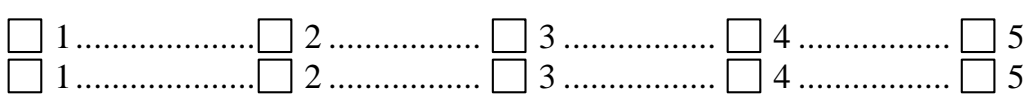

Problema enorme

a Ter satisfação sexual?

b Ficar sexualmente excitado 
17. Para a questão seguinte, por favor avalie seu sono, usando uma escala variando de 0 , (representando "muito ruim") à 10, (representando "muito bom")

Se você acha que seu sono está meio termo entre "muito ruim" e "muito bom," por favor marque um $X$ abaixo do número 5. Se você acha que seu sono está em um nível melhor do que 5, marque um $X$ abaixo do 6. Se você acha que seu sono está pior do que 5, marque um X abaixo do 4 (e assim por diante).

Em uma escala de 0 a 10, como você avaliaria seu sono em geral? [Marque um X abaixo do número.]

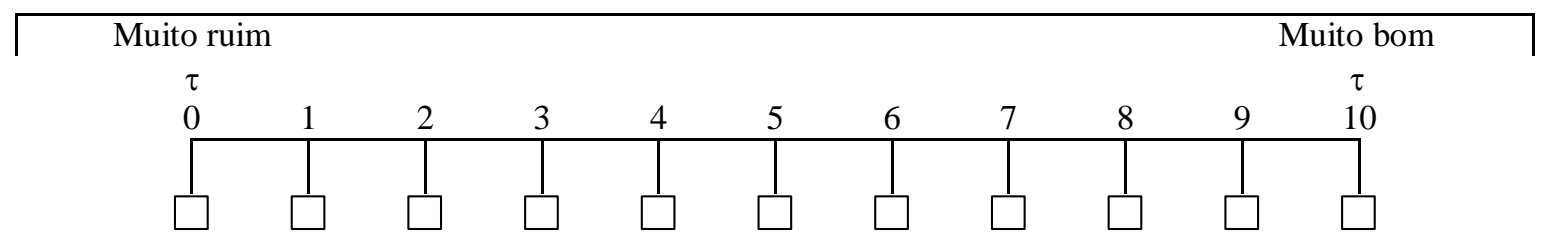

18. Com que freqüiência, durante as 4 últimas semanas você...

a

Acordou durante a noite e teve

dificuldade para voltar a

dormir?.

b Dormiu pelo tempo

necessário?

c Teve dificuldade para ficar acordado durante o dia?

\begin{tabular}{|cccccc|}
\hline $\begin{array}{c}\text { Nenhum } \\
\text { momento }\end{array}$ & Uma & Alguma & Uma boa & A maior & Todo o \\
& pequena & parte do & parte do & parte do & tempo \\
& tempo & tempo & tempo & tempo & \\
& & & & &
\end{tabular}

$\tau$
$1 \ldots \ldots \ldots \ldots$

$1 \ldots \ldots \ldots \ldots . . . \square 2$

$1 \ldots \ldots \ldots \ldots \square 2$

$2 \ldots \ldots \ldots \ldots . . . .$.

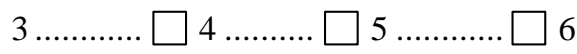

19.Em relação à sua família e amigos, até que ponto você está satisfeito com...

a A quantidade de tempo que você passa com sua família e amigos?

b O apoio que você recebe de sua família e amigos?

$\begin{array}{cc}\text { Muito } & \text { Um pouco } \\ \text { insatisfeito } & \text { insatisfeito }\end{array}$

$\tau$ $\tau$

2

2
Um pouco satisfeito

$\tau$

3

3
Muito satisfeito

$\tau$

20. Durante as 4 últimas semanas, você recebeu dinheiro para trabalhar?

$\begin{array}{ll}\text { Sim } & \text { Não } \\ \tau & \tau \\ \square & \tau 2\end{array}$

21. Sua saúde o impossibilitou de ter um trabalho pago?

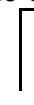

\section{Não}


22. No geral, como você avaliaria sua saúde?

\begin{tabular}{|ccc|}
\hline $\begin{array}{c}\text { A pior possível } \\
\text { (tão ruim ou pior do que } \\
\text { estar morto) }\end{array}$ & Meio termo entre pior e & A melhor \\
melhor & possível
\end{tabular}

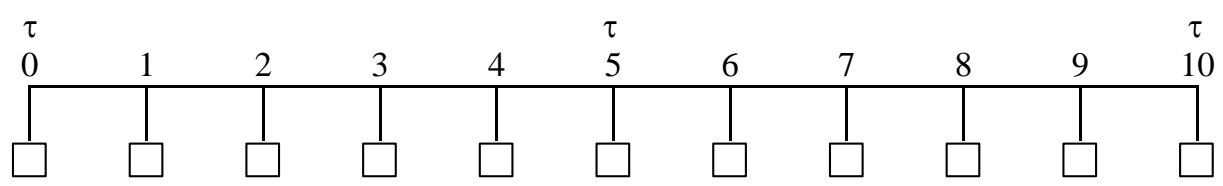

Satisfação Com O Tratamento

23. Pense a respeito dos cuidados que você recebe na diálise. Em termos de satisfação, como você classificaria a amizade e o interese deles demonstrado em você como pessoa?

\begin{tabular}{|ccccccc|}
\hline $\begin{array}{c}\text { Muito } \\
\text { ruim }\end{array}$ & Ruim & Regular & Bom & Muito bom & Excelente & O melhor \\
$\tau$ & $\tau$ & $\tau$ & $\tau$ & $\tau$ & $\tau$ & $\tau$ \\
$\square 1$ & $\square 2$ & $\square$ & $\square$ & $\square$ & $\square 6$ & $\square 7$
\end{tabular}

24. Quanto cada uma das afirmações a seguir é verdadeira ou falsa?

a O pessoal da diálise me encorajou a ser o (a) mais independente possível

b O pessoal da diálise ajudou-me a lidar com minha doença renal.

\section{Sem dúvida Geralmente} verdadeiro verdadeiro

Não sei Geralmente falso

$\tau$

$\tau$

$\tau$

$\tau$ em dúvida

2 .

3.

4.

3.

2

1.

$2 \ldots$

4

\section{Obrigado por você completar estas questões!}


ANEXO C - Dosagem de citocinas, cortisol e proteína C reativa em soro humano (valores absolutos)

\begin{tabular}{lccccc}
\hline & Controle & DRC-pré & DRC-pós & DRC-Cl-pré & DRC-Cl-pós \\
\hline IL-6 $(\mathbf{p g} / \mathbf{m L})$ & $7,1 \pm 1,3$ & $227,8 \pm 331,8$ & $71,2 \pm 86,4$ & $19,5 \pm 30,0$ & $76,4 \pm 110,4$ \\
TNF $(\mathbf{p g} / \mathbf{m L})$ & $14,4 \pm 9,6$ & $53,7 \pm 29,8$ & $37,9 \pm 17,5$ & $30,2 \pm 15,3$ & $28,4 \pm 15,3$ \\
IL-10 $(\mathbf{p g} / \mathbf{m L})$ & $7,4 \pm 6,0$ & $8,6 \pm 4,6$ & $8,5 \pm 4,0$ & $22,6 \pm 23,7$ & $32,41 \pm 24,1$ \\
IL-1 $\beta(\mathbf{p g} / \mathbf{m L})$ & $0,15 \pm 0,05$ & $0,31 \pm 0,26$ & $0,22 \pm 0,24$ & $0,38 \pm 0,39$ & $0,20 \pm 0,16$ \\
Cortisol $(\mathbf{n g} / \mathbf{m L})$ & $0,16 \pm 0,006$ & $0,17 \pm 0,08$ & $0,08 \pm 0,06$ & $0,38 \pm 0,13$ & $0,63 \pm 1,04$ \\
Proteína C Reativa $(\mathbf{m g} / \mathbf{m L})$ & $7,1 \pm 3,1$ & $6,2 \pm 3,4$ & $6,7 \pm 4,3$ & $21,3 \pm 34,3$ & $22,2 \pm 33,1$ \\
\hline
\end{tabular}

